\title{
Peripheral arterial occlusive disease: incidence, prognosis and determinants : a population-based study in a primary care setting
}

Citation for published version (APA):

Hooi, J. D. (1998). Peripheral arterial occlusive disease: incidence, prognosis and determinants : a population-based study in a primary care setting. [Doctoral Thesis, Maastricht University]. Universiteit Maastricht. https://doi.org/10.26481/dis.19981204jh

Document status and date:

Published: 01/01/1998

DOI:

10.26481/dis.19981204jh

Document Version:

Publisher's PDF, also known as Version of record

Please check the document version of this publication:

- A submitted manuscript is the version of the article upon submission and before peer-review. There can be important differences between the submitted version and the official published version of record.

People interested in the research are advised to contact the author for the final version of the publication, or visit the DOI to the publisher's website.

- The final author version and the galley proof are versions of the publication after peer review.

- The final published version features the final layout of the paper including the volume, issue and page numbers.

Link to publication

\footnotetext{
General rights rights.

- You may freely distribute the URL identifying the publication in the public portal. please follow below link for the End User Agreement:

www.umlib.nl/taverne-license

Take down policy

If you believe that this document breaches copyright please contact us at:

repository@maastrichtuniversity.nl

providing details and we will investigate your claim.
}

Copyright and moral rights for the publications made accessible in the public portal are retained by the authors and/or other copyright owners and it is a condition of accessing publications that users recognise and abide by the legal requirements associated with these

- Users may download and print one copy of any publication from the public portal for the purpose of private study or research.

- You may not further distribute the material or use it for any profit-making activity or commercial gain

If the publication is distributed under the terms of Article $25 \mathrm{fa}$ of the Dutch Copyright Act, indicated by the "Taverne" license above, 
Peripheral arterial occlusive disease: incidence, prognosis and determinants A population-based study in a primary care setting 
The study presented in this thesis was conducted at the Research Institute for Extramural and Transmural Health Care (ExTra), which participates in the Netherlands School of Primary Care Research (CaRe), acknowledged in 1995 by the Royal Dutch Academy of Science ( $K N \mathrm{AW}_{\mathrm{W}}$ ).

Peripheral arterial occlusive disease: incidence, prognosis and determinants

Hooi, Jurenne Deonisia. Thesis Maastricht

- With Ref. - With summary in Dutch

ISBN $90-5681-046-4$

Subject headings: peripheral arterial occlusive disease / epidemiology / prognosis / general practice

All rights reserved. No part of this book may be reproduced or transmitted in any form or by any means, electronic or mechanical including photocopying, recording, or by any information storage and retrieval system without written permission from the publisher, except for the inclusion of brief quotations in a review.

Cover illustration:

Marco Swaen

Book preparation, cover design and printing: Unigrsphic, Maastricht 
Peripheral arterial occlusive disease: incidence, prognosis and determinants A population-based study in a primary care setting

Proefschrift

ter verkrijging van de graad van doctor

aan de Universiteit Maastricht,

op gezag van de Rector Magnificus,

Prof. dr. A.C. Nieuwenhuijzen Kruseman,

volgens het besluit van het College van Decanen,

in het openbaar te verdedigen

op vrijdag 4 december 1998 om 14.00 uur

door

Jurenne D. Hooi 


\section{Promotores}

Prof. dr. J.A. Knotnerus

Prof. dr. J.W. $\operatorname{van}$ Ree

\section{Co-promotor}

Dr. H.E.J.H. Stoffers

\section{Beoordelingscommissie}

Prof. dr. P.J.E.H.M. Kitslaar (voorzitter)

Prof. dr. A.L.M. Lagro-Janssen (Katholieke Universiteit Nijmegen)

Prof. dr. P.W. de Leeuw

Dr. J.W.M. Muris

Dr. ir. H.C.W. de Vet

The study presented in this thesis was supported by grant no. 92.170 from the Netherlands Heart Foundation.

Publication of this thesis was made possible by a grant from:

Parke-Davis bv, Asta Medica bv, Pfizer bv and Merck Sharp \& Dohme bv. 
"I say, that this (angina pectoris) exacty corresponds to the sense of weakness and want of muscular power which exists in persons who have the arteries of the legs obstructed or ossified."

BC Brodie, 1841 . 
Voor min vader Aan minn moeder 


\section{Contents}

\section{Chapter 1}

Introduction

\section{Chapter 2}

The prognosis of non-critical limb ischaemia: a systematic review of population-based evidence

\section{Chapter 3}

Risk factors and cardiovascular diseases associated with asymptomatic peripheral arterial occlusive disease: The Limburg PAOD Study

\section{Chapter 4}

Asymptomatic peripheral arterial occlusive disease and erection

Problems

\section{Chapter 5}

Incidence and risk factors for asymptomatic peripheral arterial occlusive disease: a longitudinal study

\section{Chapter 6}

Cardiovascular morbidity and mortality of asymptomatic peripheral arterial occlusive disease: a seven-year follow-up study

\section{Chapter 7}

Peripheral arterial occlusive disease: prognostic value of signs, symptorns and the ankle-brachial pressure indiex

\section{Chapter 8}

General discussion 
Chapter 9

Summary

Chapter 10

Samenvatting

Dankwoord 
Introduction 



\section{Introduction}

\section{Background}

Peripheral arterial occlusive disease (PAOD), a common chronic disorder in the elderly, is a manifestation of atherosclerosis. The majority of PAOD subjects appears to be asymptomatic (Fontaine stage I) ${ }^{1,2}$. The first symptom in patients with PAOD usually is intermittent claudication (IC, stage II). In a small group of PAOD subjects, the symptoms are continuously present (stage III) or they experience gangrene or necrosis (stage IV). The prevalence of PAOD (including asymptomatic PAOD), assessed by means of the ankle-brachial pressure index (ABPI), increases with age and recent studies indicate that it is relatively similar in both men and women ${ }^{4-4}$. In epidemiological studies, prevalences of IC vary, dependent on the selected study population and the diagnostic criteria used ${ }^{3,4}$. Until recently, scarce data were available on the prevalence of asymptomatic $\mathrm{PAOD}$.

Most of the follow-up data on PAOD are derived from populations referred to a vascular surgery unit or vascular function department because of IC complaints. These studies show that deterioration of the symptoms in the legs are common'. Furthermore, referred PAOD patients have increased mortality risks, mainly due to other cardiovascular diseases ${ }^{5}$. Follow-up data from refered PAOD patients are not directly applicable to earlier stages of the disease in the general population, the grades that are most relevant to the general practitioner ${ }^{6}$. It appears that the vast majority of PAOD patients does not seek regular medical care, even though these subjects may have elevated risks for subsequent coronary heart disease and cerebrovascular disease ${ }^{7.8}$. Of all PAOD cases in the Limburg PAOD cohort, $68 \%$ was not known to the general practitioner ${ }^{3}$. The ability to identify groups at risk for the development or deterioration of PAOD or other cardiovascular complications associated with PAOD has, clearly, important implications for the general practitioner"s medical decision making (primary and secondary preventive interventions). This was the rationale behind the Limburg PAOD Longitudinal Study.

\section{Scope and aims of this thesis}

The Limburg PAOD Study began in 1987 in collaboration with 18 general practice centres. The aim of the first research project was to investigate the prevalence and diagnostic management of $\mathrm{PAOD}^{1,9}$ "1. The objective of the second research project (a randomised controlled trial), was to analyse the effectiveness of calcium-carbasalate intervention, on the progression of $\mathrm{BAOD}$. 
The third project that started in 1994, was the Limburg PAOD Longitudinal Study, on the incidence, natural course and prognostic determinants of symptomatic and asymptomatic PAOD. The results of the longitudinal study will be presented in the following chapters of this thesis.

\section{Aims of the Liwburg PAOD Longitudiwal Study:}

The Limburg PAOD Longitudinal Study has three main objectives:

1. To investigate the age- and sex-specific incidence and risk factors associated with asymptomatic and symptomatic PAOD;

2. To study the course of asymptomatic and symptomatic $P A O D$ in subjects aged $40-78$ with regard to progression, and also to determine the general cardiovascular morbidity and mortality;

3. To identify prognostic determinants and assess the prognostic value of data obtained through history physical examination and the level of the ABPI with regard to the clinical course and prognosis of PAOD.

\section{Outline of this thesis}

Chapter two of this thesis presents a critical review of population-based studies on the course and prognosis of PAOD. In this chapter the attention is focused primarily on what is known so far on the natural history and prognosis of asymptomatic as well as symptomatic PAOD in the general population.

In chaptex three the baseline risk-factor profile and cardiovascular co-morbidity of asymptomatic PAOD subjects from the Limburg PAOD cohort are compared with those of the symptomatic subjects.

Chapter four describes perceived erection problems from the asymptomatic and symptomatic male PAOD subjects.

Chapter five addresses the first results of the follow-up study. It presents the age- and sex-specific incidence rates and possible atherosclerotic risk factors for asymptomatic and symptomatic PAOD. Additionally, this chapter examines the incidence of internittent claudication symptoms among those who were asymptomatic at baseline.

Chapter six reports on the seven-year follow-up of coronary heart disease and cerebrovascular disease morbidity and mortality of asymptomatic and symptomatic PAOD subjects. It also reports on possible gender differences for the various adverse outcome events. 
Chapter seven shows the prognostic value of signs, symptoms and levels of the ankle-brachial pressure index for progressive ischaemia in the extremities, non-fatal and fatal cardiovascular diseases.

Chapter eight, the general discussion, provides a short summary of the results and a critical appraisal of the methodology used. Furthermore, the implications are discussed of the presented results for primary health care and recommendations for future research are given.

Chapters nine and ten, respectively consist of summaries in English and Dutch. 


\section{References}

1. Stoffers HENH, Rinkens PELM, Kester ADM, Kaiser V, Knotmerus IA. The prevalence of asymptomatic and unrecogrized peripheral arterial occlusive disease. Int J Epidemiol 1996:25:282-90.

2. Fowkes FGR, Housley E, Cawood EHH, Macintyre CCA, Ruckley CV, Prescott RJ. Edinburgh Artery Study: Prevalence of asymptomatic and symptornatic peripheral arterial disease in the general population. Int I Epidemiol $1991 ; 20(2): 3844-92$.

3. Vogt MT, Wolfson SK, Kuiller LH. Lower extremity arerial disease and the aging process: a review. I Clin Epidemiol 1992:45:529:42.

4. Balkau B, Vray M, Eschwege E. Epideniology of peripheral antrial disease. $J$ Cardiovasc Pham $1994 ; 23$ (suppli3):S8-Si6.

5. McDaniel $M D_{1}$ Cronenwett $\Omega$. Basic data related to the natural history of intermittent clandication. Ann Vasc Surg 1989:3:273-7.

6. Knottnerus JA, Knipschild PG, Sturmans F. Symptons and selection bias: the influence of selection towards specialist care on the relationship between symptoms and diagnoses. Theoretical Medicine 1989;10:67-81.

7. Crioui MH, Langer RD, Fronek A, Feigelson HS, Klauber MR, McCann TH, Browner D. Mortality over a period of 10 years in patients with peripheral arterial disease. New Engl J Med 1992;326:381-6.

8. Leng GC, Lee AJ, Fowkes FGR, Whiteman M, Dunbar I, Housley E, Ruckley CV. Incidence, natural history and cardliovascular events in symptomatic and asymptomatic peripheral arterial disease in the general population. Inter $\mathrm{J}$ Epidemiol 1996;25:1172-81

9. Stoffers HEJH, Kester ADM, Kaiser V, Rinkens PELM. Knottnerus JA. Diagnostic value of signs and symptoms associated wich peripheral anterial occlusive disease seen in general practice: A multivariable approach. Med Decis Making 1997;17:61-70.

10. Stoffers HEJH, Kaiser V, Kester ADM, Schouten HJA, Knotmerus JA. Peripheral anterial occlusive disease in general practice: the reproducibility of the ankle-arm systolic pressure ratio. Scand J Prim Health Care 1991;9:109-14.

11. Stoffers HEJH, Kester ADM, Kaiser V, Rinkens PELM, Kitslaar PJEHM, Knotinerus IA. The diagnostic value of measurement of the ankle-brachial systolic pressure index in primary health care. 1 Clin Epidemiol 1996:49:140105. 
The prognosis of non-critical limb ischaemia: a systematic review of population-based evidence

Jurenne D Hooi

Herri E J H Stoffers

J André Knottmerus

Ian W van Ree 


\section{Abstract}

Background and aim. Peripheral arterial occlusive disease (PAOD) is the most common peripheral vascular disorder in the elderly. A clear picture of the course of especially the patient with noncritical limb ischaemia (Fontaine stages $I$ and II) is essential for the general practitioner, who plays a key role in the diagnosis and management of PAOD. In this review, we evaluated the populationbased evidence on the course and prognosis of PAOD.

Methods. An exhaustive literature search yielded 16 population-based studies on the prognosis of PAOD. The methodological qualities of the studies were assessed according to eight criteria.

Results. The results of 13 studies of high methodological quality show that data on the course, cardiovascular morbidity and mortality of asymptomatic PAOD are scarce. Only a small group of asymptomatic patients seem to develop intermittent claudication symptoms. Yet, asymptomatic patients appear to have the same increased risk for cardiovascular morbidity and mortality when compared with claudicants. No data were available on prognostic factors for intemittent claudication and cardiovascular morbidity in asymptomatic patients.

The course, cardiovascular morbidity and mortality of symptomatic PAOD were better documented. A small group of claudicants experience symptom progression. Smoking, hypertension, increasing age and diabetes are the most relevant risk factors for intermittent claudication. Claudicants are at a higher risk for developing other cardiovascular diseases, resulting in a significantly increased mortality mainly due to coronary heart disease. Intermittent claudication and a low ankle-brachial pressure index are significant predictors of mortality. Men more often had intermittent claudication and symptom progression than women. Cardiovascular (co-)morbidity was common in both male and female PAOD patients, but male PAOD patients had a higher montality compared with female PAOD patients.

Conclusion. Given the current knowledge on the prognosis of PAOD in the general population, an important task on (secondary) prevention is reserved for the general practitioner. Further research is required to document the course and prognosis of asymptomatic PAOD patients.

Keywords: Peripheral arterial occlusive disease, epidemiology, prognosis. 


\section{Introduction}

Peripheral arterial occlusive disease (PAOD) is a common health problem among the elderly'. The prevalence of $\mathrm{PAOD}$, assessed by means of the ankle-brachial pressure index, ranges fron $4.2 \%$ to $35 \%$.

The majority of PAOD patients have asymptomatic PAOD (Fontaine stage $\mathbb{l}$ ) or intermittent claudication symptoms (stage II). Intermittent claudication can be physically disabling and claudicants have a diminished quality of life because of the impact of their symptoms on their daily life activities ${ }^{5}$. In a small group of PAOD patients, symptoms are continuously present (stage III) and a small minority experiences gangrene and/or necrosis (stage IV). Stage I and II are denoted as noncritical limb ischaemia and stage III and IV as critical limb ischaemia ${ }^{6}$.

Much research has been done on the prognosis of PAOD in referred patients with disabling claudication complaints or critical ischaemia ${ }^{7 / 17}$. However, these referral-based studies are not representative for $P A O D$ patients in primary care, since in this setting the majority of patients have non-critical limb ischaemia. Data from population-based studies can provide the general practitioner with valuable information. Which factors are of prognostic importance in the clinical course of asymptomatic and mildly symptomatic PAOD? Do patients with non-critical limb ischaemia more often have advanced atherosclerosis in other parts of the circulation, resulting in an increased risk for cardiovascular morbidity and mortality? Is PAOD a predominantly male disease? And to what extent is the knowledge on these issues based on results of methodologically well-designed epidemiological studies? In order to answer these questions, we present a systematic review of methodologically well-designed population-based studies on the prognosis of non-critical ischaemia.

\section{Methods}

\section{Identification and selection procedure}

A Medline literature search of the period 1980-1996 was conducted, using the key words: "peripheral occlusive disease, peripheral arterial disease, peripheral vascular disease, atherosclerosis, internittent claudication, epidemiology " prognosis, ankle-brachial pressure index, prospective, follow-up, morbidity, mortality, not surgery, not clinical trial". Snudies were selected if they were population-based, primarily aimed to investigate prognosis, with at least one year of follow-up. References cited in these sndies were screened for additional relevant publications. 


\section{Assessment of methodological quality}

To evaluate the methodological quality of the selected papers, a set of eight criteria was formulated according to Tugwell and Silagy ${ }^{18,19}$ : (1) clear description of the study population; (2) clearly defined diagnosis of PAOD; (3) baseline measurements for all subjects; (4) documentation of follow-up length; (5) less than $20 \%$ loss to follow-up; (6) documentation of measurements of prognostic factors; (7) documentation of end points; (8) adequate statistical methods. The scoring categories for each item were + (present), \pm (questionable) and - (absent). The questionable score was assigned if a criterion was incompletely specified. When no information was present a negative score was given. The selected papers were independently reviewed by the first two authors of this paper. The results were compared and disagreements were discussed until consensus was reached. Studies were included in this review if they had not more than one questionable or negative criterion.

\section{Results}

\section{General remarks}

The literature search resulted in the identification of 19 population-based studies ${ }^{20.38}$. Four sets of papers reported on the same populations. Consequently, in some papers the results overlapped or were complimentary. In one set (three papers) ${ }^{34-36}$, the two papers with the longest follow-up period with complimentary data were selected ${ }^{35,36}$ "In the second set (three papers) ${ }^{27.29}$, the paper that included the most accurate information on the prognosis of PAOD was chosen ${ }^{28}$. The third (four papers) 30-33 $^{30}$ and fourth set (two papers) ${ }^{37-38}$ were fully presented in the methodological quality assessment, because each paper contained additionall data. Thus, 16 papers were selected for the methodological assessment.

\section{Methodological quality assessment}

Table 1 describes the methodological qualities of the 16 papers. Thirteen papers met our inclusion condition. In the older papers, loss to follow-up (criterion 5) and measurements of prognostic factors (criterion 6) were often not accurately documented. Older papers also applied less adequate statistical analyses (criterion 8). 
Table 1. Methodological scores of the studies on the prognasis of PAOD

\begin{tabular}{|c|c|c|c|c|c|c|c|c|}
\hline Author ${ }^{a}$ & 1 & 2 & 3 & 4 & 5 & 6 & 7 & 8 \\
\hline Widmer ${ }^{26}, 1964$ & + & + & + & + & \pm & \pm & \pm & \pm \\
\hline Kannel $^{30}, 1970$ & + & + & $\div$ & + & + & + & + & \pm \\
\hline Newton Peabody ${ }^{3}, 1974$ & + & + & $\div$ & + & + & + & + & . \\
\hline Agner $^{23}, 1981$ & + & + & + & + & - & \pm & + & \pm \\
\hline Reunanen $^{22}, 1982$ & + & + & $\div$ & + & - & + & + & + \\
\hline Kanne $^{32}, 1985$ & $\div$ & + & $\div$ & + & + & \pm & + & \pm \\
\hline Stokes ${ }^{3 \tilde{3}}, 1987$ & + & $\div$ & th & $\psi$ & . & $\div$ & + & 4 \\
\hline Davey Smith ${ }^{20}, 1990$ & + & + & + & + & + & + & + & + \\
\hline Criqui: $^{35}, 1991$ & + & + & + & $=$ & + & + & + & + \\
\hline Dagenais $^{21}, 1991$ & + & + & + & $4+$ & + & + & + & + \\
\hline Criquit: 1992 & + & $\dot{+}$ & + & - & + & + & + & + \\
\hline Ögren ${ }^{28}, 1993$ & + & + & + & +4 & + & + & + & tw \\
\hline $\operatorname{vog} t^{24}, 1993$ & t & + & + & $+\div$ & + & + & + & + \\
\hline Komitzer $^{25}, 1995$ & + & + & + & + & + & t: & + & + \\
\hline Leng $^{37}, 1996$ & + & + & + & + & + & + & + & + \\
\hline Leng $^{3 / 4}, 1996$ & + & + & + & 4 & + & + & + & ti \\
\hline $\begin{array}{l}++=\text { criterion is specifiec } \\
+=\text { present } \\
=\text { absent } \\
\pm=\text { questionable }\end{array}$ & & & & & & & & \\
\hline
\end{tabular}

${ }^{2}$ Name of first author listed only; Criteria: (1) clear description of the study population; (2) clearly defined diagnosis of PAOD; (3) baseline measurement for all subjects; (4) documentation of follow up length; (5) loss to follow-up not more than $20 \%$; (6) documentation of measurements of prognostic factors; (7) documentation of end points; $(8)$ adequate statistical methods.

\section{Study populations and diagnostic measurements}

Table 2 reviews the study populations and diagnostic measurements of the 13 papers. The 13 study populations in fact consisted of nine cohorts, with age ranging from 29 to 93 years. In four cohorts cases were defined by the presence of intermittent claudication, measured with the WHO questionnaire 39.40 . In the other five studies, ankle-brachial pressure index was included in the case 


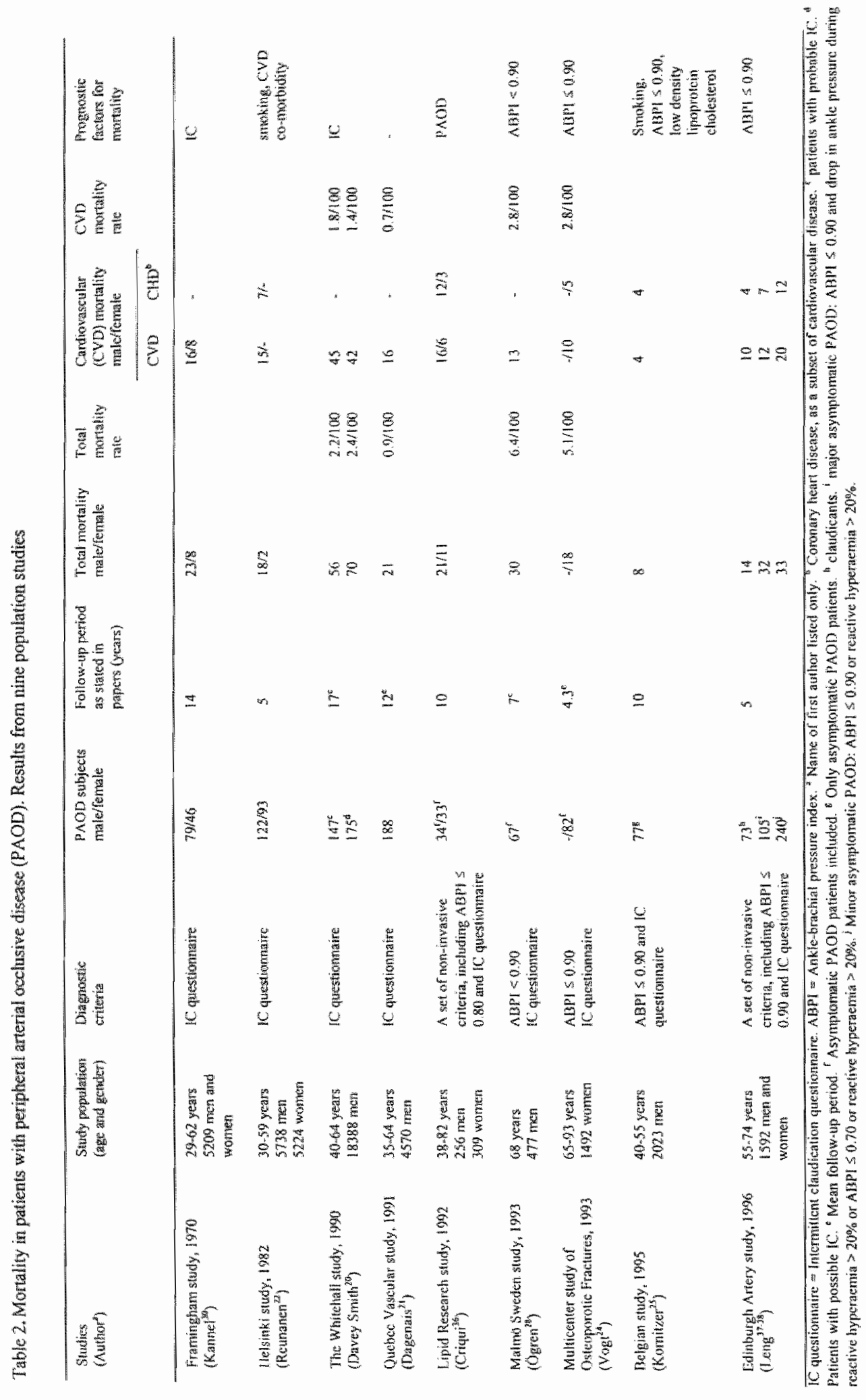


definition "A1,42 An ankle-brachial pressure $\leq 0.90$ or $<0.90$ was considered indicative for PAOD in three of these five studies. The other two studies used a variety of non-invasive measurements including an ankle-brachial pressure index $\leq 0.90$ or $\leq 0.80$ as case definition.

\section{Cardiowascular mortality}

Table 2 also summarises the data on the mortallty of PAOD. Most of the total mortality could be attributed to cardiovascular death. Four studies presented the mean follow-up period ${ }^{20,21,24.28}$. From these studies, the person-years at risk were retrievable and the crude total and cardiovascular mortality rates calculated. The crude total mortality rate ranged from 0.9 to 6.4 per 100 person-years at risk ${ }^{20,23,24,28}$. The crude cardiovascullar mortality rate ranged from 0.7 to 2.8 per 100 person-years at risk $20,21,24,28$. The adjusted relative risks of total, cardiovascular and coronary heart disease mortality were significantly elevated in claudicants, even when these patients were free of a history of cardiovascular disease at baseline (table 3). When the ankle-brachial pressure index was included in the case definition, PAOD patients even had a greater risk for cardiovascular mortality. Statistical pooling of the relative risks was not leasible because of the heterogeneity of the study populations.

Both the Belgian study and the Edimburgh Artery study showed a trend of an increased total and cardiovascular mortality in asymptomatic PAOD patients. ${ }^{25,38}$. Asymptomatic PAOD was associated with significantly elevated cardiovascular mortality risks, even when these patients had no history of cardiovascular disease at baseline (table 3 ).

All but two studies confirmed either intermittent claudication, an ankle-brachial pressure index $\leq 0.90 /<0.90$ or other abnormal non-invasive test results as significantly independent prognostic factors for cardiovascular death in PAOD patients.

Only the Whitehall study and the Edinburgh Artery study reported on cerebrovascular death. Cerebrovascular death was less common than coranary death, but still elevated in PAOD patients.

\section{The clinical course of symptomatic and asymptomatic $P A O D$}

Table 4 summarises risk factors and clinical course of PAOD. Increasing age, smoking, diabetes and hypertension were risk factors for the development of intermittent claudication in the Framingham and the Quebec Vascular studies ${ }^{21,33}$. The contribution of smoking was the strongest, increasing the risk two to four times. In the Framingham study, high serum cholesterol was also a risk factor for claudication, but this was not confirmed by the Quebec Vascular study. In the Framingham study, 
Tabie 3. Adjusted Relative Risks (RR) of Total Mortality, Cardiovascular (CVD) Mortality and Coronary Heat Disease (CHD) Mortality for PAOD. Resulis from population-based studies

\begin{tabular}{|c|c|c|c|c|}
\hline $\begin{array}{l}\text { Swodies } \\
\text { (Author })\end{array}$ & & $\begin{array}{l}\text { Total Mortality } \\
\operatorname{RR}(95 \% \mathrm{CI})\end{array}$ & $\begin{array}{l}\text { CVD Mortality } \\
\text { RR }(95 \% \mathrm{CI})\end{array}$ & $\begin{array}{l}\text { CHD Mortalit } \\
\text { RR }(95 \% \text { CD })\end{array}$ \\
\hline $\begin{array}{l}\text { Framingham study, } \\
1970 \\
\left.\text { (Katne }{ }^{30}\right)\end{array}$ & $\begin{array}{l}\text { Claudicants (male) } \\
\text { Claudicans (female) }\end{array}$ & $\begin{array}{l}1.9 \\
2.3\end{array}$ & - & - \\
\hline $\begin{array}{l}\text { Helsinki stady, } \\
1982 \\
\text { (Reunanen }^{24} \text { ) }\end{array}$ & Claudicants (male) & $1.4(p>0.05)$ & $1.2(p>0.05)$ & $0.9(p>0.05)$ \\
\hline $\begin{array}{l}\text { The Whitehall study, } \\
1990 \\
\text { (Davey Smith } 20\end{array}$ & $\begin{array}{l}\text { Possible claudicants (male) } \\
\text { Possible claudicants with no } \\
\text { history of CVD at baseline } \\
\text { (male) } \\
\text { Probable claudicants (male) } \\
\text { Probable claudicants with no } \\
\text { bistory of CVD at baseline } \\
\text { (nale) }\end{array}$ & $\begin{array}{l}1.7(1.3-2.3) \\
1.6(1.1-2.3)\end{array}$ & $\begin{array}{l}2.7(2.0 \cdot 3.7) \\
2.6(1.7 \cdot 4.0)\end{array}$ & $\begin{array}{l}2.9(2.0-4.1) \\
2.8(1.8-4.5)\end{array}$ \\
\hline $\begin{array}{l}\text { Lipid Research study, } \\
1992 \\
(\text { Criquid }\end{array}$ & $\begin{array}{l}\text { Asymptomatic } P A O D \text { patients } \\
\text { Asympromatic } P A O D \text { patients } \\
\text { with no history of } C V D \text { at } \\
\text { baseline } \\
\text { Claudicants } \\
\text { Claudicants with no history of } \\
\text { CVD at baseline }\end{array}$ & $\begin{array}{l}4.7(2.3-9.6) \\
6.7(2.5-17.6)\end{array}$ & $\begin{array}{l}11.2(4.5-27.9) \\
14.9(3.8-58.2)\end{array}$ & $\begin{array}{l}11.4(3.6-35.8 \\
13.1(2.5-67.6\end{array}$ \\
\hline $\begin{array}{l}\text { Malmö Sweden study, } \\
1993 \\
\left(O_{g r e n}^{28}\right)\end{array}$ & $\begin{array}{l}\text { Patients with an ABPI }<0.90 \\
\text { (male) }\end{array}$ & $2.3(1.4-3.8)$ & - & $2.6(4.2-5.9)$ \\
\hline $\begin{array}{l}\text { Multicenter study of } \\
\text { Osteoporotic Fractions, } \\
1993 \\
\text { (Vogti }\end{array}$ & $\begin{array}{l}\text { Patients with an ABPI } \leq 0.90 \\
\text { (fernale) } \\
\text { Patients with an ABPI } \leq 0.90 \text {, } \\
\text { with no history of CVD at } \\
\text { baseline (ferriale) }\end{array}$ & $3.1(1.7-5.5)$ & $\begin{array}{l}4.0(1.7-9.1) \\
4.5(1.5-6.7)\end{array}$ & $3.7(1.2-11.6)$ \\
\hline $\begin{array}{l}\text { Belgian study, } \\
\text { 1.995 } \\
\text { (Kormitzerts }\end{array}$ & Asymptonatic patients (male) & $2.8(1.4-5.5)$ & $42(1.7-10.5)$ & $5.0(1.8-11.4)$ \\
\hline $\begin{array}{l}\text { Edinbargh artery study } \\
1996 \\
\text { (Leng }^{3 n_{n} 3} \text { ) }\end{array}$ & $\begin{array}{l}\text { Patients with an } A B P I \leq 0.90 \\
\text { Claudicants } \\
\text { Patients with major } \\
\text { asymptomatic PAOD } \\
\text { Patients with minor } \\
\text { asymptomatic PAOD }\end{array}$ & $\begin{array}{l}1.6(1.1-2.2) \\
1.6(0.9-2.8) \\
2.4(1.6-3.7)\end{array}$ & $\begin{array}{l}1.9(1.2-3.0) \\
2.7(1.3-5.3) \\
2.1(1.1-3.8)\end{array}$ & $\begin{array}{c}1.9(1.0-3.5) \\
-\end{array}$ \\
\hline
\end{tabular}

$\mathrm{Cl}=$ Confidence interva]. ABPI = Ankle-brachial pressure index. ${ }^{a} \mathrm{RR}$ adjusted for other cardiovascular risk factors.

"Name of first author listed only, "major asymptomatic PAOD: ABPI $=0.90$ and drop in ankle pressure during reactive hyperaemia $>20 \%$ or ABPI $\leq 0.70$ or reactive hyperaemia $>20 \%$ " Minor asymptomatic PAOD: ABPI $s$ 0.90 or reactive hyperaemia $>20 \%$ 
Table 4. Risk factors, clinical course, prognostic facrors and curdiovasular morbidity in patients with peripheral atterial occillusive disease (PAOD). Results from population-based studies

\section{Claudicants Asymptomatic PAOD patients}

\begin{tabular}{|c|c|}
\hline Risk factors & 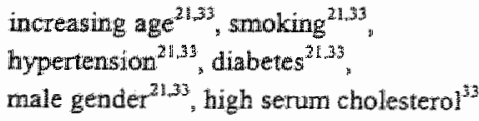 \\
\hline
\end{tabular}

Proportion with symaptom progression

$4.3 \%(6 \text { males } 1 \text { female })^{31}, 9.6 \%$

$10.4 \%$

Proportion with

$4.3 \%(6 \text { males } 1 \text { female })^{31}, 8.2 \% \%^{38}$

$0.99^{30}$

unfawourable outcone

(surgery, ampulation)

Prognostic factors for

smoking ${ }^{31}$, diabetes mellitus ${ }^{31}$

no datat

symptom progression

Proportion with

cardiovascular morbidity incident cases in male and formale $29 \%{ }^{38}$ incident cases mald: $5 \%-56 \% 21,31,35 *$ incident cases female: $16 \%-66 \% \%^{3} t^{35}$ prevalent cases male: $15.4 \%-29 \% 31.3 \%$ prevalent cases female: $16 \% \%^{3 \%}$ incident cases in male and fervale: $22.3 \%$

\footnotetext{
Total PAOD group, including asymptomatic patients
}

\section{Discussion}

We found six papers that met all relevant methodological criteria while a further seven had only one questionable or megative item. In general, recent studies were of better methodological quality than older studies. Nevertheless, the duration of the mean follow-up period, essential for the calculation of the person-years at risk for an event, was specified in only four studies.

In four studies, symptomatic PAOD was defined by means of the stanciardised WHO questionnaire on intermittent claudication. In five studies, the ankle-brachial pressure index was used as well. The WHO questionnaire is highly specific but only moderately sensitive ${ }^{41.43}$. Given the fact that in the general population asymptomatic PAOD is more common than symptomatic PAOD ${ }^{3,4}$, and that use of the WHO questionnaire does not reveal asymptomatic PAOD, its use in identifying patients at risk is less adequate. The ankle-brachial pressure index currently is the most common and widely 
applicable diagnostic method in epidemiologic studies, having a quite high sensitivity and a

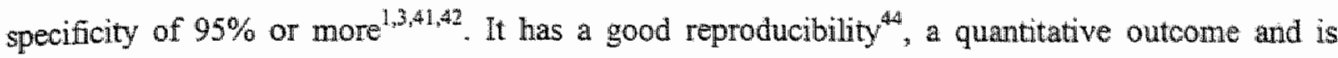
significantly associated with the severity of $\mathrm{PAOD}^{48}$.

The following conclusions can be drawn from this systematic review of population-based data:

- Important risk factors for symptomatic PAOD are smoking, increasing age, hypertension and diabetes;

- Claudicants do not often experience symptom progression with unfavourable outcomes, unless smoking or diabetes are involved;

- Compared with asymptomatic PAOD patients and normal subjects, claudicants have a higher cardiovascular morbidity, mainly coronary heart diseases;

- Claudicants have an increased risk of cardiovascular death (main cause: coronary heart disease), compared to the general population;

- There is a lack of scientific data on the prognosis of asymptomatic PAOD. The data available indicate a relatively benign course as far as the legs are concerned. However, also in these patients, a trend of increased cardiovascular morbidity and mortality is observed;

- Strong independent predictors for cardiovascular mortality are intermittent claudication and an ankle-brachial pressure index $\leq 0.90 /<0.90$ or other abnormal non-invasive test results;

- In women, PAOD seems to follow a more benign course as compared with men. The incidence of non-fatal cardiovascular events appears to be higher in female PAOD patients than in male PAOD patients. Increased mortality risks are observed in both sexes, but total mortality is higher in male PAOD patients.

\section{Comparison with referral-based studies}

Population-based evidence on risk factors, prevalence, incidence and risk factors is more suitable for primary care than referral-based evidence. When comparing the results of this review with the evidence from referral-based studies, the following similarities emerge. Increasing age, smoking and hypertension are the most significant risk factors and smoking and diabetes are important prognostic determinants for symptom progression ${ }^{46,47}$. The proportion cardiovascular death in referral-based and population-based studies is quite similar, and referted claudicants also have mortality risks two to five times higher than the general population ${ }^{48-50}$. The presence of intermittent claudication and an abnormal ankle-brachial pressure index $(\leq 0.90)$ are strong independent predictors for cardiovascular mortality in referral-based PAOD cohorts ${ }^{1,13,16,485}$. Male referred claudicants have a higher total 
mortality compared with female referted PAOD patients ${ }^{4}$, the same trend that is observed in population-based studies.

However, there are also differences between population-based and referral-based studies. In referralbased studies, hypercholesterolaemia is mentioned as a risk factor ${ }^{46}$, whereas in population-based studies its role remains inconclusive. A much higher proportion of referred claudicants experience symptom progression (25\%) and they have a higher prevalence of coexisting coronary and cerebrovascular disease $(40-60 \%)^{45-4 \%}$ than claudicants from population-based studies $(5-10 \%$ and $15-30 \%$, respectively). Nevertheless, the reported incidences of non-fatal coronary and cerebrovascular disease in referral-based studies seem lower (19-35\% ${ }^{45}$ compared with population-based studies (5-66\%). Total mortality also seems to be higher in referred claudicants ( 5 to $80 \%)^{45}$ compared with claudicants from population-based studies $(2-62 \%)$.

\section{Clinical implications}

The general practitioner has an important task in (secondary) prevention of cardiovascular diseases. With respect to PAOD, preventive objectives are: averting symptom progression and decreasing cardiovascular morbidity and mortality ${ }^{51}$. The present knowledge suggests that cessation of smoking and treatment of hypertension and diabetes are the principal preventive actions, whereas treatment of hypercholesterolaemia seems less important. Obviously, a patient with intermittent claudication complaints should be treated in accordance with the rule "stop smoking and keep walking", to prevent symptom progression and to improve the level of functioning. Furthermore, improvement of the atherosclerotic risk-factor profile is of significance for prevention of coronary heart disease and cerebrovascular disease in claudicants and asymptomatic PAOD patients, - patients with an abnomal non-invasive test result like an ankle-brachial pressure index lower than $0.90-1.00^{1,42,52}$-. The ankle-brachial pressure index, measured with a Doppler probe and a sphygmomanometer, is a reproducible and valid diagnostic tool, suitable for use in primary care ${ }^{42.52}$. In addition, the height of the ankle-brachial pressure index is inversely associated with disease severity and the occurrence of cardiovascular events ${ }^{3748}$. Thus, in patients over 50 years of age, with one or more conventional atherosclerotic risk factors, assessment of the ankle-brachial pressure index by the general practitioner could provide additional infomation on the risk of developing manifest atherosclerotic disease. 


\section{Key points}

- In the general population only 5-10\% of PAOD patients experience symptom progression. This is lower than had been reported in referral-based studies (25\%).

- Claudicants as well as asymptomatic PAOD patients frequently have coexisting cardiovascular diseases and are at high risk for developing non-fatal and fatal coronary heart disease.

- In subjects aged over 50 years with presence of cardiovascular risk factors, measurement of the ankle-brachial pressure index is appropriate.

- Patients with symptomatic as well as asymptomatic atherosclerosis in the legs, especially men, should be carefully monitored with regard to their cardiovascular risk profile.

- Preventive activities in primary care should focus primarily on smoking cessation and treatment of diabetes and hypertension.

\section{Acknowledgements}

This work and the ongoing prospective cohort study (Limburg PAOD Study, part three) is supported by a research grant from the Netherlands Heart Foundation (92.170). 


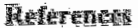

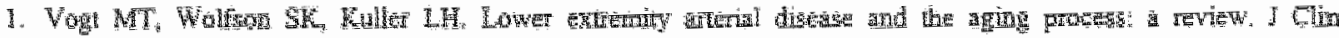

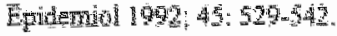

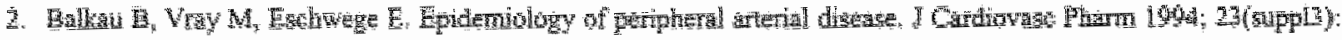
S.

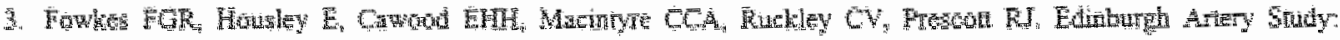

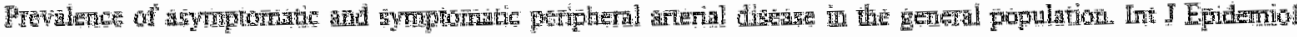

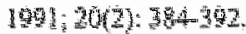

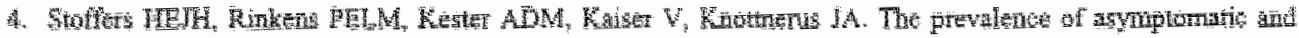

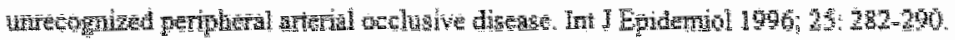

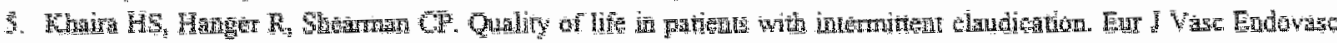
Surg $1906,11: 65$.

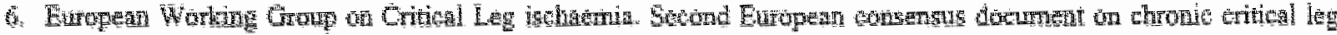
igehas

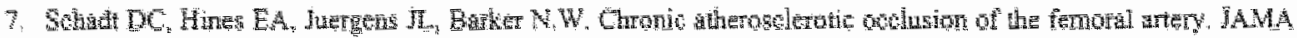

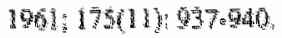

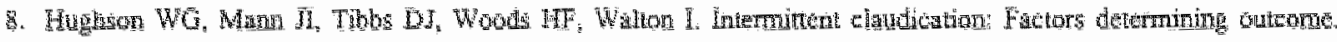

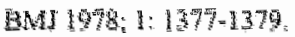

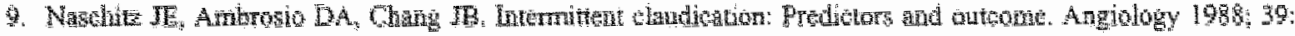
16.22

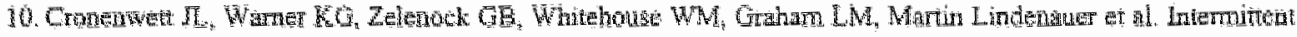

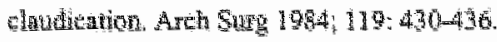

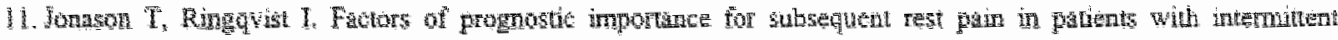
clavdir

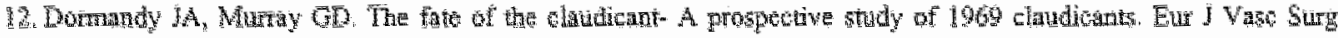

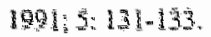

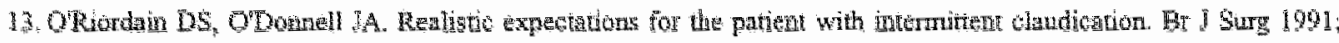
$78.861-463$.

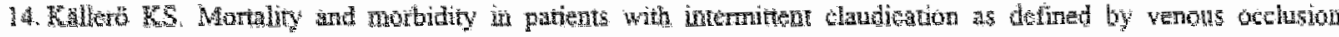

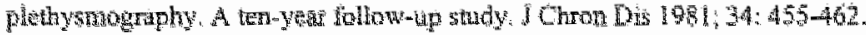

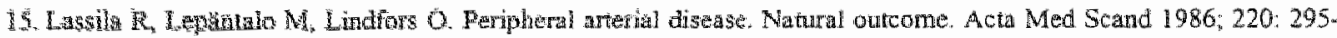
301 .

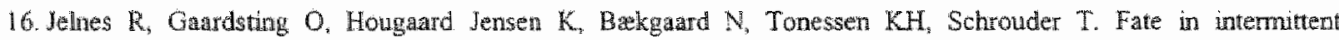
claudication: Outcome and risk factors. BMJ 1986;29: 1137-1140

17. Rogenbloom MS, Preston Flanigan D, Schuler JJ, Meyer JP, Durham IR, Eldirup-Jorgensen $J$ et al. Risk factors affecting the natural history of intermittent clandication. Arch Surg 1988; 123:867-870.

18. Tugwell PX. How to read clinical journals: II To leam the clinical course and prognosis of disease. CMA Journal $1981 ; 124: 869-872$.

19. Silagy CA. An analysis of review articles published in prinary care joumals. Fann Pract 1993; 10; 337-341.

20. Davey Smith $G$, Shipley M, Rose G. Intermittent claudication, hear disease risk factors, and mortality. The Whitehall Sudy. Circulation 1990; 82: 1925-1931.

21. Dagenais GR, Marice S, Robitalle NM, Gingras S, Lupien PJ. Intermittent clatudication in Quebec men from 1974 1986: The Quebec cardiovascular study. Clin Lnvest Med 1991; 14:93-100.

22. Reunanen A, Takkunen $\mathbb{E}$, Aromaa A. Prevalence of intermitient claudication and its effect on mortality. Acta Med Scand 1982: $211: 249-256$

23. Agner E. Natural history of angina pectoris, possible myocardial infarction and internittent claudication during the eight decade. Acta Med Seand 1981; 210:271-276.

24. Vogt MT, Cauley JA, Newman AB, Kuller LF, Hulley SB. Decreased ankle/arm blood pressure index and mortaliry in elderly women. JAMA $1993 ; 270: 465-469$. 
25. Konitzer M, Dramaix M, Sobolski J, Degre S, De Backer $G$. Ankle/am pressure index in asymptonatic niddile-aged males: an independent predictor of ten-year coronary heart disease mortality. Angiology 1995; 46: $211-219$.

26. Widmer LK, Greensher A, Kannel WB. Occlusion of peripheral arteries. A study of 6,400 working subjects. Circulation $1964 ; 30: 836-842$.

27. Ogren M, Hedblad B, Isacsson S-O, Janzon $L$, Jungqist $G$, Lindell S-E. Non-invasively detected carotid stenosis and ischaemic heart disease in men with leg arteriosclerosis. The Lancer 1993; 342:1138-1141.

28. Ögren M, Hedblad B, Jungqist $G_{5}$ Isacsson S-O, Lindell S-E, Janzon L. Low ankie-brachial pressure index in 68 -yearold men: prevalence, risk factors and prognosis. Eur J Vasc Surg 1993: 7: 500-506.

29. Hedblad B, Ogren M, Janzon L, Isacsson S-O, Lindell SE. Low pulse-wave amplitude during reactive leg hyperaemia: an independent, early marker for ischaemic heart disease and death results from the 21 -year follow-up of the prospective cohort study "men born in 1914", Malmö, Sweden, I Int Med 1994; 236: $161-168$

30. Kamel WB, Skinner JJ, Schwartz MJ, Shurteff D. Intemittent claudication. Incidence in the Franinghan Study. Circulation 1970;61:875-883.

31. Newton Peabody C, Kannel WB, MeNamara PM. Intermittent claudication. Surgical significance. Arch Surg 1974; 109: 693.697 .

32. Kannel WB, McGee DL. Update on some epidemiologic features of intermittent claudication: The Franingham Study. J Am Geriatr Soc 1985; 33: 13-18.

33. Stokes J, Kannel WB, Wolf PA, Cupples LA, D'Agostino RB. The relative importance of selected risk factors for various manifestations of cardiovascular disease among men and women from 35 to 64 years old: 30 years of followup in the Framinghan study. Circulation 1987, 75(suppl V): V65-V73.

34. Criqui MH, Coughlin SS, Fronek. A. Noninvasiwely diagnosed peripheral arterial disease as a predictor of mortality: Results from a prospective study. Circulation 1985; 72(4): 768-773

35. Criqu MH, Langer RD, Fronek A, Feigelson HS. Coronary disease and stroke in patients with large-vessel peripheral arterial disease. Drugs 1991; 42(suppl 5): 16-21.

36. Criqui MH, Langer RD, Fronek A, Feigelson HS, Klauber MR, MeCann TJ, Browner D. Mortality over a period of 10 years in patients with peripheral arterial disease. New Engl I Med 1992; 326: 381 -386.

37. Leng GC, Fowkes FGR, Lee AJ, Dumbar $\mathrm{J}_{\mathrm{s}}$ Housley E, Ruckley $\mathrm{CV}$. Use of ankle-brachial pressure index to predict cardiovascular events and death: a cohort study. BMJ 1996; 313; 1440-1444.

38. Leng GC, Lee AJ, Fowkes FGR, Whiteman M, Dunbar J, Houssley E Ruckley CV. Incidence, natural history and cardiovascular events in symptomatic and asymptomatic peripheral arterial disease in the general population. Int $\sharp$ Epidemiol 1996; 25: 1172-81.

39. Rose GA. The diagnosis of ischaemic heart pain and intermittent cladication in field surveys. BuIl WHO 1962; 27 . $645-58$.

40. Rose G, McCartney P, Reid D. Self-administration of a questionnaure on chest pain and intermittent claudication. B I Prewent and Soc Med 1977, 31:42-8

41. Fowkes FGR. The measurement of atherosclerotic peripheral anterial disease in epidemiological surweys. Int I Epidemiol 1988; 2: 248-54.

42. Stoffers HEJH, Kester ADM, Kaiser $V$, Rinkens. PELM, Kitslaar PJEHM, Knothenus JA. The diagnostic value of the measurement of the ankle-brachial systolic pressure index in primary health care. J Clin Epidemiol 1996; 49: 1401. 05.

43. Stoffers HEJH, Kester ADM, Kaiser V, Rinkens PELM, Knottnerus JA. Diagnostic value of signs and symptome associated with peripheral arterial occlusive disease seen in general practice: A multivariable approach. Med Decis Making 1997; 17: 61-70.

44. Stoffers HEJH, Kaiser V, Kester ADM, Schouten HIA, Knottherus JA. Peripheral arterial occlusiwe disease in general practice: the reproducibility of the ankle-arm systolic pressure ratio. Scand I Prim Health Care 1991; 9: $109-14$.

45. Dormandy J, Mahir M, Ascady G et all. Fate of the patient with chronic leg ischaemia. J Cardiowasc Surg 1989; 30: $50-7$.

46. McGrae MeDermott M, MeCarthy W. Intermittent Claudication. The matural history. Surgical Clinics of North America $1995 ; 75: 581-91$. 
47. McDaniel $\mathrm{MD}_{1}$ Cronerwwett IL. Basic data related to the matural history of intermittent clandication. Ann Vasc Surg 1989; 3:273-7.

48. McGrae McDermot M, Feinglass $\mathbb{d}$, Slavensky $R$, Pearce WH. The ankle-brachial index as a predictor of survival in patients with peripheral vascular disease. J Gen Intera Med 1994, 9:445-9.

49. Vogt MT, McKena M, Wolfson SK, Kuller LH. The relationship berween ankle brachial index, other atherosclerotix disease, diabetes, smoking and mortality in older men and women. Atherosclerosis 1993; 101: 1991-202.

50. Mckenna $M$, Wolfson $S$, Kuller $L$. The ratio of amkle and am arterial pressure as an independent predictor of mortality. Atherosclerosis 1991; 87:119-128.

51. Wan Ree J. Who is at risk of intervention? The role of the general practitioner in preventive cardiology, Eur J Gen Pract 1995, 1: 99-100.

52. Hiat WR, Marshall IA, Baxter J et all. Diagnostic methods for peripheral arterial disease in the San Luis valley diabetes study. J Clin Epidemiol 1990; 43:597 - 606.

53. Kilslaar PJEHM. Consensus diagnostiek en behandeling van arteriele claudicatio intermintens (Consensus on the diagnosis and trealment of intermittent claudication). Ned Tijdschr Geneeskd 1997; 141: 2396 - 400. 
Risk factors and cardiovascular diseases associated with asymptomatic peripheral arterial occlusive disease: The Limburg PAOD Study

Jurenne D Hooi

Henri EJ H Stoffers

Arnold D M Kester

Paula E L M Rinkens

Victor Kaiser

Jan W van Ree

J André Knottnerus 


\begin{abstract}
Objectives. To describe the risk-factor profile and cardiowascular co-morbidity of asymptomatic peripheral arterial occlusive disease (PAOD).

Design. A crosz-sectional survey. Asymptomatic PAOD was defined as an ankle-brachial pressure index $<0.95$, measured on two consecutive occasions, without intermittent claudication. Logistic regression analyses were performed to investigate independent associations between age, gender, smoking status, hypertension, obesity, diabetes, hypercholesterolaemia, physical activity, a family history of cardiovascular disease, the occurrence of ischaemic heart disease (IHD) and cerebrovascular disease (CeVD) and asymptomatic PAOD.
\end{abstract}

Setting. 18 General practices in the province of Limburg, the Netherlands.

Subjects. A total of 3649 subjects, aged 40 to 78 years.

Main results. Asymptomatic PAOD was present in $8.6 \%(\mathrm{n}=314)$ and symptomatic disease in $3.8 \%$ $(\mathrm{n}=138$ ) of the participants. Age, smoking status, hypertension and diabetes were significantly associated with asymptomatic $\mathrm{PAOD}$. The ratio of asymptomatic to symptomatic PAOD was higher among the younger age groups. Male gender, hypertension and smoking status were stronger associated with symptomatic PAOD compared with asymptomatic PAOD. Asymptomatic subjects had more IHD and CEVD co-morbidity compared with the healthy population.

Conchsion. Our findings suggest that the risk-factor profile and cardiovascular co-morbidity of asymptomatic subjects is comparable to claudicants. Preventive efforts could be made to diminish the influence of especially smoking, diabetes and hypertension in asymptomatic subjects.

Key words: peripheral artenal occlusive disease, risk factors, cardiovascular disease, general practice. 


\section{Introduction}

Peripheral arterial occlusive disease (PAOD) is becoming major public health problern. PAOD usually manifests itself in middle-aged and elderly people by intermittent claudication complaints (IC). Smoking, diabetes, hypertension and age are well-known risk factors ${ }^{1-7}$. The role of hypercholesterolaemia, obesity and male gender as potential risk factors is apparent in some studies ${ }^{67}$, but not confirmed in others ${ }^{2,4,7}$. Data on the role of a sedentary lifestyle $e^{6,8}$ and atherosclerotic predisposition in the family ${ }^{6,3}$ are scarce.

Most studies conceming PAOD and its risk factors discuss $I C$, the first symptomatic stage of PAOD. These patients are at higher risk for other cardiovascular diseases and mortality ${ }^{910}$. PAOD also has an asymptomatic stage, with a higher prevalence in the general population than symptomatic $\mathrm{PAOD}^{1,11,12}$. Practically no data are available on the risk-factor profile of asymptomatic PAOD subjects. Furthermore, only a few population-based studies investigated the relationship between asymptomatic $\mathrm{PAOD}$ and cardiovascullar diseases ${ }^{13,14}$. Is the risk-factor profile of asymptomatic PAOD subjects comparable with the risk-factor profile of claudicants? Is asymptomatic PAOD associated with the same occurrence of cardiovascular diseases as symptomatic PAOD? The answer to these questions are important in setting goals for prevention of symptomatic PAOD and the occurrence of other cardiovascular diseases.

The aims of this study were to describe the risk-factor profile and cardiovascular co-norbidity of asymptomatic PAOD subjects.

\section{Methods}

\section{Study population}

The study population of the Limburg PAOD study included residents of the province of Limburg, the Netherlands. Every citizen of the Netherlands is registered at a general practice. Therefore, the registered population of a general practice is segment of the general population. The participants were selected out of a group of 26,620 subjects, aged 40 to 78 years, within 18 general practices. A postal screening questionnaire was mailled to these subjects with five questions mostly about factors possibly relevant to $\mathrm{PAOD}$, so that responders could be characterised to a "prior risk score" between 0 and 5 . The study population included subgroups corresponding with parts of the clinical spectrum relevant to the general practice. After a stratified sampling procedure, 5301 subjects were invited and 3649 of them (mean age: 59 years, 53\% fernale) agreed to participate in the study. No statistically significant differences between participants and non-participants with regard to age and gender were found. The details of recruitment and selection procedures were extensively described elsewhere ${ }^{11,15}$. 


\section{Data collection}

All participants wisited their general practice. With a self-administered questionnaire, information was compiled on gender, age, IC complaints, current and former smoking habits, physical activities and the occurrence of cardiovascular disease in the family.

The general practice assistants measured height and weight of the subjects and the ankle-brachial pressure inclex (ABPT) by means of a pocket Doppler device (Huntleigh Mini Dopplex D500, 8 Mhz) and a mercury sphygmomanometer. Participants were measured in a supine position. The measurements included the systolic blood pressure on both arms (brachial artery) and ankles (dorsalis pedis or posterior tibial artery). The ABPI was calculated as the ratio of the ankle systolic blood pressure to the highest arm systolic blood pressure. To achieve unifomity of Doppler assessments, the assistants had been trained ${ }^{16}$.

From the subjects' medicaj, records, data were collected regarding the presence of hypertension, hypercholesterolaemia, diabetes, and the occurrence of ischaemic heart disease (IHD) and cerebrovascular disease (CeVD). In the Netherlands the general practitioners receive all correspondence for every patient whom is referred to a specialist.

\section{Diagnostic criteria and definitions}

PAOD was considered present when a subject twice had a resting $\mathrm{ABPI}<0.95$ for at least one leg, measured on two occasions with a one-week interval. IC was defined as pain in the calf while walking, disappearing when standing still, and not present when resting (typical IC) ${ }^{11,1 v_{0} 18}$. Other complaints of the calf, and complaints of foot, thigh, or buttock showing this ischaemic pattern were also included in the definition of IC (atypical IC). Asymptomatic PAOD was defined as the combination of an ABPI $<0.95$ without IC symptoms. Symptomatic PAOD was defined as the combination of an $\mathrm{ABPI}<0.95$ with $\mathrm{IC}$ (typical or atypical)

Obesity was defined as a body mass index $\left(\mathrm{kg}^{2}\right)>30$. Hypertension, diabetes and hypercholesterolaemia were considered present when specific guidelines were net ${ }^{19}$. Hypertension: either a diastolic pressure between $95-104 \mathrm{mmHg}$ measured on five separate occasions, or a diastolic pressure $\geq 105 \mathrm{~mm} H \mathrm{H}$ measured on three separate occasions. Diabetes; either typical complaints and one abnormal serum glucose level (fasting $\geq 6.7 \mathrm{mmol} / \mathrm{l}, 2$ hours postprandial $\geq 11.1 \mathrm{mmol} / \mathrm{\text {) }}$ or two incidents of an abnormal senum glucose level. Hypercholesterolaemia: a mean of three serum cholesterol measurements $\geq 6.5 \mathrm{mmol} /$ 
Daily work and leisure-time activities were scored on a scale of heavy, moderate, or light physical activity. A family history of cardiovascular disease was positive when subjects had a first-or seconddegree relative who suffered from $\mathbb{I H D}, \mathrm{CeVD}$ and/or PAOD under the age of 65 . IHD comprised angina pectoris and myocardial infarction. CeVD comprised transient ischaemic attack, carotid stenosis and cerebrovascular accidents.

\section{Data analysis}

Univariate and bivariate analyses were performed, estimating the prevallence of the risk factors and the corresponding crude odds ratios (cOR) with $95 \%$ confidence intervals (CI), respectively. Four logistic regression analyses were carried out to determine the independent association of each risk factor with PAOD (BMDP statistical package). The dependent variables were overall PAOD (vs no PAOD) in the first model, asymptomatic PAOD (vs no PAOD) in the second model and symptomatic PAOD (vS no PAOD) in the third model. In the fourth model, used to investigate risk factors that might be more specific for symptomatic PAOD, the analysis was restricted to the sub-group of PAOD cases, with symptomatic PAOD as the dependent variable (vs asymptomatic PAOD).

Contingency tables were used to calculate the age-specific prevalence of IHD and CeVD for asymptomatic subjects and claudicants. With two logistic regression models, the associations of IHD (dependent variable in the first model) and $\mathrm{CeVD}$ (dependent variable in the second model) with the independent variables asymptomatic PAOD and symptomatic PAOD were investigated, adjusted for other cardiovascular risk factors.

\section{Results}

Among the study population, 458 subjects $(12.5 \%)$ had PAOD, of whom $138(3.8 \%)$ were symptomatic, $314(8.6 \%)$ were asymptomatic and $6(0.2 \%)$ had PAOD of unspecified type. These 6 subjects were excluded from the analyses, except for the analyses with the overall PAOD group.

\section{Risk factors associated with asymptomatic $P A O D$}

Table 1 presents the prevalence and the corresponding cORs of each risk factor in the asymptomatic and symptomatic group. Significant positive associations were found for age, current- and exsmoking, hypertension, diabetes and hypercholesterolaemia with asymptomatic and symptomatic PAOD. A sedentary lifestyle and male gender were significantly related only to symptomatic PAOD. 
Table 1. Prevalence (P) and crude odds ratios (COR) of rist factors for asymptomatic and symptomatic PAOD in the study population $(n=3649)$

\begin{tabular}{|c|c|c|c|c|c|c|}
\hline \multirow[b]{2}{*}{ Risk tactor } & \multicolumn{2}{|c|}{$\begin{array}{l}\text { Overall PAOD } \\
(n=458)^{1}\end{array}$} & \multicolumn{2}{|c|}{$\begin{array}{l}\text { Asymptomate PAOD } \\
\qquad(\mathrm{n}=314)\end{array}$} & \multicolumn{2}{|c|}{$\begin{array}{c}\text { Symptomatic PAOD } \\
(n=138)\end{array}$} \\
\hline & $\begin{array}{r}\mathrm{P} \\
(\%)\end{array}$ & $\begin{array}{c}\mathrm{cOR} \\
(95 \% \mathrm{CI})\end{array}$ & $\begin{array}{r}\mathrm{p} \\
(6)\end{array}$ & $\begin{array}{c}0 \mathrm{OR} \\
65 \% \mathrm{Cl})\end{array}$ & $\begin{array}{r}P \\
\% \\
\end{array}$ & $\begin{array}{c}100 R \\
(95 \% \mathrm{CI})\end{array}$ \\
\hline Age: & & & & & & \\
\hline $50-59$ & 7.6 & $1.9(1.3-2.9)$ & 5.6 & $2.1(1.3-3.4)$ & 2.1 & $1.6(0.7-3.4)$ \\
\hline $60-69$ & 17.4 & $5.0(3.4-7.3)$ & 13.2 & $5.3(3.3-8.5)$ & 5.3 & $4.1(2.1-8.1)$ \\
\hline 270 & 24.7 & $7.8(5.2-11.7)$ & 16.5 & $6.9(4.2-11.3)$ & 10.8 & $8.9(4.5-17.7)$ \\
\hline Male & 14.6 & $1.4(1.2 \cdot 1.7)$ & 9.6 & $1.2(0.9-1.5)$ & 5.9 & $2.3(1.6-3.3)$ \\
\hline Ex-smoker & 13.0 & $1.6(1.2-2.2)$ & 9.2 & $1.4(1.0-1.9)$ & 4.6 & $2.6(1.4-4.6)$ \\
\hline Current smoker & 14.7 & $1.9(1.4 \cdot 2.4)$ & 10.1 & $1.5(1.1-2.1)$ & 5.3 & $3.0(1.8-3.1)$ \\
\hline Hypentension" & 159 & $1.6(1.3-2.0)$ & 11.1 & $1.5(1.5-1.9)$ & 5.8 & $2.0(1.4-2.8)$ \\
\hline Obesity $^{2}$ & 9.8 & $0.7(0.6-2.0)$ & 7.4 & $0.8(0.6-1.1)$ & 2.7 & $0.6(0.4-1.0)$ \\
\hline Diabetes mellitus ${ }^{2}$ & 23.9 & $2.5(1.9-3.2)$ & 18.3 & $2.6(2.0-3.5)$ & 8.0 & $2.2(1.4-3.5)$ \\
\hline Hypercholesterolaemia ${ }^{2}$ & 17.0 & $1.5(1.5-2.1)$ & 11.5 & $1.4(1.0-2.0)$ & 6.9 & $1.9(1.2 * 3.0)$ \\
\hline Light physical activity ${ }^{2}$ & 13.1 & $1.4(1.1-1.9)$ & 9.3 & $1.3(0.9-1.8)$ & 4.4 & $1.7(1.0-2.8)$ \\
\hline $\begin{array}{l}\text { Family history of } \\
\text { cardiovascular disease }\end{array}$ & 12.3 & $0.9(0,7-1.1)$ & 8.9 & $0.9(0.7-1.2)$ & 4.0 & $0.8(0.6-1.2)$ \\
\hline
\end{tabular}

${ }^{1}$ Including the 6 patients that had non-specified PAOD. These patients were excluded from further analyses with the asymptomatic and symptomatic PAOD group. ${ }^{2}$ Definitions: see Methods.

Table 2 presents the results of the logistic regression analyses. Age, curreni- and ex-smoking, hypertension and diabetes were significantly associated with asymptomatic as well as symptomatic PAOD (models 2 and 3). In the asymptomatic group, no difference in sex distrioution was found, whereas in claudicants male gender was predominant. Further analysis, restricted to the PAOD subgroup (model 4), showed that male gender was significantly more associated with symptomatic PAOD than asymptomatic PAOD. There was also a positive correlation between current- and exsmoking, hypertension and a sedenterary lifestyle and symptomatic PAOD. Asymptomatic PAOD seemed more predominant in the younger age groups. 


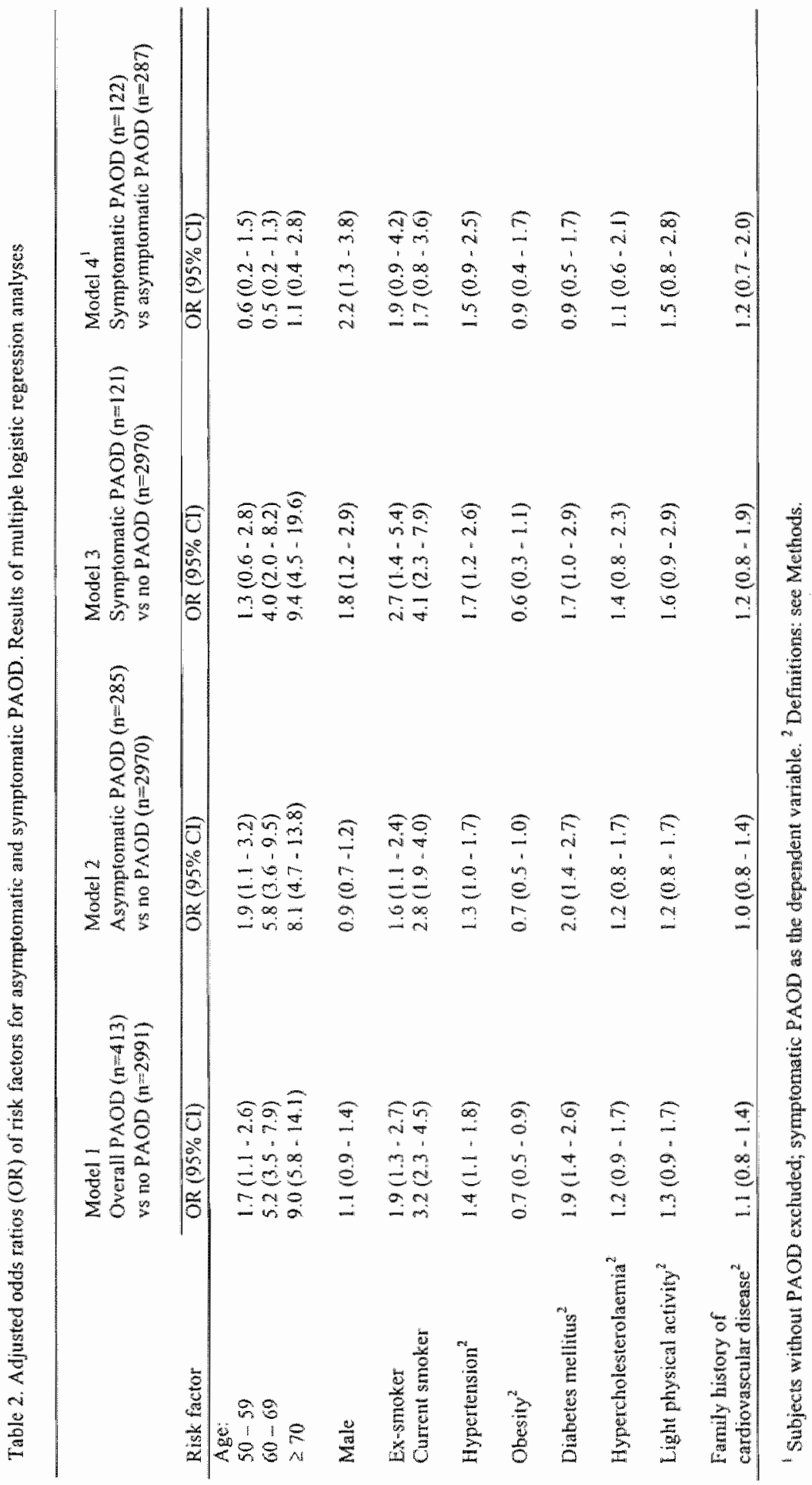


Ischaemic heart disease, cerebrovascular disease and asymptomatic PAOD

IHD was present in $822(22.7 \%)$ subjects, and CeVD occurred in $190(5.2 \%)$ subjects. Table 3 shows the age-specific prevalences of cardiovascular co-morbidity in asymptomatic subjects and claudicants. The prevalence of IHD increased with age and was almost twice as common in asymptomatic and symptomatic subjects compared with the healthy population. CeVD co-morbidity also increased with age and was even higher in asymptomatic subjects compared with claudicants.

Table 3. Age-specific prevalence of ischaemic heart disease (IHD) and cerebrowascular disease (CeVD) for asymptomictic and symptomatic PAOD in the study population

\begin{tabular}{|c|c|c|c|c|c|c|}
\hline \multirow[t]{2}{*}{ Age: } & \multicolumn{3}{|c|}{$\begin{array}{l}\text { Prevalence HHD \% } \\
\text { (absolute numbers) }\end{array}$} & \multicolumn{3}{|c|}{$\begin{array}{l}\text { Prevalence CeVD \% } \\
\text { (absolute numbers) }\end{array}$} \\
\hline & $\begin{array}{l}\text { No } \\
\text { PAOD } \\
(n=3170)\end{array}$ & $\begin{array}{l}\text { Asymptomatic } \\
\text { PAOD } \\
(n=312)\end{array}$ & $\begin{array}{l}\text { Symptomatic } \\
\text { PAOD } \\
(n=138)\end{array}$ & $\begin{array}{l}\text { MO } \\
\text { PAOD } \\
(n=3175)\end{array}$ & $\begin{array}{l}\text { Asymptomatic } \\
\text { PAOD } \\
(n=311)\end{array}$ & $\begin{array}{l}\text { Symptomatic } \\
\text { PAOD } \\
(\mathrm{n}=137)\end{array}$ \\
\hline $40-49$ & $5.9(43)$ & $15.0(3)$ & $20.0(2)$ & $1.0(7)$ & $5.0(1)$ & $0(0)$ \\
\hline $50 \cdot 59$ & $15.7(166)$ & $33.3(21)$ & $34.8(8)$ & $2.5(26)$ & $9.7(6)$ & $0(0)$ \\
\hline $60-69$ & $28.7(279)$ & $46.3(69)$ & $50.9(28)$ & $6.6(64)$ & $11.5(17)$ & $9.3(5)$ \\
\hline$\geq 70$ & $34.1(139)$ & $52.5(42)$ & $52.5(22)$ & $8.5(35)$ & $29.6(24)$ & $10.0(5)$ \\
\hline Total & $19.8(627)$ & $43.3(135)$ & $43.5(60)$ & $4.2(132)$ & $15.4(48)$ & $7.3(10)$ \\
\hline
\end{tabular}

Table 4. Adjusted odds ratios (OR) of asymptomatic and symptomatic PAOD for ischaemic heart disease (IHD) and corebrovascular disease (CeVD). Results of muliple logistio regression analyses

$\begin{array}{ll}\text { IHD }(n=791) & \operatorname{CeVD}(n=183) \\ \text { ws no IHD }(n=2753) & \text { vs no CeVD }(n=3367)\end{array}$

\begin{tabular}{lll} 
PAOD & OR $(95 \% \mathrm{CI})$ & OR $(95 \% \mathrm{CD})$ \\
\hline Asymptomatic PAOD & \\
Symptomatic PAOD & \\
\hline
\end{tabular}

${ }^{\prime}$ Adjusted for age, gender, smoking siatus, hypertension, obesity, diabetes mellitus and hypercholesterolaemia

${ }^{2}$ Definitions: see Methods. No PAOD as reference category. 
Multivariable analyses showed significant associations for IHD with asymptomatic and symptomatic PAOD (table 4). CeVD was significantly associated only with asymptomatic PAOD. Compared with symptomatic PAOD, asymptomatic PAOD was associated with a significant higher occurrence of $\mathrm{CeVD}$ (OR: $3.2,95 \% \mathrm{CI}: 1.5-6.9)$.

\section{Discussion}

Our study, using both the ABPI and IC questionnaire, showed that the risk-factot profiles of asymptomatic subjects and claudicants are quite similar. Male hypertensive PAOD subjects, smoking or ex-smoking with a sedentary lifestyle, were more likely to have IC symptoms. Asymptomatic PAOD seemed more common among the younger age groups than symptomatic PAOD. IHD was significantly associated with asymptomatic and symptomatic PAOD, but CeVD was significantly associated only with asymptomatic PAOD.

The risk factor associations presented in this study were analysed with cross-sectional data. In a crosssectional study design, the causal direction of a relationship between unstable study factors and a disease cannot be established with certainty. Nevertheless, the existing evidence from longitudinal studies has indicated that most of the risk factors studied precede PAOD. Due to the sampling procedure, subjects with a higher risk were overrepresented in the study population. This, however has little consequences for the calculated ORs, because the sample proportions for diseased and nondiseased participants were identical.

\section{Risk-facior profile}

Smoking and age are indisputably the most impoitant risk factors for PAOD, whether diagnosed by a history of IC or by ABPI, in essentially all epidemiological studies 6,7 . Hypertension and diabetes are also associated with PAOD in most studies ${ }^{67}$. Our results are in agreement with these studies, confirming the evidence of an association between smoking, age, hypertension and diabetes with PAOD.

The inverse association found for obesity (not significant) with asymptomatic and symptomatic PAOD, add more to the inconsistencies in the available data. The Cardiovascular Health study demonstrated also an inverse association cross-sectionally. The Framingham incidence study showed a. U-shaped association in female claudicants as opposed to a significantly inwerse relationship in male claudicants ${ }^{2}$.

Hypercholesterolaemia as a possibie risk factor has given inconclusive results, in some studies 
depending on the gender of the subjects $2,6,7,9$. In our data, hypercholesterolaemia was not significainty associated with asymptomatic and symptomatic PAOD in the multivariable analyses.

The evidence of a possible relationship between a sedentary lifestyle and PAOD is limited. Strenuous exercise appears to be protective". Our data are compatible with these findings. It should be pointed out however that when physical activity is measured cross-sectionally, claudicants might report less physical activity due to their symptoms.

We found no associations between a family history of cardiovascular disease and asymptomatic or symptomatic PAOD. This is in accordance with the Quebec Cardiovascular study of male claudicants's?

In the present investigation, asymptomatic PAOD was more pronounced in the younger age groups. Compared with asymptomatic PAOD, symptomatic PAOD was stronger associated with male gender, smoking status, hypertension and a sedentary lifestylle. Longindinall studies are necessary to establish the role of these factors in asymptomatic subjects as possible prognostic determinants for the development of symptomatic PAOD.

In conclusion, our results indicate that asymptomatic PAOD has a risk-factor profile quite similar to symptomatic PAOD: ageing, smoking, hypertension and diabetes were significantly associated with asymptomatic and symptomatic PAOD. Ageing, smoking, hypertension and male gender showed a stronger association with symptomatic disease.

\section{Cardiowascular co-morbidity}

In our study, IHD was common in asymptomatic subjects and claudicants, supporting the results of the Edinburgh Artery Study in which increased risks of IHD in asymptomatic subjects and claudicants were demonstrated cross-sectionally ${ }^{12}$ and longitudinally ${ }^{14}$. In the Lipid Research Clinic Study, asymptomatic subjects and claudicants were at higher risk for non-fatal cardiovascular disease $^{20}$. After ten years of follow-up, these subjects had a higher mortality rate from IHD and CeVD as compared to a healthy population. ${ }^{13}$.

The finding of a strong association of CeVD with asymptomatic PAOD as opposed to symptomatic PAOD was unexpected. This is most likely a chance finding due to the small numbers of claudicants whom had CeVD co-morbidity. CeVD has a high fatality rate. Claudicants could have a lower survival chance after a cerebrovascular accident whereas asymptomatic subjects may develop minor strokes with a better prognosis. In the Lipid Research. Clinic Study and the Edinburgh Artery Study, the risk of cardiovascular death was (slightly) lower in asymptomatic PAOD subjects as compared 
with claudicants, providing some longitudinal evidence in this direction ${ }^{13.44}$. Furthermore, cerebrovascular morbidity is known to cause physical inactivity. It is possible that some claudicants whom had experienced a cerebrovascular accident, may have not reported IC and consequently were classified as asymptomatic. Another explanation could be a higher use of salicylic acid derivates in the claudicants. Additional analyses showed no difference in the use of salicylic acid derivates in asymptomatic subjects $(17.8 \%)$ as compared with claudicants $(18.1 \%)$.

In conclusion, our results show that IHD and CeVD are significantly associated with asymptomatic PAOD.

\section{Clinical implications}

The general practitioner plays a major role in the diagnosis and management of symptomatic PAOD, i.e. intermittent claudication. Moreover, cardiovascular risk management is a principal function of primary health care ${ }^{21}$. Identifying asymptomatic subjects is clinically relevant, since risk-factor reduction in an early stage of PAOD could prevent worsening of disease, other cardiovascular events and consequent mortality. Asymptomatic PAOD is identified by non-invasive testing, e.g. measuring the $A B P I^{1,12,17,22,23}$. The ABPI is a reproducible and valid diagnostic tool, not only to the vascular specialist, but also in primary care ${ }^{23}$. In asymptomatic subjects thus identified, smoking, hypertension and diabetes would be the most relevant risk factors to tackle.

\section{Acknowledgements}

We thank the participating general practitioners and the practice assistants for their contribution to this study. The Limburg PAOD Study was supported by a research grant of the Netherlands Organization for Scientific Research (900-715.154) and the Dutch "Praeventiefonds" (28-1323). Doppler devices were donated by Asta Medica BV. An ongoing prospective cohort study is supponted. by a research grant from the Nietherlands Heart Foundation (92.170). 


\section{References}

1. Ogren M, Hedblad $B$, Jungquist $\mathrm{G}$, Isacsson S-O, Lindell SE, Janzon L. Low ankle-brachial pressure index in 68-yearold men: Prevalence, nisk factors and prognosis. Eur J Vase Surg 1993;7:500-5

2. Kannel WB, MCGee DL. Update on some epidemiologic features of intermittent claudication: The Framingham Study. J Am Geriatr Soc 1985;33:13-8.

3. Skalkidis $Y$, Katcoulyanni R, Petridou E, Sehas M, Trichopoullos D. Risk factors of peripheral arterial occhisive disease: A case-control stady in Greece. Int J Epidemiol 1989;18:614-8.

4. Criqui MH, Browner D, Fronek A, Klatiber MR, Coughlin SS, Barreti-Connor E, et al Peripheral arterial disease in large vessels is epidemiologically distinct from small vessel disease. An analysis of risk factors. Am I Epidemiol $1989 ; 129: 1110 \% 9$.

5. Newman AB, Siscovick DS, Manolio TA, Polak J, Fried LP, Borhani NO, el al Ankle-arm index as a marker of atheroscierosis in the cardiovascular health sudy. Circulation 1993;88:837-45.

6. Ballkau $B$, Vray $M$, Eschwege E. Epidemiology of peripheral arterial disease J Card Pharm 1994;23:S8-S16.

7. Vogt MT, Wolfson SK, Kuller LH. Lower extrenity arierial disease and the aging process: a rewew. J Clin Epidemiol $1992,45: 529-42$.

8. Housley E, Leng GC, Donnan PT, Fowkes FGR. Physical activity and risk of peripheral arterial disease in the general population: Edinburgh Artery Study. I Epidemiol Com Health 1993;47:475-80.

9. Dagenais GR, Maurice S, Robitaille NM, Gingras S, Lupien PJ. Intermittent claudication in Quebec men from 1974. 1986: The Quebec Cardiowascular Study. Clin Invest Med 1991;14:93-100.

10. Davey Snith G, Shipley MI, Roge G. Intemnittent claudication, heart disease risk factors, and morality. The Whitehall Study. Circulation 1990;82:1925-31.

11. Stoffers HEJH, Rinkens PELM, Kester ADM, Kaiser $V$, Knottnerus JA. The prevalence of asymptomatic and unrecognized peripheral arterial occlusive disease. Int J Epidemiol 1996,25:282-90.

12. Fowkes FGR, Housley E, Cawood EHH, Macintyre CCA, Ruckley CV, Prescott RJ. Edinburgh Artery Study: Prevalence of asymptomatic and symptomatic peripheral arterial disease in the general population. Int J Epidemiol $1991 ; 20: 384-92$.

13. Criqui MH, Langer RD, Fronek A, Feigelson HS, Klauber MR, McCann MH, et al Mortality over a period of 10 years in patients with peripheral arterial disease. New Engl J Med 1992;326:381-6.

14. Leng GC, Lee AJ, Fowkes $F G R$, Whiteman $M$, Dunbar J, Honsley $E$, et al. Incidence, natural history and cardiovascular events in symptomatic and asymptomatic peripheral arterial disease in the general population. Inter I Epidemiol 1996;25:1172-81.

15. Stoffers HEJH, Kester ADM, Kaiser V, Rinkens PELM, Knottienus JA. Diagnostic value of signs and sympioms associated with periphieral arterial occlusive disease seen in general practice: A multivariable approach. Med Decis Making 1997:17:61-70.

16. Stoffers HEJH, Kaiser V, Kester ADM, Schouten HJA, Knottierus JA. Peripheral arterial occlusive disease in general practice: the reproducibility of the ankle-arm systolic pressure ratio. Scand J Prim Health Care 1991;9:109-14.

17. Rose GA, Blackbum H, Gillum RF, Prineas RJ. Cardiovascular Survey Methods. 2nd ed. Geneva: WHO, 1982:162-5.

18. Leng GC. Questionnaires. In: Fowkes FGR, editor. Epidemiology of peripheral vascular disease. London: Springer Verlag $1991: 29-40$.

19. Rutten GEHM, Thonas S, editors. NHG-Standaarden voor de huisarts. (Clinical guidelines of the Duitch College of General Practitioners). Utrecht: Bunge, 1993:107-21:132-40;155-68.

20. Criqui MHI, Langer RD, Fronek A, Feigeison HS. Coronary disense and stroke in patients with large-vessel peripheral arterial disease. Drugs 1991:42:16-21

21. Van Ree J. Who is at risk of intervention? The role of the general practitioner in preventive cardiollogy. Eur J Gen Pract $1995 ; 1: 99-100$.

22. Hialt WR, Marshall JA, Baxcer J, Sandoval R, Hildebrandt W, Kahn LR, et al Diagnostic methods for peripheral arterial disease in the San Luis Valley Diabetes Study. I Clin Epidemiol 1990;43:597-606.

23. Stoffers HENH, Kester ADM, Kaiser V, Rinkens PELM, Kitslaar JEFM, Knottnens JA. The diagnostic value of the measurement of the ankle-brachial systolic pressure index in primary health care. J Clin Epidemiol; 1996:1401-5. 
Asymptomatic peripheral arterial occlusive disease and erection problems

Jurenne D Hooi

Henri EJH Stoffers

I André Knottnerus

Paula ELM Rinkens

Jan W van Ree 


\section{Introduction}

Intermittent claudication (IC) is the first symptomatic stage of peripheral arterial occlusive disease $(P A O D)$, a common atherosclerotic condition in the legs, affecting mostly elderly subjects". Nevertheless, the majority of PAOD cases are asymptomatic". Symptomatic PAOD, particularly when the occlusion involves the aortoiliac vascular bed, is associated with organic impotence? Atherosclerotic risk factors such as smoking, diabetes, hypercholesterolaemia and hypertension seem also to play a role in the development of erectile disorders ${ }^{3,4}$. Data on the prevalence of erectile impairment in asymptomatic PAOD subjects are non-existent.

We describe here the association between asymptomatic PAOD and perceived erection problems in a population-based cohort.

\section{Subjects, methods and results}

The recruitment and selection procedures carried out in the context of the Limburg PAOD study have been extensively described elsewhere. In summary: the study population consists of 3649 subjects ( $47 \%$ male), with age ranging from 40 to 78 years (mean: 59 years). The participants were selected out of a group of 26620 subjects from 18 general practice centres. Every citizen in the Netherlands is registered in a general practice. Therefore, the registered population of a general practice is a segment of the general population.

To detect PAOD, especially trained general practice assistants carried out Doppler measurements, with the participants in a supine position. The ankle-brachial pressure index (ABPI), the ratio of the ankle and brachial systolic blood pressures, was calculated in a standardised fashion. PAOD was defined as an ABPI $<0.95$ for at least one $1 \mathrm{eg}$, measured wice with one week interval. Intermittent claudication was assessed according to a modified version of the Rose questionnaire". Asymptomatic PAOD was defined as an ABPI $<0.95$ without IC complaints. With a self-administered questionnaire data were collected on possible experienced erection problems and smoking habits. From the subjects' medical records data were collected on the presence of hypertension, diabetes and hypercholesterolaemia.

Multiple logistic regression analyses were performed to investigate the independent association of asymptomatic and symptomatic PAOD with perceived erection problems (dependent variable), adjusted for age, smoking, diabetes, hypercholesterolaemia and hypertension.

The prevalence of PAOD in the study population was $12.5 \%$. Asymptomatic PAOD was present in 314 participants (49.4\% male) and symptomatic PAOD in 138 (65.9\% male). Among the 237 male 
PAOD subjects, 107 (45.1\%) reported erection problems. For male asymptomatic PAOD subjects, this number was 66 (44\%) and for male clandicants it was 41 (47\%). Complaints of erection problems were lower among the 1405 male subjects without PAOD: 358 (25.0\%) reported erection problems. Experienced erection problems were significantly associated with asymptomatic PAOD (odds ratio (OR) 1.6), as well as with symptomatic PAOD (OR 1.9), adjusted for age and atherosclerotic risk factors. The OR for overall PAOD was 1.7 (table).

Adjusted odds ratios (95\% confidence interval) of asymptomatic and symptomatic peripheral arterial occlusive disease (PAOD) for erection problems. Results of multiple logistic regression analyses $(\mathrm{n}=1627$ )

PAOD $\quad$ Erection problens

\begin{tabular}{ll} 
Asymplomatic & $1.6(1.1-2.4)$ \\
Symptomatic & $1.9(1.2-2.9)$ \\
Overall & $1.7(1.3-2.3)$ \\
\hline
\end{tabular}

'Adjusted for age, smoking stanus, hypercholesterolaemia, bypertension and diabetes. "Definitions: see Methods.

"No PAOD" as reference category.

\section{Comments}

This population-based study showed that experienced erection problems are significantly associated with both asymptomatic and symptomatic PAOD. Subclinical atherosclerosis of the aorta and arteries distal of the aortic bifurcation (aortoiliac, penile and testicular arteries) may result in penile ischaemia. In case of suspected organic impotence in a patient complaining of erection problems, a vascular physical examination including ABPI measurements and assessment of atherosclerotic risk factors should be performed. Reversely, in male subjects with asymptomatic or symptomatic $\mathrm{PAOD}$, attention must also be focused on possible erection problems.

We thank the participating physicians and the assistants for their contribution to this study.

Funding: The Netherlands. Organization for Scientific Research (grant no 900-715.154) and the Dutch "Praeventiefonds" (grant no 28-1323). Doppler devices were donated by Asta Medica BV.

Conflict of interest: None. 


\section{References}

1. Stoffers HEJ, Rinkews PELM, Kester ADM, Kaiser V, Knotmerus IA. The prevalence of asymptomatic and unrecognized peripheral arterial occlusive disease. Int I Epidemiol 1996;25:282-90

2. Michal V. Arterial disease as a cause of impotence. Clin Endoerinol Metab 1982;11:725-48.

3. Virag $\mathrm{R}$, Boublly $P$, Feydman D. Is inmotence an arterial disorder? Lancet 1985, i:181-4,

4. Shabsigh $R$, Fishmian 1 , Schum $C$, Dunn JK. Cigarette smoking and other vascular risk factors in yasculogenic inpotence. Urology 1991;38:227-31.

5. Rose GA, BJackburn H, Gilium RF, Prineas RJ. Cardiovascular Surwey Methods. 2nd Edm. Geneva: WHO, 1982, pp 162-5. 
Incidence and risk factors for asymptomatic peripheral arterial occlusive disease: a longitudinal study

Jureme D Hooi

Arnold DM Kester

Henri EJH Stoffers

Marjori M Overdijk

Jan W van Ree

J André Knottnerus 


\section{Abstract}

This prospective longitudinal study describes the age- and sex-specific incidence rates and risk factors for asymptomatic and symptomatic peripheral arterial occlusive disease (PAOD) among 2332 subjects ( $40-78$ years). Furthermore, the incidence of intermittent claudication in a subgroup of asymptomatic PAOD subjects at baseline was assessed.

Age- and sex-specific incidence rates were calculated by means of the person-years method. With multiple logistic regression analyses, associations were investigated between the development of asymptomatic and symptomatic PAOD and the baseline variables: age, gender, smoking habits, sedentary lifestyle, occurrence of atherosclerosis in the family, hypertension, diabetes, hypercholesterolaemia and overweight.

After 7.2 years, the overall incidence rate for asymptomatic PAOD was 9.9 per 1000 person-years at risk, 7.8 for men and 12.4 for women. For symptomatic PAOD the owerall incidence rate was 1.0 per 1000 person-years at risk, 0.4 for men and 1.8 for women. Increasing age, smoking, hypertension and diabetes were the most important risk factors for asymptomatic and symptomatic PAOD.

The overall incidence rate for intermittent claudication among asymptomatic PAOD subjects at baseline was 90.5 per 1000 person-years at risk, 154.4 for men and 15.1 for women.

In conclusion, in the general population, the incidence of asymptomatic PAOD is higher than the incidence of symptomatic PAOD. Women seem to develop PAOD more often compared with men. Nevertheless, once asymptomatic PAOD is present, men appear to develop intermittent claudication symptoms more often than women. When developing preventive strategies for primary health care, modification of atherosclerotic risk factors like smoking, hypertension and diabetes should be the main goals.

Keywords: asymptomatic peripheral arterial occlusive disease, incidence, longitudinal, risk factors. 


\section{Introduction}

All epidemiological cross-sectional studies show that in the general population, asymptomatic peripheral arterial occlusive disease (PAOD) is more common than symptomatic PAOD ${ }^{1-3}$. Less than half of all PAOD patients have intermittent claudication (IC) symptoms. PAOD is part of a systemic illness caused by atherosclerosis, and its prevalence is positively associated with age 4,5 . Population-based studies indicate that PAOD has a relatively benign course as far as the legs are concemed $^{7,8}$. However, claudicants show more cardiovascular co-morbidity and have at least a twofold risk of fatal ischemic heart disease and cerebrovascular accidents compared to the general population $^{9-11}$. Concomitant cardiovascular disease and cardiovascular mortality is even more frequent in studies where the ankle-brachial pressure index ( $A B P I)$, the ratio of the ankle to the arm systolic pressure, has been used to indicate PAOD. The ABPI is currently the most common and useful diagnostic instrument to detect PAOD, including asymptomatic cases ${ }^{4-6,14}$. The ABPI is adversely associated with manifestation of severe disease and cardiovascular mortality ${ }^{11,12}$. Not only intermittent claudication, but also asymptomatic PAOD seems to be associated with a higher cardiovascular morbidity and mortality. However, data on the prognosis of asymptomatic PAOD subjects are scarce ${ }^{7,13}$.

Despite the relatively decreased life expectancy of asymptomatic and symptomatic PAOD subjects due to cardiovascular morbidity, only a few incidence studies on PAOD have been published. Furthermore, there are almost no prospective studies on risk factors for asymptomatic PAOD, or on the development of IC symptoms when asymptomatic disease is already present ${ }^{11}$.

In this paper, we report the age- and sex-specific incidence of asymptomatic and symptomatic PAOD in a population-based prospective study. In addition, we present the incidence of IC in the subgroup of asymptomatic PAOD subjects at baseline. We also investigated possible risk factors for the development of asymptomatic and symptomatic PAOD.

\section{Materials and methods}

The Limburg PAOD study started in $1987^{1}$. The study population was selected from a source population of 26,620 subjects, aged 40 to 78 years, within 18 general practice centres. In the Netherlands every subject is registered at a general practice centre. Therefore, the registered population of these general practices is a segment of the general population. A postal screening questionnaire was mailed to these subjects with five questions mainly about risk factors possibly 
relevant to $\mathrm{PAOD}$, so that responders could be characterised according to a "prior risk score" between 0 and 5. The study population thus included subgroups corresponding with parts of the clinical spectrum relevant to the general practice. After a stratified sampling procedure, on the basis of the subjects prior risk score, 5301 subjects were invited and 3649 respondents ( $53 \%$ female) participated in the study. The response rate was $68.9 \%$ and no statistically significant differences between responders and non-responders with regard to age and gender were found. The population characteristics have been extensively described elsewhere". All participants gave their informed consent and the study was approved by the Medical Ethics Committee of the University Hospital Mastricht. For the current study, data at baseline were related to the measurement after follow-up. Therefore, those who died before the follow-up measurement $(n=481)$ were not included in these analyses, but their baseline data were compared with those of the included subjects.

\section{Baseline measurements}

Each participant completed a questionnaire on age, gender, intermittent claudication symptoms, current and former smoking habits, physical activities and the occurrence of atherosclerosis in the family. Subsequently, a physical examination was performed by a general practitioner / physician in the general practice centres. A practice assistant measured height, weight and the ABPI with a pocket Doppler device (Huntleigh Mini Dopplex D500 8Mhz) and a sphygmomanometer. Systolic pressures were recorded on both arms and ankles (posterior tibial artery or dorsalis pedis artery), with the subject in supine position. The ABPIs were callculated as the ratio of each ankle systolic blood pressure to the highest arm systolic blood pressure. To achieve uniformity of Doppler assessments, the assistants had been trained ${ }^{15}$. An $\mathrm{ABPI}<0.95$, for at least one leg, measured twice at weekly intervals, was considered indicative for PAOD. In addition, relevant data on the presence of hypertension (guideline: five instances of diastolic pressure 95-104 $\mathrm{mmHg}$ or three instances of diastolic pressure $\geq 105 \mathrm{mmHg}$ ), hypercholesterolaemia (guideline: mean of three measurements $\geq$ $6.5 \mathrm{mmol} / \mathrm{L}$ ) and diabetes mellitus (guideline: typical complaints and one instance of abnormal serum. glucose (fasting $\geq 6.7 \mathrm{mmol} / \mathrm{L}, 2 \mathrm{hr}$ postprandial $\geq 11.1 \mathrm{mmol} / \mathrm{L}$ ) or two instances of abnormal serum glucose) were collected from the patient's medical record.

Intermittent claudication was defined as pain in the calf while walking, disappearing when standing still and not present when resting (typical $I C)^{16}$. Other complaints involving the calf and complaints involving the foot, thigh or buttock showing this ischemic pattern were included in the definition of atypical IC ${ }^{1,7}$. Asymptomatic PAOD was defined as an ABPI $<0.95$ without 
intermittent claudication symptoms. Symptomatic PAOD was defined as an ABPI $<0.95$ with intermittent claudication symptoms . Overweight was defined as a body mass index $>30$. Familial atherosclerosis was positive when participants had a first-or second-degree relative who suffered from atherosclerotic disease under the age of 65 . Daily work and leisure-time activities were cllassified as heavy, moderate or light physical activity. Participants who scored light for both daily work and leisure-time activities were categorised as having a sedentary lifestyle.

\section{Follow-up evaluation}

All participants were traced by means of the general practice registers. The subjects still alive were invited for a re-examination between January 1995 and April 1997, according to the same procedures as for the baseline measurements. Participants that had switched from general practice during the follow-up period, but still resided in the province of Limburg, were located, contacted and invited. Participants who could not attend the examination in the general practices were visited at home.

\section{Statistical analyses}

Total, sex- and age-specific (three categories: $40-54,55-64, \geq 65$ years) incidence rates for asymptomatic and symptomatic PAOD were estimated by means of the person-years method (number of new cases divided by the person-years at risk of the initial population, excluding all PAOD subjects at baseline). Incidence rates were recalculated to the source population as appropriately weighted means of incidence rates per prior risk category. Because of small numbers of observed events, the nomal approximation method for confidence intervals was not valid and therefore the method proposed by Waller et al was used with an adaptation for the assumed Poisson distribution for the numbers of events.

At the end of the follow-up period the following conditions were present: normal subjects (without PAOD) at baseline and at follow-up; normal subjects at baseline but asymptomatic at follow-up; nomal subjects at baseline but symptomatic at follow-up; asymptomatic subjects at baseline and not symptomatic at follow-up; asymptomatic subjects at baseline but symptornatic at follow-up. Person-years at risk were calculated with the approximation that subjects who developed the disease during the follow-up period, were assumed to contribute half of the follow-up time to the person-years at risk.

Backwards multiple logistic regression analyses were carried out to investigate the association of 
the possible risk factors: age, gender, smoking, hypertension, overweight, diabetes, hypercholesterolaemia, a sedentary lifestyle and the occurrence of atherosclerosis in the family (independent variables) with the incidence of asymptomatic and symptomatic PAOD (dependent variables). Multivariable analysis was also performed in the subgroup of asymptomatic PAOD subjects at baseline, to investigate the prognostic importance of these variables in the transition of asymptomatic to symptomatic disease. In this subgroup, the dependent variable was the presence of IC symptoms at the end of the follow-up.

\section{Results}

After 7.2 years, 2589 subjects (54.2\% female) with a mean age of 64.1 years (range $48.1-85.5$ years) had participated in the follow-up measurements. The attendance rate was $71 \%$.

During the follow-up period, 481 participants $(13.2 \%)$ died, of whom $61.4 \%$ were males. From the total cohort, death occurred in $11 \%$ of the normal subjects at baseline, $25.2 \%$ in the asymptomatic PAOD subjects and $31.2 \%$ in the claudicants at baseline. The comparison of the baseline variables age, sex, ABPI, possible risk factors and cardiovascular co-morbidity of those who died and those who completed follow-up showed that those who died were mainly men, older, with lower ABPI, more prevalent cardiovascular diseases and a more unfavourable risk-factor profille. The main causes of death were cardiovascular diseases and cancer. A detailed mortality follow-up of this cohort will be reported in a subsequent paper.

Thus, $84.2 \%(71 \%$ and $13.2 \%)$ of the original cohort was followed up. The remaining group $(15.8 \%)$ did not respond because of two main reasons: refusal to take part or being incapable because of severe illness or hospitalisation. Non-responders and responders did not significantly differ in age and gender. Furthermore, non-responders did not have a worse risk-factor profile at baseline compared with responders, except for diabetes.

A total of 257 subjects were excluded because of presence of PAOD at baseline. Overall, 2332 subjects were included in the incidence analyses.

\section{Incidence of asymptomatic and symptomatic PAOD in the normal group at baseline}

At the end of the follow-up period 200 participants had asymptomatic and 46 symptomatic PAOD. Table 1 shows the age- and sex-specific incidence rates of asymptomatic and symptomatic PAOD among the survivors. The highest rates were observed for asymptomatic PAOD. The overall incidence rate for asymptomatic PAOD was 9.9 per 1000 person-years at risk, 7.8 for male and 
12.4 for female subjects. For symptomatic PAOD, the overall incidence rate was 1.0 per 1000 person-years at risk, 0.4 for male and 1.8 for female subjects, respectively.

Asymptomatic and symptomatic PAOD incidence rates increased with age among men and women. In both men and women, the incidence of asymptomatic PAOD compared with the imcidence of symptomatic PAOD was higher. A difference (not significant) was observed between the PAOD incidence rates of men and women: women in the wo younger age categories developed asymptomatic disease four to five times more often than men. Among those older than 54 years the incidence rates of symptomatic PAOD were also higher in women as compared with men.

Table 1. Age- and sex-specific incidence rates for asymptomatic and symptomatic PAOD. The Limburg PAOD Longitudinal Study, 1988-1997 $(\mathrm{n}=2332)$

\begin{tabular}{|c|c|c|c|c|c|c|c|}
\hline & \multicolumn{4}{|c|}{ Asymptomatic PAOD } & \multicolumn{3}{|c|}{ Symptontic PAOD } \\
\hline & Age group & $\mathrm{n}^{*}$ & $\begin{array}{l}\text { rate/1000 } \\
\text { person-years }\end{array}$ & $95 \% \mathrm{Cl}$ & $\mathrm{n}^{*}$ & $\begin{array}{l}\text { rate/1000 } \\
\text { personn-years }\end{array}$ & $95 \% \mathrm{CI}$ \\
\hline Total & $\begin{array}{l}40-54 \\
55-64 \\
\geq 65\end{array}$ & $\begin{array}{l}25 \\
36 \\
23 \\
84\end{array}$ & $\begin{array}{r}1.5 \\
1.1 \\
17.2 \\
7.8\end{array}$ & $\begin{array}{l}0.7 \cdot 7.8 \\
0.8-14.4 \\
6.9-51.1 \\
4.9 \cdot 20.3\end{array}$ & $\begin{array}{l}7 \\
13 \\
6 \\
26\end{array}$ & $\begin{array}{l}0.2 \\
0.4 \\
0.5 \\
0.4\end{array}$ & $\begin{array}{l}0.1-5.9 \\
0.2-13.6 \\
0.2-23.7 \\
0.3-10.0\end{array}$ \\
\hline Female & $\begin{array}{l}40-54 \\
55-64 \\
\geq 65\end{array}$ & $\begin{array}{l}27 \\
33 \\
56 \\
116\end{array}$ & $\begin{array}{r}5.8 \\
5.9 \\
20.8 \\
12.4\end{array}$ & $\begin{array}{l}2.8-13.1 \\
2.7-15.7 \\
8.7-53.0 \\
7.7-24.8\end{array}$ & $\begin{array}{l}4 \\
4 \\
12 \\
20\end{array}$ & $\begin{array}{l}0.1 \\
3.2 \\
1.9 \\
1.8\end{array}$ & $\begin{array}{l}0.06-4.8 \\
1.3-11.7 \\
0.6-23.2 \\
1.0-10.3\end{array}$ \\
\hline Whole group & & 200 & 9.9 & $7.3-18.8$ & 46 & 1.0 & $0.7-7.5$ \\
\hline
\end{tabular}

$\mathrm{Cl}=$ confidence interval. * Number of incident cases duning 7.2 years.

\section{Risk-factor pattern of the normal group at baseline}

Table 2 presents the results of the multiple logistic regression analyses. Older age, smoking, hypertension, diabetes, hypercholesterolaemia and a sedentary lifestyle were the most important risk factors for asymptomatic PAOD. Older age, smoking, hypertension and diabetes were the most important predisposing factors for symptomatic PAOD.

From the reduced logistic regression models, predicted probabilities for asymptomatic and symptomatic PAOD incidence according to the baseline risk-factor profile were calculated. The probability for developing both asymptomatic and symptomatic PAOD increased with the numbers of risk factors present at baseline. For asymptomatic PAOD the additional increased 
Table 2. Risk factors associated with the probability of asympitomatic and symptomatic PAOD after 7.2 years. Results of backwards multiple logistic regression analyses (reduced models). The Limburg PAOD Longitudinal Study, 19881997 ( $\mathrm{n}=2332$ subjects)

\begin{tabular}{|c|c|c|c|}
\hline & Ovarall $\mathrm{BAOD}$ & Asymptomatic PAOD & Symptomatio BAOD \\
\hline Risk factor & $\mathrm{OR}(95 \% \mathrm{Cl})$ & OR $(95 \% \mathrm{Cl})$ & OR $(95 \% \mathrm{Cl})$ \\
\hline \multicolumn{4}{|l|}{ Age } \\
\hline $40-54$ & 1.0 (referent) & 1.0 (referent) & 1.0 (referent) \\
\hline $55-64$ & $1.8(1.3-2.6)$ & $1.7(1.2-2.6)$ & $2.1(0.9-4.8)$ \\
\hline$\geq 65$ & $4.0(2.8-5.9)$ & $3.8(2.5-5.7)$ & $5.3(2.3-12.2)$ \\
\hline \multicolumn{4}{|l|}{ Smoking status* } \\
\hline non-smoker & 1.0 (ueferent) & 1.0 (referent) & 1.0 (referent) \\
\hline ex-smoker & $0.9(0.6-1.4)$ & $0.8(0.5-1.3)$ & $1.4(0.5-3.7)$ \\
\hline current smoker & $2.2(1.5-3.1)$ & $1.9(1.3-2.8)$ & $4.3(1.9-10.1)$ \\
\hline Hypertension & $1.7(1.3-2.4)$ & $1.7(1.2-2.3)$ & $1.9(1.0-3.6)$ \\
\hline Diabetes Mellitus* & $21(1.4-3.3)$ & $1.8(1.1-2.9)$ & $3.8(1.8 \cdot 8.2)$ \\
\hline Hypercholesterolatmia & $1.5(1.0-2.3)$ & $1.6(1.1-2.5)$ & $* *$ \\
\hline Sedentary lifestyle & - & $1.6(1.0-2.5)$ & *** \\
\hline
\end{tabular}

$\mathrm{OR}=$ adds ratio; $\mathrm{CI}=$ confidence interval. * For definitions see Materials and methods. * Dropped out of the reduced model.

Table 3. Increased probability (\%) of asymptomatic and symptomatic PAOD according to the numbers and combination of the four most significant risk factors present at baseline (deduced from the backwards multiple logistic regression models). The Limburg. PAOD Longitudinal Study, 1988-1997 ( $\mathrm{n}=2332)$

Number and combination of risk factors at baseline:
Increased probability $(\%)$ Increased probability $(\%)$ Increased probability $(\%)$ of overall PAOD

$\begin{array}{lccc}\text { Reference probability } & 3 & 2 & 3 \\ \text { Age } \geq 65 & 8 & 5 & 1 \\ \text { Age } \geq 65 \text {, hypertension } & 15 & 9 & 2 \\ \text { Age } \geq 65 \text {, smoking } & 18 & 10 & 6 \\ \text { Age } \geq 65, \text { diabetes } & 18 & 10 & 5 \\ \text { Age } \geq 65 \text {, hypertension, diabetes } & 28 & 16 & 9 \\ \text { Age } 265, \text { snoking, hypertension } & 29 & 17 & 11 \\ \text { Age } \geq 65, \text { smoking, diabetes } & 33 & 18 & 19 \\ \text { Age } \geq 65, \text { smoking, hypertension, } & 47 & 27 & 31 \\ \text { diabetes } & & & \end{array}$


probability ranged from $1 \%$ to $50 \%$ (reference probability: $2 \%$ ), conditional on the numbers and combination of the significant risk factors at baseline (one to six risk factors, see table 2). For symptomatic PAOD, the additional increased probabilities varied from $1 \%$ to $31 \%$ (reference probability symptomatic PAOD: $3 \%$, numbers of significant risk factors at baseline: one to four). For overall PAOD these figures were $5 \%$ to $58 \%$ (reference probability overall PAOD: $3 \%$, numbers of risk factors at baseline: one to five). Table 3 illustrates this increasing probability for the development of overall, asymptomatic and symptomatic PAOD on the basis of the four most significant risk factors (age $\geq 65$, smoking, diabetes and hypertension) present at baseline.

Incidence of intermittent claudication and risk pattern of the asymptomatic group at baseline Of the 177 asymptomatic PAOD subjects at baseline who underwent a follow-up examination, 27 developed intermittent claudication (15 typical and 12 atypical symptoms). In this group, the overall incidence rate for symptomatic PAOD was 90.5 (95\% confidence interval (CI): 36.4-378.3) per 1000 person-years at risk, 154.4 (95\% CI: 31.9-765.8) for male and 15.1 (95\% CI: 5.7-109.1) for female subjects, respectively. Asymptomatic PAOD subjects at baseline, especially male subjects, more often developed intermittent claudication symptoms than the normal subjects at baseline

Multiple logistic regression results showed that possibly male gender (odds ratio $(O R)=1.6$, hypertension $(\mathrm{OR}=1.5)$, diabetes $(\mathrm{OR}=1.7)$ and older age $(\mathrm{OR}=2.7$ and 3.2 for the two older age categories, respectively) were associated with the development of intermittent claudication symptoms. No statistical significance was reached, which could be due to small numbers.

\section{Discussion}

The estimation of incidence rates relies on the time of disease occurrence and loss to follow-up. The exact time of disease occurrence was not known in our study, the average time lapse between visit 1 and 2 being 7.2 years. Even with the applied correction in the calculations, this probably could have led to an underestimation of the reported incidence rates. A source of bias could be constituted by subjects who refused to participate in the follow-up measurements. To minimise this potential bias, and to keep the non-response group as small as possible, we offered home visits to subjects who were not willing to visit their general practice. Subjects who missed their appointment were telephoned and invited to attend a second time. The non-responders might have had a different disease incidence than 
the responders, due to a higher prevalence of diabetes at baseline. Quantitatively, however, this did hardly had any impact on the incidence rates.

The attrition of the cohort could also have influenced the incidence rate calculations. Mortality may censor the diagnosis of PAOD and consequently lead to conservative incidence estimations. Even though PAOD is not a short-term fatality disease, PAOD subjects have a lower survival rate due to ischemic heart disease and cerebrovascular disease mortality, compared with the general population ${ }^{79-11,13}$. We gathered data on the causes of mortality and possible non-fatal cardiovascular events before death, using hospital correspondence and the patients" medical records. Among the 349 non-PAOD subjects at baseline who died during follow-up, cardiovascular disease was the cause of death in approximately 50\%. New cases of PAOD are especially probable in this group.

\section{Incidence of asymptomatic and symptomatic PAOD in the nomal group at baseline}

We found that the incidence of asymptomatic and symptomatic PAOD increased with age in both men and women. Furthermore, the incidence of asymptomatic PAOD was much higher in the general population than that of symptomatic PAOD. Surprisingly, a trend was observed that women developed asymptomatic and symptomatic PAOD more often than men, after 7.2 years of follow-up.

In several studies, both asymptomatic and symptomatic PAOD increased with age, consistent with our findings ${ }^{9,8,19}$. Our incidence rates for asymptomatic PAOD are difficult to compare with others due to a lack of data and different diagnostic methods used. In the Basle study, a cohort of 2630 men followed up for five years, asymptomatic PAOD, defined as pathological findings at pulse palpation, auscultation or electronic oscillography, was three times more frequent than symptomatic PAOD ${ }^{18}$. This is in accordance with our results.

In the Framingham study, an annual symptomatic PAOD incidence rate of 1.8 for women was reported, comparable with our findings ${ }^{19}$. The Framingham study, however, presented a two-fold male predominance with an incidence rate similar to that of the Quebec Cardiovascular study (3.6 and 4.1 , respectively) ${ }^{19,9}$. The Edinburgh Artery study presented the highest overall symptomatic PAOD incidence rates ( 15.5 per 1000 person-years) ${ }^{7}$, men being at a slightly higher risk than women. Various explanations can be postulated for the differences in these results and ours. Firstly, the Limburg PAOD study population was younger than the Framingham ${ }^{19}$ and the Edinburgh study ${ }^{\imath}$ populations. Secondly, the Edinburgh Artery study did not exclude asymptomatic PAOD subjects at baseline from the denominator in its incidence calculations for 
symptomatic PAOD, even though asymptomatic subjects have, as sinown in our study, an incidence rate of intermittent claudication that is much higher than subjects without PAOD. In fact, when we calculated the overall symptomatic PAOD incidence rate, including the asymptomatic subjects at baseline in our calculations, the incidence rate for symptomatic PAOD almost doubled. Thirdly, in the Quebec study",70\% of the men were smokers compared with $58.6 \%$ in our study, smoking being one of the most powerful risk factors for PAOD. The higher incidence for women compared with men found in our study (not signinicant) could be partly explained by selective survival. The consequences of PAOD might be worse for men compared with women, not only resulting in a faster progression from asymptomatic to symptomatic disease, but also resulting in a higher mortality. In our study, mortality in the male subjects was more pronounced than in the female subjects: from the 153 asymptomatic and 91 symptomatic male subjects at baseline, $33 \%$ and $34 \%$ died during the follow-up, respectively, whereas for the female asymptomatic and symptomatic subjects these figures were $18 \%$ and $26 \%$, respectively. On the other hand, the trend of a female predominance may well be a chance finding, since this difference was not significant.

\section{Risk pattern of the normal group at baseline}

To identify risk factors for disease, the focus should ideally be on incident cases. We demonstrated that older age, smoking, hypertension, diabetes, hypercholesterolaemia and a sedentary lifestyle were significant risk factors for the development of asymptomatic PAOD. We cannot compare these results with other studies due to a lack of data. Furthermore, we found that older age, smoking, diabetes and hypertension were strongly associated with the development of symptomatic PAOD, supporting the results of other studies $9,19,20$. In addition, the probability of developing both asymptomatic and symptomatic PAOD increased with the numbers of risk factors at baseline, concordant with the Basle study ${ }^{18}$.

The role of hypercholesterolaemia and a sedentary lifestyle was not evident for symptomatic PAOD. In some studies, hypercholesterolaemia is reported to be a possible risk factor for symptomatic PAOD $^{20,21}$ but this is not confimed in others ${ }^{4,5}$. At the time of our baseline data collection, measurement of hypercholesterolaemia in Dutch general practice was just receiving more attention. Thus, the weak association found in our study might reflect an underreporting of hypercholesterolaemia in the general practice centres. The relationship between physical activity and PAOD has not been thoroughly investigated to date. There are indications that a sedentary lifestyle is 
associated with $P A O D^{22}$. We must point out however, that intemittent claudication symptoms can be disguised by a sedentary lifestyle.

\section{Incidence of intermittent claudication and risk pattern of the asymptomatic group at baseline}

This is the first study that reports on the incidence of IC among asymptomatic PAOD subjects, and investigated the prognostic role of several risk factors. We found that PAOD subjects who were asymptomatic at baseline, developed intermittent claudication symptoms more often than normal subjects. This is not surprising, since asymptomatic and symptomatic PAOD are not different entities, but atherosclerotic manifestations at different points in time. In particular, asymptomatic male subjects seemed at high risk for developing symptoms compared with asymptomatic female subjects, providing further evidence that PAOD might have a worse prognosis in men.

Older age, hypertension and diabetes probably play a role in the progression of asymptomatic to symptomatic PAOD.

\section{Implications}

Asymptomatic as well as symptomatic PAOD subjects have increased risks of cardiovascular mortality ${ }^{\prime \prime}$. The incidence of asymptomatic PAOD is higher in the general population than that of symptomatic PAOD. Once asymptomatic disease is present, the incidence rate of intermittent claudication is significantly elevated. Claudicants have a reduced quality of life because of limited independence and mobility ${ }^{23}$, impaired functioning being the main reason for referral to a vascular specialist. One of the goals of public and primary health care is to maintain a good quality of life in the elderly. To achieve this goal with regard to internittent claudication, detection of asymptomatic PAOD subjects is important. Measuring the ABPI with a Doppler device assists the general practitioner in case-finding. It is a reproducible and valid diagnostic tool, not only appropriate to deteci asymptomatic PAOD in epidemiological studies, but also suitable for use in primary care ${ }^{14}$. Our data suggest that in primary care, cessation of smoking and adequate treatment of hypertension and diabetes are the principal preventive objectives in PAOD subjects. Treatment of hypercholesterolaemia seems to be less important.

Thus, in patients over 50 years of age, with one or more conventional atherosclerotic risk factors, assessment of the ankle-brachial pressure index by the general practitioner could provide additional information on the risk of developing manifest atherosclerotic disease. 


\section{Acknowledgements}

We thank the participating physicians and the assistants for their contribution to this study. This study was funded by: The Netherlands Heart Foundation (grant no 92170). 


\section{References}

1. Stoffers HEJH, Rinkers PELM, Kester ADM, Kasier W, Krotmenus JA. The prevalence of asymptomatic and writecognized peripheral arterial occhsive disease. Int $J$ Epidemial $1996,25,282-90$.

2. Fowkes FGR, Housley E, Cawood EHH, Macintyre CCA, Ruckey CV, Prescott RJ. Edirburgh Artery Sudy. Prevalence of asymptomatic and symptomatic peripheral arterial disease in the general population. Int I Epidemiol $1991 ; 20: 384-92$.

3. Criqui MIH Bromer D, Fronek A, Klauber MR, Coughlin SS, Barrent-Connor E el Peripheral arterial disease in large vessels is epidemiologically distiact from small wessel disease. Am J Epidemiol 1989:129:1110-9.

4. Vog Mil" Wolfon SK, Kuller LH. Lower extremity arterial disease and the aging process: A review. I Clin Epidemiol $1992,45,529-42$

5. Balkgu B, Way M, Eschwege E. Ephomology of peripheral arterial disease. J Cardiowasc Pharm $1994 ; 23,58-516$.

6. Fowkes FGR. The measurement of atheroscleronc peripheral anterial disease in epidemiological surveys. Int I Epidemiol 1988;17:248-54.

7. Leng GC, Lee AJ, Fowkes FGR, Whiteman M, Dubar $\mathbb{J}$, Housley E, Ruckley CW. Incidence, natural history and cardiowascular events in symptomatic and asymptomatic peripheral anterial disease in the general population. Int I Epidemiol 1996:25:1172-81.

8. Newton Peabody $\mathrm{C}$, Karmel WB, McNimara PM. Internittent claudication. Surgical signinicance. Arch Surg $1974: 109: 693-7$

9. Dagenais GR, Maurice S, Robitaille N-M, Gingtas S, Lupien PI. Intermittent Claudication in Quebec men from 1974-1986: the Quebec Cardiovascular Study. Clin Invest Med 1991;14:2:93-100.

10. Leng GC, Fowkes IGR, Lee AJ, Dunbar J, Housley E, Ruckley CW. Use of ankle brachial pressure index to predict cardiovasicular ewents and death a cohort study. BMJ 1996;313:1440-3.

11. Hooi JD, Stoffers HEJH, Knotmenus JA, Ree JW van. The prognosis of nori-critical limb ischaemia: a systematic review of population-based evidence. Br 1 Gen Pract (accepted).

12. McGrae McDemott M, Fenglass I, Slawenky R, Fearce WH. The ankle-brachial index as a predictor of survial in patients; with peripheral vascular disease. J Gen Intern Med 1994;9:445-9.

13. Criqui MH, Langer RD, Fronek A, Feigelson $\mathrm{HS}, \mathrm{K}$ llaber MR, McCann TJ, Browner D. Mortaliry over a period of 10 years in patients with peripheral arterial disease. New Engl J Med 1992;326:381-6.

14. Stoffers HEJH, Kester ADM, Kaiser V, Rinkens PELM, Kitslaar PJEHM, Knotimenis JA. The diagnostic value of the measurement of the anklebrachial systolic pressure index in primary tealth care. J Clin Epidemiol 1996 ; 49: $1401-5$.

15. Stoffers HEJH, Kaiser W, Kester ADM, Schouten HIA, Knotmens. JA. Peripheral arterial occhusive disease in general practice; the reproducibility of the ankle-arm pressure ratio. Scand J Prim Health Care 1991,9:109-14.

16. Rose GA, Blackburn H, Gilum RF, Prineas RJ. Cardiovascular survey merhods. $2^{\text {ad }}$ Edn. Genewa: WHO, 1982 , pp $162-5$.

17. Waller $\mathrm{IL}$, Addy $\mathrm{CL}$, Jackson $\mathrm{KL}$, Garrison $\mathrm{CZ}$. Confidence intervals for weighted propiortions. Stat Med 1994;13:1071-82.

18. Wicher L.K, Biland L. Irvidence and course of occlusive peripheral antery disease in geriatric patients. Int Angio $1985 ; 4289.94$

19. Karnel WB, McGee DL. Update on some epidemiologic features of intemittent claudication. The framingham Study. Am Gariatr Soc $1985 ; 33: 13-8$.

20. Bowhin S.T, Medalie JH, Flocke SA, Zyzanski SJ, Goldbourt U. Epidemiology of intermittent claudication in nitudleaged men. Am IJ Epidemiol 1994:140:418-30.

21. Irigolfson 10 , Sigurdsson $\mathrm{G}_{\mathrm{r}}$ Sigvaldason $\mathrm{H}$, Thorgeirsson $\mathrm{G}$, Sigfusson $\mathrm{N}$. A marked decline in the prevalence and incidence of interrittent claudication in Icelandic men 1969 - 1986: a strong relationship to smoking and serunl cholesterol - The deykjavik Study. J Clin Epidemiol 1994,47:1237-43.

22. Housley E, Leng GC, Donman $\mathrm{PT}$, Fowkes FGR. Physical activity and risk of peripheral arterial disease in the general population: Edinburgh Artery Study. J Epidemiol Community Health 1993;47:475-80.

23. Khaira $\mathrm{HS}$, Hanger R. Sheaman CP. Quality of life in patients with intermittent claudication. Eur IVasc Endovasc Surg $1996: 11: 65-9$. 
Cardiovascular morbidity and mortality of asymptomatic peripheral arterial occlusive disease: a seven-year follow-up study

Jurenne D Hooj

Amold DM Kester

Henri EJH Stoffers

Paula ELM Rinkens

$\mathrm{J}$ André Knottnerus

Jan W van Ree 


\begin{abstract}
Background. Asymptomatic peripheral arterial occlusive disease (PAOD) is a common atherosclerotic disorder among the elderly. Nevertheless, scarce data are available on the risk of non-fatal and fatal cardiovascular diseases in these subjects.

We investigated the cardiovascullar morbidity and mortality of asymptomatic PAOD subjects and possible gender differences for outcome.

Methods. A sample of 3649 subjects (40 - 78 years) was selected in collaboration with 18 general practice centres, and followed up after the initial screening. Asymptomatic PAOD was determined by means of the ankle-brachial pressure index (ABPI). Main outcome measures were non-fatal cardiovascular events and mortality.

Results. Cox proportional hazard modeis showed that after a mean follow-up period of 7.2 years, asymptomatic PAOD was significantly associated with cardiovascular morbidity (hazard ratio (HR): 1.6; 95\% CI: $1.3-2.1$ ), total mortality (HR: 1.4;95\% CI: 1.1 - 1.8), and cardiovascular mortality (HR: $1.5 ; 95 \%$ CI: 1.1 - 2.1). Female asymptomatic PAOD subjects seemed to be at higher risk for a non-fatal myocardial infarction whereas male asymptomatic PAOD subjects had elevated risks for cardiovascular death, mainly due to fatal strokes.

Conciusions. Asymptomatic PAOD is a significant predictor of cardiovascular morbidity and mortality. In high-risk subjects, measurement of the ABPI is appropriate, providing valuable information on the present and future atherosclerotic status.
\end{abstract}

Key Words: peripheral arterial occlusive disease, cardiovascular morbidity, mortality, anklebrachill pressure index. 


\section{Introduction}

Prevention of atherosclerotic diseases, associated with high morbidity and mortality, such as coronary heart disease and cerebrovascular disease are main goals of public health policy in industrialised countries. Therefore, identification of high-risk groups is relewant for implementation of preventive measures.

Peripheral arterial occlusive disease (PAOD), also caused by atherosclerosis, is rarely fatal. The majority of PAOD subjects are asymptomatic and of older age ${ }^{1,2}$. Intermittent claudication (IC) is the most common symptom manifestation and PAOD has a relatively benign course as far as the extremities are concerned ${ }^{3}$. Only a small minority develops critical ischaemia, justifying specialist intervention ${ }^{3}$. Cross-sectional studies, however, show that almost half of all PAOD subjects seem to have some clinical evidence of coronary heart disease or cerebrovascular disease ${ }^{3-5}$. Few followup studies on PAOD have described subsequent cardiovascular morbidity, especially in asymptomatic subjects ${ }^{6,7}$.

More evidence exists on the increased risk for mortality in claudicants. Symptomatic PAOD is consistently associated with an increased risk for atherosclerotic death ${ }^{3}$. For the mortality of asymptomatic PAOD, scarce data are available. The relative risk of death appears to be higher in asymptomatic subjects compared with the non-PAOD population ${ }^{3}$.

Gender disparities for adverse outcome are also scanty. Cardiovascular morbidity rates seem higher in women with $\mathrm{PAOD}$, whereas male PAOD subjects seem more at risk for cardiovascular death $^{3}$.

The aim of our longitudinal study was to describe the cardiovascular morbidity and mortality of asymptomatic PAOD subjects, after seven years of follow-up. In addition, we also investigated possible gender differences for outcome.

\section{Methods}

\section{Situdy population}

The Limburg PAOD Study was set up in 1987 in collaboration with 18 general practice centres. The study methods have been extensively described elsewhere, "In summary: The sampling frame for the study population consisted of 26620 subjects, aged $40-78$ years, whom were registered at the general practices. Every citizen in the Netherlands is registered at a general practice. Therefore, the registered population of a general practice is a segment of the general population. A postal screening questionnaire with five questions mostly about risk factors posisibly 
relevant for $\mathrm{PAOD}$ were sent to these subjects. The responders were then categorised to a "prior risk score" between 0 and 5 . Through a stratified sampling procedure, 5301 subjects, representing all parts of the clinical spectrum relevant to the general practice, were invited to participate in the study. From these, 3649 subjects agreed to participate in the study (mean age: 59 years; $53 \%$ female). No significant differences between participants and non-participants were found with regard to age and gender.

The study was approved by the Medical Ethics Committee of the University Hospital Maastricht.

\section{Baseline measurements}

With a self-administered questionnaire, data were collected regarding age, gender, possible $1 \mathrm{C}$ symptoms, cument and former smoking habits. In addition, each participant underwent a physical examination, including the measurement of the ankle-brachial pressure index (ABPI) in both legs. The ABPI was measured by trained practice assistants, using a pocket Dopplex device (Huntleigh Mini Doppler D500 8Mhz) and a sphygmomanometer. Systolic pressures were recorded on both arms and ankles (posterior tibial artery or dorsalis pedis artery), with the subject in supine position. The ABPIs were calculated as the ratio of each ankle systolic blood pressure to the highest arm systolic blood pressure. Interobserver and intraobserver variability for the Doppler measurements have been shown to be acceptable 9,10 .

PAOD was present when participants twice had an $\mathrm{ABPI}<0.95$ for at least one leg, measured with a week interval. IC was assessed by means of a modified version of the WHO questionnaire ${ }^{1,11}$. Symptomatic PAOD was defined as an ABPI < 0.95 in combination with IC. Asymptomatic PAOD was defined as an $\mathrm{ABPI}<0.95$ without IC complaints.

Data on the presence of hypertension, hypercholesterolaemia, diabetes mellitus, coronary heart disease and cerebrovascular disease were collected from the participants" medical records.

\section{Ascertaimment of nonfatal cardiovascular events during the follow-tup period}

For the non-fatal cardiovascular events, the collaborating physicians collected data on the following end points according to a specific criteria list: transient ischaemic attack (TIA), stroke, angina pectoris, silent or manifest myocardial infarction. congestive heart fallure and abdominal aortic aneurysm. The criteria list was developed by the Limburg PAOD research group, including three general practitioners, a cardiologist, a vascular surgeon and a neurologist. An end point was categorised as definite when a subject had signs and/or symptoms corresponding with the disease and supplementary examinations confirmed the diagnosis. The participants" medical records were 
used to collect information on the end points. In the Netherlands the general practitioner receives all: correspondence for every patient who is referred to a specialist. This correspondence was attached to the cardiovascular morbidity questionnaire of each participant.

All subjects who changed address or general practice during the follow-up period were traced and documentation was given by the new general practice.

\section{Definitions of non-fatal cardiovascular events}

TIA: clinical signs and symptoms corresponding with a totally reversible focal disturbance of the cerebral function lasting less than 48 hours, the general practitioner being present at the time of episode occurrence. Stroke: clinical diagnosis confurmed by a positive computed tomography scan or magnetic resonance imaging. Angina pectoris: clinical diagnosis confimed by a positive resting or exercise electrocardiogram, coronary angiograpiny or cardiac catheterisation. Myocardial infarction: manifest: clinical diagnosis confirmed by a positive electrocardiogram or coronary angiography and elevated cardiac enzymes; silent: a positive electrocardiogram without clinical diagnosis or elevated cardiac enzymes. Congestive heart failure: clinical diagnosis confirmed by a positive echocardiography or chest roentgenogram (cardiac enlargement). Abdominal aortic aneurysm: clinical diagnosis confirmed by a positive ultra-sound scan or computed tomograplyy scan.

Cerebrovascular disease comprised TLA and stroke. Coronary heart disease comprised angina, myocardial infarction and congestive heart failure. Cardiovascular disease comprised cerebrovascular disease, coronary heart disease and abdominal aortic aneurysm.

\section{Ascertainment of deaths during the follow up period}

Mortality data were also collected by the general practice centres. In the Netherlands, copies of hospital discharge summaries or postmortem findings from all deaths occurring in the hospitals are sent to the general practitioner. The collaborating physicians completed a cardiovascular morbidity - and mortality questionnaire for the deceased participants. Data on fatal strokes, myocardial infarctions, sudden deaths, abdominal aortic aneurysms and deaths due to PAOD complications were obtained. Deaths due to other cardiovascular and non-cardiovascular causes were also reported and coded based on the Intemational Classification of Primary Care (ICPC) ${ }^{12}$. For subjects of whom the date of death was uncertain, the exact date was sought from the muricipal registries. 
Cerebrovascular death comprised fatal strokes. Coronary heart disease mortality comprised sudden deaths, deaths due to myocardial infarction, congestive heart failure, atrial fibrillation and nonrheumatic heart walwe disease. Cardiovascular mortality comprised cerebrovascular death, coronary heart disease mortality, deaths due to abdominal aortic aneurysm and complications of PAOD.

To ensure that the protocol criteria were fulfilled, the cardiovascular morbidity and mortality lists were checked by two investigators ( $\mathrm{JH}$ and $\mathrm{HS}$ ).

\section{Statistical analyses}

Baseline theasurements between groups were compared using the $\chi^{2}$ test statistics (for categorical variables) and Student's t test (for continuous wariables).

Total and sex-specific incidence rates for cardiovascular morbidity and mortality were calculated based on person-years at risk (number of events divided by the person-years at risk of the initial population). Morbidity and mortality rates were recalculated to the source population as appropriately weighted means of morbidity and mortality rates per prior risk category. Because of small numbers of observed events, the normal approximation method for confidence intervals was not valid and therefore the method proposed by Waller et al was used with an adlaptation for the assumed Poisson distribution for the numbers of events ${ }^{13}$.

Cox proportional hazards analysis was used to determine associations between asymptomatic and symptomatic PAOD versus mortality or non-fatal event-free survival time, adjusted for differences in follow-up time and baseline covariates: age, gender, smoking status, diabetes, hypertension, the presence of cardiowascular diseases at baseline and hypercholesterolaemia. Cox models were also run for men and women separately. The hazard ratio (HR) derived from these models is comparable to a relative risk. Follow-up time was defined from the baseline measurement date to the end-point or end of the study (April 1997).

When more than one event of the same type occurred, only the first of these was counted in the analyses.

\section{Results}

Among the total study population, 314 had asymptomatic PAOD (50.6\% female), 138 had symptomatic PAOD (34.1\% fermale) and six had PAOD of unspecified type at baseline. Table 1 shows the baseline characteristics of the asymptomatic, symptomatic and non-PAOD subjects. 
Asymptomatic PAOD subjects and claudicants were significantly older, with a worse risk-factor protile and more often a history of other cardiovascular diseases compared with the non-PAOD subjects.

After a mean follow-up of 7.2 years, 3070 subjects ( $51.8 \%$ female) with a mean age of 64 years (range: $48-85$ years) were followed up $(84.2 \%$ of the initial cohort). The remaining group $(15.8 \%)$ did not respond because of two main reasons; refusal to take part (the majority) or being incapable because of severe illness (e.g. Alzheimer's disease) or hospitalisation. Non-responders did not significantly differ in age, gender and risk-factor profile from responders except for diabetes which was more common among the non-responders.

Table 1. The Limburg PAOD Longitudinal Study. Baseline characteristics of the study population

\begin{tabular}{|c|c|c|c|c|}
\hline Variable & $\begin{array}{l}\text { Non-PAOD } \\
(N=3176)\end{array}$ & $\begin{array}{l}\text { Overall PAOD } \\
\left(\mathrm{N}=458^{\circ}\right)\end{array}$ & $\begin{array}{l}\text { Asymptomatic PAOD } \\
(\mathrm{N}=314)\end{array}$ & $\begin{array}{l}\text { Symptomatic PAOD } \\
(\mathrm{N}=139)\end{array}$ \\
\hline Mean age & 58.3 & $64.6^{6}$ & $64.2^{71}$ & $65.4^{15}$ \\
\hline Mean ABPI & 110.2 & $75.3^{b}$ & $78.1^{\mathrm{b}}$ & $69.4^{b}$ \\
\hline Gender ( $\%$ men) & 45.9 & $53.9^{\mathrm{c}}$ & 48.7 & $65.9^{6}$ \\
\hline Smoking $(\%)$ & 47.2 & $56.5^{\mathrm{b}}$ & $54.0^{\mathrm{d}}$ & $60.9^{6}$ \\
\hline Hypertension (\%) & 37.1 & $49.2^{6}$ & $47.4^{b}$ & $53.7^{6}$ \\
\hline Diabetes $(\%)$ & 9.4 & $20.6^{b}$ & $21.4^{b}$ & $18.8^{6}$ \\
\hline Hypercholesterolaemia $(\%)$ & 10.7 & $15.6^{\circ}$ & $14.6^{d}$ & $18.4^{\mathrm{e}}$ \\
\hline Cardiovascular disease ( $\%$ ) & 22.1 & $49.5^{b}$ & $50.5^{6}$ & $47.4^{10}$ \\
\hline
\end{tabular}

"6 Subjects had PAOD of unspecified type. $\mathrm{P}<0.001$, compared with the non-PAOD group ${ }^{c} \mathrm{P}<0.01$, compared with the non-PAOD group. ${ }^{2} \mathrm{P}<0.05$, compared with the non-PAOD group.

Non-fatal cardiovascular disease and asymptomatic PAOD: incidence rates and prognostic factors

A total of 562 subjects (18.8\%) developed cardiovascular diseases, 427 of the non-PAOD subjects $(16.2 \%)$ and 135 of the subjects with PAOD at baseline (36.8\%). Non-fatal cardiovascular events occurred in $85(34.7 \%)$ of the asymptomatic subjects, in $47(40.2 \%)$ of the claudicants and in three subjects who had PAOD of unspecified type at baseline.

Cardiovascular morbidity rate for asymptomatic PAOD subjects was estimated at 76.8 per 1000 person-years at risk respectively, compared with 13.6 for the non-PAOD population, but the confidence interval for the PAOD group was large (table 2). Cardiovascular morbidity rate for claudicants could not be calculated because of zero person-years in one stratum (no claudicants present in this prior risk category). 
Table 2. The Limburg PAOD Longindinal Study. Morbidity and montality rates per 1000 person-years at risk fin asymptomatic and overall PAOD

\begin{tabular}{|c|c|}
\hline Events & $\begin{array}{l}\text { Non-PAOD } \\
(\mathrm{r}=2628)\end{array}$ \\
\hline
\end{tabular}

\begin{tabular}{|c|c|c|c|c|c|c|}
\hline Non-fatal & D & & $\mathbb{I}$ & & $\mathrm{n}$ & \\
\hline Cardioviscular disease & 427 & $14.6(11.6-19.3)$ & 135 & $79.6(38.7-247.3)$ & 85 & $8[.2(39.8-252.2)$ \\
\hline Coronary heart diserset & 342 & $12.2(9.5-16.6)$ & 110 & $39.1(21.2-157.9)$ & 68 & $40.7(21.7 .1639)$ \\
\hline Angina pectoris ${ }^{b}$ & 231 & $7.4(5.5-11.1)$ & 57 & $8.3(4.3-108.3)$ & 37 & $11.0(5.6-115.7)$ \\
\hline Myocardial infarction ${ }^{b}$ & 128 & $4.7(3.3-7.9)$ & 46 & $7.9(4.0-108.0)$ & 29 & $10.7(5.3-115.5)$ \\
\hline Cerebrovascular disease & 91 & $2.9(1.9-5.7)$ & 36 & $40.5(17.6-186.2)$ & 28 & $40.7(18.3-188.3)$ \\
\hline \multicolumn{7}{|l|}{ Fatat ${ }^{e}$} \\
\hline Total & $349^{d}$ & $10.9(8.5-14.8)$ & $126^{\mathrm{fi}}$ & $44.1(21.5-149.9)$ & 81 & $42.8(21.2-152.6)$ \\
\hline Cardiovascular disease & 161 & $2.3(1.6-4.6)$ & 74 & $34.5(15.4-137.2)$ & 47 & $35.8(16.5 \cdot 143.6)$ \\
\hline Coronary heart disease & 133 & $2.0(1.4-4.2)$ & $\$ 3$ & $6.2(3.1-94.4)$ & 35 & $7.6(3.7-101.3)$ \\
\hline Myocardial infarction $^{b}$ & 59 & $0.8(0.5-2.7)$ & 27 & $3.7(1.8-90.9)$ & 16 & $5.0(2.3+97.6)$ \\
\hline Cerebrovascular disease $^{b}$ & 23 & $0.3(0.2-2.0)$ & 12 & $0.3(0.2-85.9)$ & 7 & $0.3(0.2-90.6)$ \\
\hline Other $^{b}$ & $188^{\mathrm{t}}$ & $8.6(6.4-12.2)$ & $52^{8}$ & $9.6(5.1-99.1)$ & 34 & $7.0(4.0-99.8)$ \\
\hline
\end{tabular}

For symptomatic PAOD no separate incidence rates could be calculated because of lack of data in one of the prior risk strata. ${ }^{2}$ Including 5 subjects who had PAOD of unspecified type, 3 developed a non-fatal event and 2 died. ${ }^{b}$ For definitions see methods. "For fatal events, the non-responders were also included in the analyses. "Total no of deaths when non-PAOD and deceased subjects are counted does not add to 481: an additional 6 subjects died who could not be classified due to missing ABPI, for one the cause of death was unknown. ${ }^{\text {E }}$ Including 11 subjects of whom the cause of death was unknown. ${ }^{f}$ Including 6 subjects of whom the cause of death was unknown.

Table 3. The Limburg PAOD Longitudinal Study. Adjusted hazard ratios (HR) of asymptomatic and symptomatic PAOD for non-fatal and fatal cardiowascular events.

\begin{tabular}{|c|c|c|c|c|c|c|c|}
\hline Events & $\begin{array}{l}\text { Non-PAOD } \\
(\mathrm{n}=2628)\end{array}$ & $\begin{array}{l}\text { Over } \\
(\mathrm{n}=36\end{array}$ & (1) PAOD & & $\begin{array}{l}\text { ptomatic PAOD } \\
\text { 5) }\end{array}$ & & $\begin{array}{l}\text { tomatic PAOD } \\
\text { 7) }\end{array}$ \\
\hline Non-fatal: & $n$ & $n$ & HR $(95 \% \mathrm{Cl})$ & $n$ & $\mathrm{HR}(95 \% \mathrm{Cl})$ & $\mathrm{n}$ & $\mathrm{HR}(95 \% \mathrm{CI})$ \\
\hline Crardiovascular disease & 427 & 135 & $1.6(1.3-1.9)$ & 85 & $1.6(1.3-2.1)$ & 47 & $1.4(1.0-2.0)$ \\
\hline Coronary leeart disease" & 342 & 110 & $1.6(1.2-2.0)$ & 68 & $1.6(1.2 \cdot 2.1)$ & 39 & $1.5(1.0-2.1)$ \\
\hline Angina pectors & 231 & 57 & $1.3(0.9-1.7)$ & 37 & $1.3(0.9-1.9)$ & 18 & $1.1(0.7-1.9)$ \\
\hline Myocardial infaretioni" & 128 & 46 & $1.6(1.1-2.4)$ & 29 & $1.7(1.1-2.6)$ & 16 & $1.5(0.9-2.6)$ \\
\hline $\begin{array}{l}\text { Cerebrovascular disegste } \\
\text { Fatal: }\end{array}$ & 91 & 36 & $1.7(1.1-2.5)$ & 28 & $2.1(1.4-3.3)$ & 8 & $1.0(0.5-2.1)$ \\
\hline Total & $349^{\mathfrak{e}}$ & $126^{\mathrm{t}}$ & $1.4(1.1-1.7)$ & 81 & $1.4(1.1-1.8)$ & 43 & $1.4(1.0-2.0)$ \\
\hline Cardiovascular disease & 161 & 74 & $1.6(1.2-2,1)$ & 47 & $1.5(1.1-2.2)$ & 25 & $1.6(1.0-2.5)$ \\
\hline Coronary heart disease & 133 & 53 & $1.4(1.0 \cdot 2.0)$ & 35 & $1.5(1.0-2.2)$ & 17 & $1.3(0.8-2.3)$ \\
\hline Myocardial infarction ${ }^{c}$ & 59 & 27 & $1.5(0.9-2.5)$ & 16 & $1.4(0.8-2.6)$ & 10 & $1.7(0.8-3.5)$ \\
\hline Cerebroviscular disease. & 23 & 12 & $1.7(0.8-3.7)$ & 7 & $1.6(0.7-3.8)$ & 5 & $2.1(0.8-5.8)$ \\
\hline Other ${ }^{e}$ & $188^{\circ}$ & $52^{\mathrm{g}}$ & $1.0(0.9-1.2)$ & 34 & $1.0(0.9-1.2)$ & 18 & $1.0(0.8-1.2)$ \\
\hline
\end{tabular}

$\mathrm{Cl}=$ confidence interval. " Adjusted for age, gender, smoking, hypertension, diabetes, bypercholesterolaemia and CVD prevalence at baseline. ${ }^{b}$ Including 5 subjects who had PAOD of unspecified type, 3 developed a non-fatal event and 2 died. ${ }^{e}$ For definitions see methods. "For fatal events, the non-responders were also included in the analyses. "Total no of deaths when non-PAOD and deceased subjects are counted does not add to 481 : an additional 6 subjects died who could not be classifjed due to missing ABPI, for one the cause of death was unknown. "Including 11 subjects of whom the cause of death was unknown. ${ }^{8}$ Including 6 subjects of whom the cause of death was unknown. 
Asymptomatic and symptomatic PAOD were strongly associated with non-fatal events both cerebrovascular and coronary heart disease) after adjustment for other covariates (table 3 ).

Other significant independent predictors of cardiovascular morbidity were increasing age, male gender, hypertension, diabetes and cardiovascular disease co-morbidity at baseline. The adjusted HR for a non-fatal event of co-exilsting cardiovascular disease at baseline was 2.5.

Total and cause-specific mortality and asymptomatic $P A O D$ : incidence rates and prognostic factors

A total of 481 subjects (13.2\%) from the study population died during the follow-up period, 349 $(10.9 \%)$ in the non-PAOD group, $81(25.8 \%)$ in the asymptomatic group and $43(31.2 \%)$ in the symptomatic PAOD group, respectively. Six subjects who could not be classified because of a missing ABPI and two subjects who had PAOD of unspecified type at baseline also died during the follow-up period.

Much higher total and cardiovascular mortality rates were observed in asymptomatic PAOD subjects (42.8 and 35.8 per 1000 person-years, respectively), compared with the non-PAOD subjects (10.9 and 2.4 per 1000 person-years, respectively) (table 2). Mortality rate estimates for death due to other causes were similar for the asymptomatic and non-PAOD groups.

Asymptomatic and symptomatic PAOD were significant prognostic factors for total and cardiovascular mortality (table 3). The increased risk of total mortality in these subjects was mainly due to cardiovascular mortality. The risk of cardiovascular death for asymptomatic PAOD subjects and claudicants was similar. No association was found between death from other causes and asymptomatic or symptomatic PAOD.

Other significant independent predictors of total - and cause-specific mortality were increasing age, male gender, smoking, hypertension, diabetes and cardiovascular disease co-morbidity at baseline. The adjusted HRs for total and cause-specific mortality for comexisting cardiovascular disease at baseline varied from 1.9 for total mortality to 4.1 for myocardial infaretion death.

\section{Gender differences for outcome}

During the follow-up period, $51(40.5 \%)$ of the males and $34(28.6 \%)$ of the females with asymptomatic PAOD at baseline developed a non-fatal cardiovascular event. Among the male claudicants at baseline, $32(40.0 \%)$ developed a non-fatal cardiovascullar event. Among the female claudicants at baseline, $15(40.5 \%)$ developed a non-fatal event. 
Table 4 presents the gender differences for outcome. The number of asymptomatic PAOD subjects with an adverse event, when stratified by gender was relatively small, so the power to detect significant associations was low. Nevertheless, the following trends were observed. Cardiovascular morbidity rate seemed higher for men with asymptomatic PAOD at baseline, than for women. Non-fatal coronary heart disease seemed to occur more frequent in women with asymptomatic PAOD at baseline whereas men with asymptomatic PAOD at baseline more ofter seemed to develop a non-fatal cerebrovascular event.

Multivariable analyses showed that asymptomatic PAOD was a stronger predictor for non-fatal myocardial infarction in females than in males.

Mortality occurred in $51(33.3 \%)$ of the asymptomatic male subjects and in $30(18.6 \%)$ of the asymptomatic female subjects at baseline. Among the claudicants at baseline, 31 (34.1\%) of the males and $12(25.5 \%)$ of the females died during the follow-up period.

Total and cardiovascular mortality rates seemed higher among male asymptomatic PAOD subjects than females.

Male subjects with asymptomatic disease had a higher risk of cardiovascular death, mainly due to stroke, than female subjects with asymptomatic disease.

Table 4. The Limburg PAOD Longitudinal Study. Gender differences for outcome.

\begin{tabular}{|c|c|c|}
\hline Event & Male asymptomatic subjects & Female asymptomatic sub \\
\hline Non-fatal: & Rate / 1000 person-years & Rate/ 1000 person-years \\
\hline Cardiovascular disease & $104.3(30.7-414.0)$ & $54.0(17.6-197.3)$ \\
\hline Corondry heart disease & $30.1(120-224.1)$ & $53.1(17.0-196.2)$ \\
\hline Cerebrovasoular disease & $74.3(18.4-367.0)$ & $1.2(0.6-91.3)$ \\
\hline
\end{tabular}

Fatal:

Total

Cardiovascular

Mon-fatal:

Myocardial infarction

Fatal:
$63.5(17.3-276.4)$

$61.9(159-27.4)$

$\operatorname{HR}(95 \% \mathrm{CH})$

$1.4(0.8-2.4)$
$18.5(8.8-91.7)$

$5.2(1.7-72.9)$

HR $(95 \% \mathrm{CD})$

$2.4(1.2-4.6)$

Cardiovascular disease

Gerebrovascular disease

$3.1(1.0-9.2)$

$1.3(0.7-2.3)$

$-a$

$\mathrm{HR}=$ hazard ratio for asymptomatic $\mathrm{PAOD}$, non-PAOD is the reference category. $\mathrm{CI}=$ confidence interval. ${ }^{2} \mathrm{Omly}$ one female asymptomatic PAOD subject died of stroke, no walue was obtained by Cox proportional-hazards methods. 


\section{Discussion}

Our results showed that in the general population, asymptomatic PAOD subjects more often developed non-fatal and fatal cardiovascular events than non-PAOD subjects. Asymptomatic PAOD was not only a significant predictor for non-fatal cardiovascular disease, but also for total and cardiovascular disease mortality. Surprisingly, both asymptomatic and symptomatic PAOD subjects had a comparable prognosis for both non-fatal and fatal events. Female asymptomatic PAOD subjects seemed to be at higher nisk for a non-fatal myocardial infarction whereas male asymptomatic PAOD subjects had elevated risks for cardiovascular death, mainly due to fatal strokes.

Major losses to follow-up may form a handicap in cohort studies, introducing selection - and survival bias. To restrict losses to follow-up in our study, subjects who were unable to visit the general practice were offered home visits. Those who missed their appointment were telephoned and invited a second time to attend. We cannot rule out that the non-response group might have had a different non-fatal cardiovascular disease incidence, even though quantitatively this should be minimal.

Mortality data could have been missed in the group who could not be traced during the follow-up period, resulting in an underestimation of the mortality rates. Less than one percent of the nonresponders were lost to follow-up because of out-migration or were unknown in the general practice. All the other non-responders were alive at the time of data collection. Therefore, we are confident that the mortality data are fairly complete. Cause of death was not known for 18 subjects of whom 6 had PAOD at baseline and one could not be classified because of missing ABPI. Except for the latter one, these subjects were included in the group of death due to other causes. Thus, there is a possibility that especially the PAOD subjects were not correctly classified, resulting in underestimation of the HRs for cardiovascular death.

Non-fatal cardiovascular disease and asymptomatic PAOD: incidence rates and prognostic factors

Our morbidity rates and HRs for asymptomatic subjects are difficult to compare with results from other studies due to a lack of data. The Lipid Research study reported a threefold excess of cardiovascular morbidity among, PAOD subjects, after 10 years of follow-up".

Angina pectoris seemed more frequent in asymptomatic subjects in the Edinburgh Artery study after 5 years of follow-up". In that study, subjects with an ABPI $\leq 0.90$ had significantly increased relative risks for non-fatal myocardial infarction and stroke ${ }^{14}$, in accordance with our results. 
Total and cause-specific mortality and asymptomatic PAOD: incidence rates and prognostic factors

Mortality rates for asymptomatic PAOD subjects have not been described to date. Our mortality rate estimates for owerall $P A O D$ however, are in accordance with those reported in other studies ${ }^{\text {:5 }}$ 17

Only two prospective longitudinal population-based studies explicitly addressed mortality relative risks in asymptomatic PAOD subjects ${ }^{7,15}$. The Lipid Research study, presented significant adjusted relative risks for total, cardiovascular and coronary heart disease mortality in asymptomatic PAOD subjects with no evidence of CVD at baseline, concordant with our findings ${ }^{15}$. In that study, claudicants had a worse prognosis with regard to mortality, than asymptomatic PAOD subjects.

Our observations were similar to those of the Edinburgh Artery study ${ }^{7,14}$. This 5-year prospective follow-up study showed that subjects with asymptomatic disease had a worse total - and cardiovascular mortality (RR: 2.4 and 2.1 , respectively), compared with non-PAOD subjects. These relative risks however, were only adjusted for age. In addition, no substantially higher mortality relative risks for claudicants compared with the asymptomatic POAD subjects were presented in that study. Leng et al also reported that subjects with an ABPI $\leq 0.90$ were at significantly elevated risk for total and cardiovascular mortality: the risk ratios being 1.6 and 1.9 respectively, after adjustments for age, gender, diabetes, myocardial infarction and angina pectoris at baseline were made ${ }^{14}$. Like our results, in the Edinburgh Artery study, PAOD was not associated with death due to other causes ${ }^{1.4}$.

\section{Gender differences for cardiovascular morbidity and mortality}

In the Lipid Research study, women with PAOD developed more non-fatal cardiovascular events than men ${ }^{6}$, and men with PAOD had higher cardiovascular mortality rates than women ${ }^{15}$. We did not observe higher cardiovascular morbidity rates in female PAOD subjects compared with men.

Male PAOD subjects (asymptomatic and symptomatic) are consistently at high risk for cardiovascular death in several population-based follow-up studies ${ }^{16-18}$. The Israeli Ischemic Heart Disease Project reported after 21 years of follow-up a strong and independent association between new onset of intermittent claudication and stroke in male claudicants ${ }^{19}$. Increased relative risk for fatal strokes in male claudicants was also reported in the Whitehall study ${ }^{16}$. We also demonstrated significant associations of PAOD and stroke in male subjects compared with women. Obviously, male PAOD subjects are at particular risk for cerebrowascular mortality. 


\section{Clinical implications}

Atherosclerosis is a generalised disease and therefore, subjects with asymptomatic and symptomatic PAOD have higher cardiovascular morbidity and mortality. Often, these patients have co-existing coronary heart disease and cerebrovascular disease. As shown in this study, co-existing coronary or cerebrovascular disease at baseline is a significant prognostic factor for non-fatal cardiovascular events and death. When we excluded this covariate from the analyses, asymptomatic and symptomatic $\mathrm{PAOD}$, being also indicators of cardiovascular status, became even stronger prognostic factors.

Asymptomatic PAOD subjects in general are younger than symptomatic PAOD subjects ${ }^{1}$, justifying preventive measures in an early stage. Case-finding in high-risk groups is appropriate: atherosclerotic risk factors such as diabetes and hypertension should be treated adequately and smoking strongly advised against. Our results emphasise the prognostic value of an ABPI measurement $(A B P I<0.95)$ in high-risk subjects. The $A B P I$, a valid and relatively simple measurement, is appropriate in a general practice setting, providing valuable information concerning an individual's present and future cardiovascular disease status ${ }^{8,9}$.

\section{Acknowledgements}

We thank the participating physicians and the assistants for their contributions to this study. The Limburg PAOD Study was supported by a research grant of the Netherlands Organization for Scientific Research (900-715.154) and the Dutch "Praeventiefonds" (28-1323). The longitudinal study was supported by a research grant from the Netherlands Heart Foundation (92.170). Doppler devices were donated by Asta Medica BV. 


\section{References:}

1. Stoffers HESH, Rinkens PELM, Kester ADM, Kaiser V, Knottrerus JA. The prevalence of asymptomatic and unrecognized peripheral arterial oeclusiwe discase, In J Epiderniol 1996; 25:282-290.

2. Fowkes FGR, Housley E, Cawood EHH, Macintyre CCA, Ruckley CV, Prescott RI. Edinburgh Artery Study: Prevalence of asymaptomattic and symptomatic peripheral arterial disease in the general population. Int I Epidemiol $1991 ; 20: 384.392$

3. Hooi JD, Stoffers HEJH, Knottnerus JA, kee JW van. The prognosis of non-critical limb ischaemia: a systematic review of population-based evidence. Br J Gen Pract (accepted).

4. Hooi JD, Stoffers HEJH, Knottmerus JA, Ree JW van. Risk factors and cardiovascular diseases associated with asymptomatic peripheral arterial occlusive disease: The Limburg PAOD Study. Scand I Prim Health Care (in press).

5. McGrae McDermot M, McCarthy W. Intermittent claudication the natural history. Surg Clin N Am 1995; 75:581591.

6. Criqui MH, Langer RD, Fronek A, Feigelson HS. Coronary disease and stroke in patients with large-vessel peripheral arterial disease. Drugs $1990 ; 5: 16-21$.

7. Leng GC, Lee AJ, Fowkes FGR, Whiteman M, Dunbar J, Housley E, Ruckley CW. Incidence, nanural history and cardiovascular events in symptomatic and asymptomatic peripheral arterial disease in the general population. Int J Epidemial 1996; 25: 1172-1181

8. Stoffers HEJH, Kester ADM, Kaiser V, Rinkens PELM, Kitslaar PJEHM, Knottnerus JA. The diagnostic value of the measurement of the ankle-brachial systolic pressure index in primary health care. I Clin Epidemiol 1996; 49: $14011-1405$.

9. Stoffers HEJH, Kaiser $\mathrm{V}$, Kester ADM, Schouten HJA, Knottnerus JA. Peripheral arterial occlusive disease in general practice: the reproducibility of the ankle-arm systolic pressure ratio. Scand J Prim Health Care 1991; 9: 109.114.

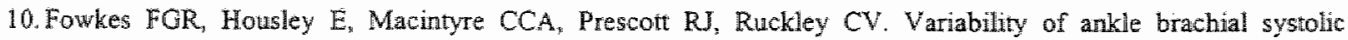
pressures in the measurement of atherosclerotic peripheral arterial disease. J Epidenviol Community Health 1988; 42: $128-133$.

11. Rose GA, Blackburn H, Gillum RF, Prineas RJ. Cardiovascular survey methods. $2^{\text {nd }} \mathrm{Edn}$. Genewa: WHO; 1982: $162-165$.

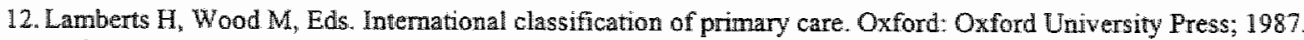

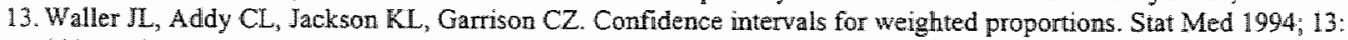
$1071-1082$.

14. Leng GC, Fowkes EGR, Lee AI, Dunbar J, Housley E, Ruckley CV. Üse of arkle brachial pressure index to predict cardiovascular events and death: a cohort study. BMJ 1996; 313: 1440-1444.

15. Criqui MH, Langer RD, Fronek A. Feigelson HS, Klauber MR, McCann TJ, Browner D. Mortality over a period of 10 years in patients with peripheral arterial disease. N Engl I Med 1992; 326: 381-386.

16. Davey Smith FD, Shipley MJ, Rose G. Intermittent claudication, heart disease risk factors, and mortality; The Whitehall Studly. Circulation 1990; 82: 1925-1931.

17. Dagenais GR. Maurice S, Robitaille N-M, Gingras $\$$, Lupien PJ. Intermittent cladudication in Quebec men from 1974 1986: the Quebec Cardiovascular Study. Clin Irvest Med 1991; 14:93-100.

18. Bowlin SJ, Medalie JH, folocke SA, Zyzanski SJ, Yaari S, Goldbourt U. Intermittent claudication in 8343 men and 21-year specific mortality follow-ap. AEP 1997; 7: 180-187.

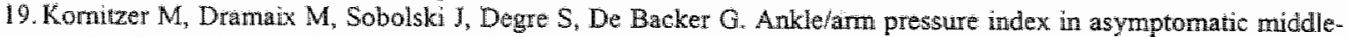
aged males: an independent predictor of ten-year coronary heart disease mortality. Angiology 1995; 46:211-219. 
Peripheral arterial occlusive disease: prognostic value of signs, symptoms and the ankle-brachial pressure index

Jurenne $\mathbb{D}$ Hooi

Henri EJH Stoffers

Arnold DM Kester

Paula ELM Rinkens

Jan W van Ree

J André Knottnerus 


\begin{abstract}
Objectives. To determine whether different levels of the ankle-brachial pressure index (ABPI) is associated with an increased risk for symptom progression, nom-fatal and fatal cardiovascular events. To investigate the prognostic value of signs and symptoms associated with peripheral arterial occlusive disease (PAOD) in subjects with an $\mathrm{ABPI}<0.95$.
\end{abstract}

Dexign. Prospective follow-up study.

Setting. Province of Limburg, in the southem part of The Netherlands.

Subjects. From 18 general practice centres, 3649 subjects ( $53 \%$ female) with a mean age of 59 years (range: $40-78$ years) were selected and followed up.

Main outcome measures. Progressive ischaemia, cardiovascular morbidity and mortality.

Results. At baseline, 458 subjects had PAOD, defined as an ABPI < 0.95. Among these, 148 $(32.2 \%)$ had an ABPI $<0.70$. Cox proportional hazards models showed that after a mean follow up period of 7.2 years, PAOD subjects with an ABPI $<0.70$ were at higher risk for cardiovascular death, compared with subjects with a moderately reduced ABPI $(<0.95-\geq 0.70)$. Older age, intermittent claudication symptoms, abnormal pedal pulses, elevated blood pressure and prevalent cardiovascular disease at baseline were also significant independent prognostic factors for one or more of the outcome events in these subjects.

Conclusion. The ABPI is inversely associated with mortality in PAOD subjects. Therefore, it is useful for early identification of high-risk subjects. It is a clinically significant supplement to the physical examination and can be easily used in a general practice setting.

Key Words: peripheral anterial occlusive disease, prognosis, ankle-brachial pressure index. 


\section{Introduction}

The clinical course of peripheral arterial occlusive disease (PAOD) is relatively benign, being stable or improving in the majority of both asymptomatic PAOD subjects and claudicants ${ }^{1}$. Approximately one out of 10 asymptomatic PAOD patients seems to develop intermittent claudication (IC) symptoms ${ }^{2}$. A small group of claudicants develops critical limb ischaemia, in some cases making specialist interventions necessary'. Worsening normally occurs gradually, and smoking, diabetes and hypertension may be important prognostic variables in this process". Despite the relative benign course in the limbs, population-based studies indicate that claudicants have a higher cardiovascular morbidity and mortality than the general population ${ }^{2-6}$. Recently with the upcoming of the ankle brachial pressure index (ABPI), a valid diagnostic instrument to detect asymptomatic $\mathrm{PAOD}^{7.9}$, more attention has been focused on possible adverse events in asymptomatic subjects also. Asymptomatic subjects seem to have elevated relative risks for mortality compared with non-PAOD subjects ${ }^{2,3,10}$. There have been a limited number of population-based prospective studies that reported to what extent the ABPI is of prognostic significance for subsequent cardiovascular morbidity and mortality ${ }^{10-12}$. Which PAOD patients are more likely to have an adverse outcome? Is there an inverse relationship between the ABPI level and the risk for progressive ischaemia in the legs, subsequent cardiovascular morbidity and mortality? Which signs and symptoms are of prognostic importance for an adverse outcome in these subjects? Identification of prognostic variables for an adverse outcome event has clearly important clinical implications.

The first aim of this study was to determine whether different levels of the ankle-brachial pressure index (ABPI) is associated with an increased risk for symptom progression, non-fatal and fatal cardiovascular events. The second aim was to investigate the prognostic value of signs and symptoms, including physical examination findings, associated with PAOD for an adverse outcome, when PAOD, defined as an ABPI < 0.95 was already present. In addition, prognostic models were constructed for each outcome event.

\section{Subjects and methods}

\section{Study population}

The Limburg PAOD study began as a cross-sectional survey in 1987 in collaboration with 18 general practice centres. Every subject in the Netherlands is registered at a general practice centre. Therefore, the registered population of a general practice centre is a segment of the general population. A postal screening questionnaire was mailed to the source population $(n=26,620)$ with 
five questions mostly about risk factors possibly relevant for PAOD. Responders were then categorised to a "prior risk score" between 0 and 5. The study population thus, included subgroups corresponding with parts of the clinical spectrum relevant to the general practice. By means of a stratified sampling procedure, 5301 subjects were invited and 3649 respondents agreed to participate in the study (mean age: 59 years; $53 \%$ female). No statistically significant differences were found between responders and non-responders with regard to age and gender. The recruitment and selection procedures have been extensively described in earlier publications ${ }^{13,14}$. Participants gave their informed consent and the study was approved by the Medical Ethics Committee of the University Hospital Maastricht.

\section{Baseline measurements}

With a self-administered questionnaire data were gathered on age, gender, possible IC symptoms and smoking habits. The participants then visited the general practices, where the practice assistant measured height, weight, blood pressure and the ABPI. Using a pocket Doppler device (Huntleigh Mini Dopplex D500, $8 \mathrm{Mhz}$ ) and a mercury sphygmomanometer, the systolic blood pressure on both arms and ankles (posterior tibial or dorsalis pedis) were assessed, with the participant in a supine position. The ABPIs were calculated as the ratio of each ankle systolic blood pressure to the highest arm systolic blood pressure. Interobserver and intraobserver variability for the Doppler measurements have been shown to be acceptable ${ }^{9,15}$. Subsequently, the general practitioner performed a physical examination, to evaluate the presence or absence of signs associated with PAOD. The physical examination included inspection of both legs, palpation of the skin and posterior tibial and dorsalis pedis arteries, palpation and auscultation of the femoral arteries. Data from the subjects' medical records conceming the prevalence of ischaemic heant diseases, cerebrovascular diseases, hypertension, hypercholesterolaemia and diabetes were also registered. PAOD was defined as an ABPI $<0.95$ measured twice at weekly intervals. IC was defined as pain in the calf while walking, disappearing when standing still and not present at resting (typical) ${ }^{16}$. Other complaints involving the foot, thigh or buttock with this ischaemic pattem were also included in the $\mathrm{IC}$ definition (atypical) ${ }^{13}$.

\section{Follow up and oucome measurements}

The follow-up took place from January 1995 until April 1997. Subjects still alive were invited for a re-examination, identical to the baseline measurements. Those who changed address (but still resided in the province of Limburg) or switched from general practice during the follow-up period 
were traced and documentation was given by the new general practice. The outcome parameters were: progressive ischaemia, documented cardiovascular morbidity and mortality. Subjects were followed up from the baseline measurement date until the outcome event or end of the study. Information on specialist intervention due to PAOD, cardiovascular morbidity and mortality were obtained from the general practices, according to a specific criteria list. The criteria list was developed by the Limburg PAOD research group, including three general practitioners, a cardiologist, a vascular surgeon and a neurologist. In the Netherlands, the general practitioner receives all correspondence of patients referred to a specialist, copies of the discharge surnmaries or postmortem findings from all deaths occurring in the hospitals.

\section{Definition of progressive ischaemia}

Progressive ischaemia included reconstructive or percutaneous transluminal angioplasty, vascular surgery or amputation.

\section{Defimitions of non-fatal evenis}

A non-fatal end point was categorised as definite when a subject had signs and/or symptoms corresponding with the disease and additional clinical examination confirming the diagnosis.

TIA: clinical signs and symptoms corresponding with a totally reversible focal disturbance of the cerebral function lasting less than 48 hours, with the general practitioner present at the time of episode occurrence. Stroke: clinical diagnosis confirmed by a positive computed tomography scan or magnetic resonance imaging. Angina pectoris: clinical diagnosis confirmed by a positive resting or exercise electrocardiogram, coronary angiography or cardiac catheterisation. Myocardial infarction: manifest: clinical diagnosis confimed by a positive electrocardiogram or coronary angiography and elevated cardiac enzymes; silent: a positive electrocardiogram without clinical signs, symptoms or elevated cardiac enzymes. Congestive heart failure: clinical diagnosis confirmed by a positive echocardiography or chest roentgenogram (cardiac enlargement). Aortic anetrysm: clinical diagnosis confirmed by a positive ultra-sound scan or computed tomography scan.

Cerebrovascular disease comprised TLA and stroke. Coronary heart disease comprised angina, myocardial infarction and congestive heart failure. Cardiovascular disease comprised cerebrovascular disease, coronary heart disease and abdominal aortic aneurysm. 


\section{Definitions of fatal events}

Cardiovascular mortality included all documented fatal strokes, myocardial infarctions, sudden deaths, aortic aneurysms and deaths due to PAOD complications. Deaths due to other cardiowascular causes were also reported and coded based on the Intemational Classification of Primary Care (ICPC) ${ }^{17}$. The ICPC codes were also used to classify deaths due to other causes. Cardiovascullar morbidity data were also gathered for the deceased subjects. For subjects of whom the date of mortality was uncertain, the exact date was sought from the municipal registries.

\section{Statistical analyses}

When multiple events of the same type occurred during the follow-up period, such as two vascular surgery interventions or myocardial infarctions, only the first was counted in the analyses.

The $\chi^{2}$ test for trend was used to evaluate the association between ABPI at baseline (with categories: $\geq 0.95:$ nomal $_{\text {i }}<0.95-\geq 0.70:$ moderately reduced; $<0.70$ : low), and progressive ischaemia, cardiovascular morbidity and mortality.

Cox proportional hazards models were used to investigate the following associations. 1 . The prognostic value of varying levels of ABPI for progressive ischaemia, adjusted for the covariates age, gender, smoking status, diabetes, hypertension and cardiovascular disease at baseline; 2 . The prognostic value of varying levels of ABPI for cardiovascular morbidity and mortality. In these models, hypercholesterolaemia was also included as a covariate.

For the subgroup of PAOD patients, event-free survival curves were calculated (Kaplan Meier) for each adverse outcome event. By means of Cox proportional hazards models the independent prognostic value for an adverse outcome of the following signs and symptoms was assessed: $1 \mathrm{C}$ complaints, blood pressure, inspection of both legs (wounds or sores, skin colour and temperature), palpation of pedal pulses (posterior tibial and dorsalis pedis arteries), palpation and auscultation of the femoral arteries and the above-mentioned covariates. The physical examination variables used in these models were found to be of diagnostic importance in a prior study ${ }^{12}$. In addition, stepwise backwards Cox analyses were performed to construct a significant predictive model for each outcome event. From these reduced models, predicted probabilities for an adverse outcome event within seven years were also calculated.

The hazard ratio (HR) derived from all models can be interpreted as a relative risk. 


\section{Results}

At baseline, 458 subjects had PAOD, of whom $32.3 \%$ had an ABPI < 0.70 . The average follow-up period was 7.2 years. A total of 2589 subjects ( $54.2 \%$ female; mean age: 64 .1 years) attended the re-examination and 481 subjects died during the follow-up period. The non-response was $15.8 \%$ mainly due to refusal to participate in the study (the majority), severe illness (e.g. Alzheimer's disease) or hospitalisation. Non-responders did not differ significantly in age, gender or risk-factor profile at baseline than responders, except for diabetes which was more common among the nonresponders.

During the follow-up period, 52 of the PAOD subjects $(8.4 \%)$ underwent a specialist intervention because of symptom progression. Non-fatal cardiovascular events and mortality occurred in 135 $(36.8 \%)$ and $126(27.3 \%)$ of the PAOD subjects, respectively, compared with $16.2 \%$ and $10.9 \%$ of the non-PAOD subjects. Coranary heart disease and stroke were the main causes of death in these subjects.

ABPI categories and progressive ischaemia, cardiovascular morbidity and mortality

A significant trend was observed in the occurrence of an adverse event with decreasing baseline ABPI after 7.2 years of follow-up (table 1). However, for progressive ischaemia, the significance in trend was mainly caused by the difference between the group with an ABPI $\geq 0.95$ and the other two groups.

Table 1. The Limburg PAOD Longitudinal Study. Clinical course and prognosis of asymptomatic and symptomatic PAOD after 7.2 years of follown (\%)

\begin{tabular}{|c|c|c|c|c|}
\hline \multirow[b]{2}{*}{ Ewonts } & \multicolumn{4}{|c|}{ Ankle-brachial pressure index } \\
\hline & 0.95 & $\geq 0.70-<0.95$ & $<0.70$ & Povalue for trethd \\
\hline Progressive ischaemi (n=2995) & $30(1.1 \%)$ & $21(8,7 \%)$ & $11(8.8 \%)$ & $<0.001$ \\
\hline Cardiovascular morbidity $(\mathrm{m}=2995)^{*}$ & $427(16.2 \%)$ & $77(31.8 \%)$ & $58(46.4 \%)$ & $<0.001$ \\
\hline Cardiovascular mortality $(\mathrm{n}=3634)^{*}+$ & $161(5.1 \%)$ & $36(11.6 \%)$ & $38(25.7 \%)$ & $<0.001$ \\
\hline Total mortality $(n=3634)^{*}+$ & $349(11.00 \%$ & $60(19.4 \%)^{2}$ & $66(44.6 \%)^{3}$ & $<0,001$ \\
\hline
\end{tabular}

* For definitions see Methods. Mortaliry calculations are done for the total study population. $\$$ Total rumber of deaths when non-PAOD and PAOD subjects are conted does not add to 481: an additional 6 subjects died who could not be classined due to missing ABPt, for one the catse of death was unlowown. Inoluding 11 subjects of whom the cause of death was unknown. Including 5 subjects of whom the cause of death was unkrown. ${ }^{3}$ Including 1 subject of whom the cause of death was unknow.

PAOD subjects with a moderately reduced ABPI were at higher nisk for developing progressive ischaemia compared with those with a low ABPI (table 2). The adjusted HR for a non-fatal 
cardiowascular event for an ABPI $<0.70$ was similar to that of an ABPI beween 0.70 and 0.95 . Subjects with the lowest ABPI (HR: 2.3; 95\% CI: $1.7-3.1$ ) had a poorer survival due to cardiovascular mortality, compared with those with a moderately reduced ABPI (HR: $1.2 ; 95 \%$ CI: 0.8 - 1.7). A moderately reduced ABPI was not associated with a poorer overall survival, compared with an $\mathrm{ABPI} \geq 0.95$.

Table 2. The Limburg PAOD Longitudinal Study. Adjusted hazard ratios (HR) for the development of progressive ischaemia, non-fatal and fatal cardiovascular events in 7.2 years, by various levels of baseline ankle-brachial pressure index

\begin{tabular}{|c|c|c|}
\hline & $\geq 0.70-<0.95$ & $<0.70$ \\
\hline Progressive ischaemia" & $6.0(3.3-10.8)$ & $4.3(1.9-9.7)$ \\
\hline Cardiovascular morbidity ${ }^{2}$ & $1.5(1.1-1.9)$ & $1.7(1.3-2.4)$ \\
\hline Cardiovascular mortality & $1.2(0.8-1.7)$ & $2.3(1.7-3.1)$ \\
\hline Total mortality"2 & $1.0(0.8-1.4)$ & $2.1(1.6-2.8)$ \\
\hline
\end{tabular}

Reference group: $\mathrm{ABPI} \geq 0.95 . \mathrm{CI}=$ confidence interval. * For definitions see Methods. 'Hazard ratios adjusted for age, gender, smoking, hypertension, diabetes and CVD prevalence at baseline. "Hazard ratios adjusted for age, gender, smoling, hypertension, diabetes, hypercholesterolaemia and CVD prevalence at baseline.

Prognostic value of signs and symptoms in subjects with an $A B P I<0.95$

Figure 1 illustrates the cumulative probability of event-free survival in subjects with an ABPI < 0.95. Among these subjects, $9 \%, 39 \%, 15 \%$ and $24 \%$ experienced progressive ischaemia. cardiovascular morbidity, cardiovascular mortality and total mortality, respectively, within seven years.

IC was the most significant prognostic variable for progressive ischaemia in the overall model (table 3). Wounds or sores on the toes or foot, hypertension (medical record) and unilateral lower skin temperature were possibly of prognostic importance for progressive ischaemia. However, statistical significance was not reached, probably due to smalll numbers.

Subjects with abnormal pedal pulses at baseline were at significantly elevated risk (HR: $2.2 ; 95 \%$ CI: $1.0-4.7)$ for subsequent cardiovascular morbidity. Other significant prognostic variables for a non-fatal cardiovascular event were increasing age and prevalent cardiovascular disease at baseline. An elevated blood pressure was a suggestive prognostic determinant. 


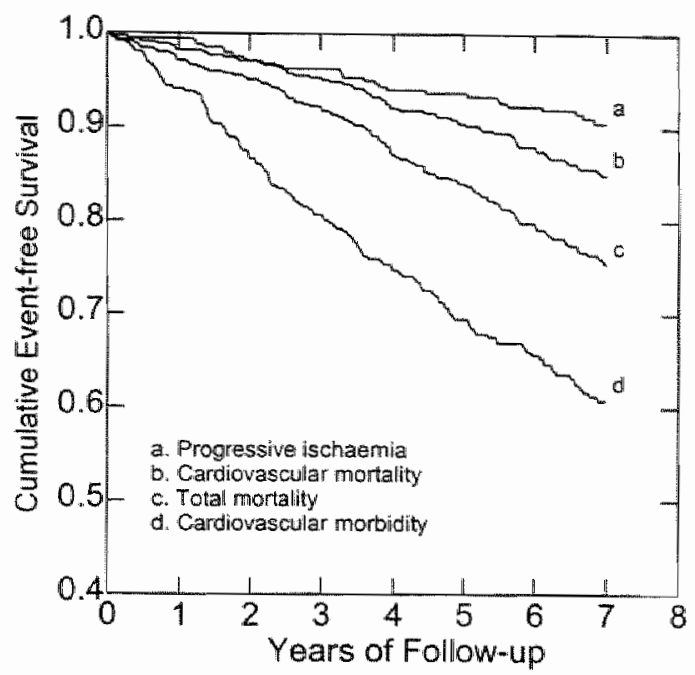

Figure 1. Estimated event-free survival curves for progressive ischaemia, cardiovascular morbidity, cardiovascular mortality and total mortality for subjects with an ABPI $<0.95$

Subjects with a low ABPI (HR: 2.2; 95\% CI: 1.3 - 3.9) or cardiovascular disease at baseline (HR: $2.2 ; 95 \%$ CI: 1.2 - 3.9) had a poorer survival due to cardiovascular death than those in the moderately reduced ABPI category or those without previlent cardiovascular disease at baseline. Male gender, diabetes and elevated blood pressure were suggestive prognostic deteminants for cardiovascular mortality. For total mortality, male gender, diabetes, cardiovascular disease at baseline, abnormal collour of the foot or leg, high blood pressure and a low ABPT were significant prognostic factors.

The reduced models showed that $\mathbb{I C}$ symptoms were most predictive for progressive ischaemia. Older age, abnormal pedal pulses, elevated blood pressure and cardiovascular disease at baseline Were the most significant prognostic variables for subsequent cardiovascular morbidity, and older age, a low ABPI and cardiovascular disease at baseline for cardiovascular death (table 4). Older age, male gender, elevated blood pressure, a low ABPI, diabetes and cardiovascular disease at 


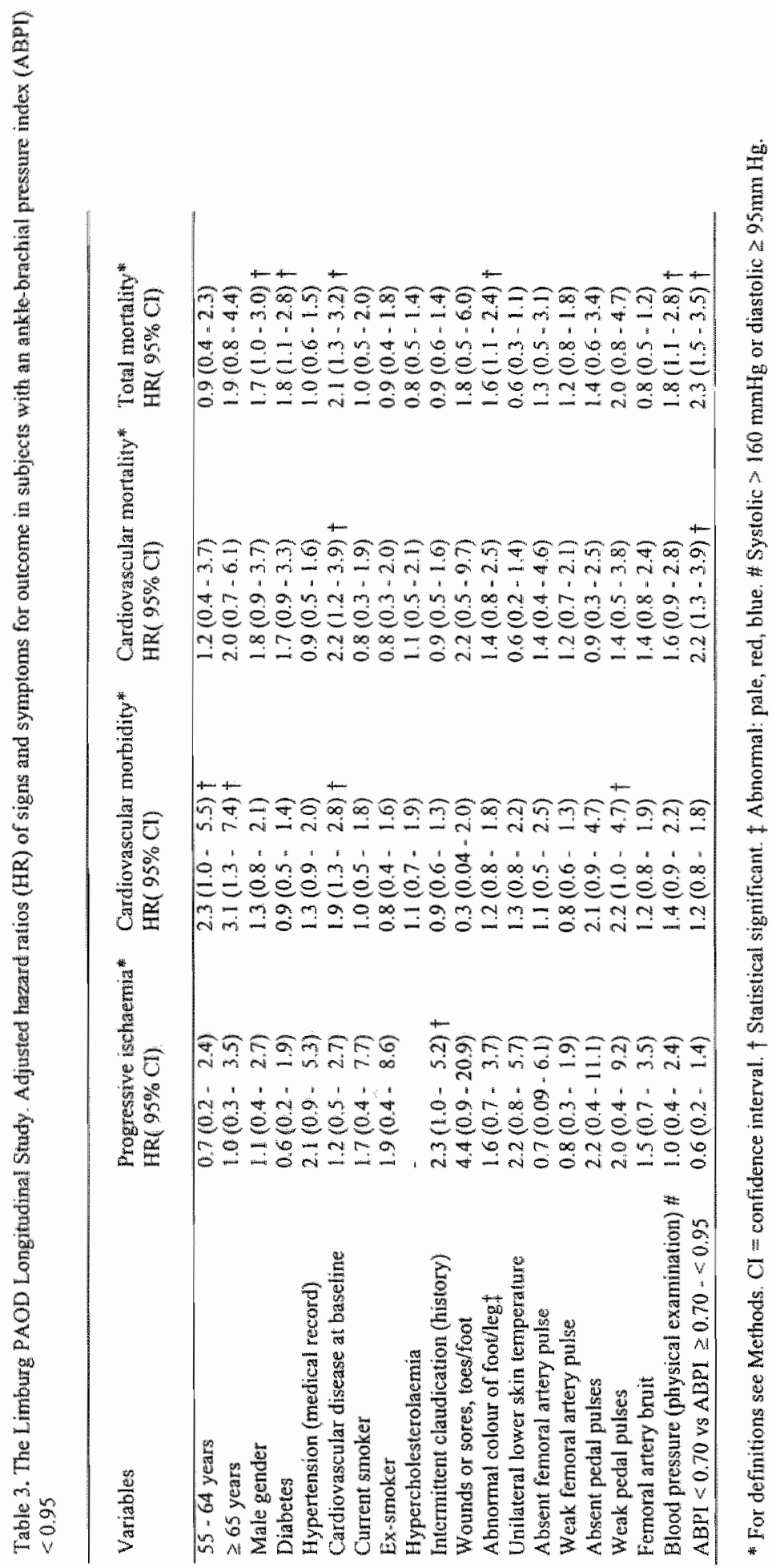


baseline were most predictive for total mortality.

The probability of undergoing a specialist intervention for progressive ischaemia in a PAOD subject with IC at baseline within 7 years of follow-up was double (15\%) that of those without IC at baseline $(7 \%)$. PAOD subjects of 65 years or older, with abnomal pedal pulses an elevated blood pressure and co-existing cardiovascular disease at baseline had a probability of $72 \%$ to develop a non-fatal event compared with $5 \%$ of those without these factors. Male subjects of older age with a low ABPI and co-existing cardiovascular disease at baseline had a probability of $42 \%$ to die of cardiovascular diseases compared with $3 \%$ of the subjects without these prognostic factors. For total mortality, when all the significant prognostic factors were present, the maximum probability of mortality was $83 \%$ compared with $4 \%$ when none of these factors were present.

Table 4. The Limburg PAOD Longitudinal Study. Prognostic models for adverse outcome event in subjects with an ABPI $<0.95$ (stepwise backwards, deduced from the models in table 3)

\begin{tabular}{|c|c|c|c|c|}
\hline Variables & $\begin{array}{l}\text { Progressive } \\
\text { ischaemia* }\end{array}$ & $\begin{array}{l}\text { Cardiavascular } \\
\text { morbidity }\end{array}$ & $\begin{array}{l}\text { Cardiowasculat } \\
\text { mortality }\end{array}$ & $\begin{array}{l}\text { Total } \\
\text { mortality }\end{array}$ \\
\hline & $\operatorname{HR}(95 \% \mathrm{CI})$ & $\operatorname{HR}(95 \% \mathrm{CI})$ & $\mathrm{HR}(95 \% \mathrm{Cl})$ & $\operatorname{HR}(950 \% \mathrm{Cl})$ \\
\hline 55 - 64 years & - & $21(0.9-4.7)$ & $1.2(0.4-3.8)$ & $1.1(0.5-2.7)$ \\
\hline$\geq 65$ years & - & $2.6(1.2-5.9)$ & $2.7(11.0-7.7)$ & $24(1.1-5.3)$ \\
\hline Malle gender & - & - & . & $1.7(1.1-2.5)$ \\
\hline Diabuetes & - & $=$ & - & $1.8(1.2-2.7)$ \\
\hline $\begin{array}{l}\text { Intermittent } \\
\text { claudication (history) }\end{array}$ & $2.2(1.1-4.5)$ & - & - & - \\
\hline Absent pedal pulses & - & $2.8(1.3-5.9)$ & - & - \\
\hline Weak pedal pulses & - & $2.7(1.3-5.6)$ & - & - \\
\hline $\begin{array}{l}\text { Bhood pressure } \\
\text { (physical examination) }+\end{array}$ & - & $1.7(1.2-2.4)$ & . & $1.5(1.0-2.2)$ \\
\hline $\mathrm{ABPI}<0.70$ & - & - & $2.3(1.4-3.6)$ & $2.1 \cdot(1.5-3.1)$ \\
\hline $\begin{array}{l}\text { Cardiovascular disease } \\
\text { at biaseline }\end{array}$ & & $1.7(1.2-2.4)$ & $2.8(1.6-4.8)$ & $1.9(1.3-2.8)$ \\
\hline
\end{tabular}

HR: hazard ratio; Cl: confrdence interval. For defimitions see Methods. \$ Systolic $>160$ muHg or diastolic $\geq 95$ min $\mathrm{Hg}$

\section{Discussion}

In the present study an inverse association was demonstrated for the development of non-fatal cardiovascular events and mortality on one hand and baseline ABPI level in PAOD subjects on the other. PAOD subjects with the lowest ABPI at baseline were not at higher risk for progressive ischaemia than those with a moderately reduced ABPI. Furthermore, we found that in PAOD subjects, IC complaints at baseline were the best predictor for a specialist intervention. Older age, 
abnomal pedal pulses, elevated blood pressure and prevalent cardiovascular disease at baseline were significant prognostic factors for cardiovascular morbidity in these subjects. Moreover, our data demonstrated the prognostic value of older age a low ABPI and prevalent cardiovascular disease at baseline in PAOD subjects for cardiovascular death. For total mortality, male gender, elevated blood pressure and diabetes were also of prognostic significance.

Several attempts were undertaken to restrict major losses to follow-up, a potential problem in cohort studies that may result in bias. We tried to obtain a response rate as high as possible by offering home visits to subjects who were unable to visit their general practice. In addition, subjects who missed their first appointment were telephoned and invited a second time to attend. However, we cannot rule out that the non-response group might have had a different outcome event incidence, even though quantitatively this should be minimal.

Mortality data could have been missed during the follow-up period, resulting in an underestimation of the mortality rates. Less than one percent of the non-responders were lost to follow-up because of out-migration or were unknown in the general practice. All the other nonresponders were alive at the time of data collection. Therefore, the mortality data are fairly complete. Cause of death was unknown for 18 subjects of whom six had PAOD at baseline. This could have had a negative effect on the HR for cardiovascular mortality because these subjects were classified as death due to other causes.

\section{ABPI categories and progressive ischaemia, cardiovascular morbidity and mortality}

The Framingham and Edinburgh Artery population-based studies reported on symptom progression justifying specialist intervention in PAOD subjects. The proportion of PAOD subjects undergoing specialist intervention ranged from $2.2 \%$ in PAOD subjects of the Edinburgh Artery study after 5 years of follow-up, to $4.3 \%$ in claudicants of the Framingham study after 18 years of follow-up ${ }^{2,18}$. Unlike these studies, we found a larger group of PAOD subjects who underwent a specialist intervention. This could be due to the upcoming of percutanous transluminal angioplasty, a relatively simple endovascular intervention for PAOD. Several referral-based studies demonstrated a significant inverse association between progressive ischaemia and the level of ABPI at baseline ${ }^{19-22}$. The fact that in our study, PAOD subjects with the lowest ABPI did not have a higher risk for progressive ischaemia compared with those with a moderately reduced ABPI, could be explaned by selective survival. Additional analyses with progressive ischaemia or mortality as the adverse outcome events showed indeed that subjects with the lowest ABPIs were at higher risk for either event compared with those with a moderately reduced ABPI. Apparently, 
subjects with a low ABPI have more advanced systemic atherosolerosis in other vascular beds, resulting in a higher probability of death before specialist interventions for symptom progression can take place.

Two population-based studies demonstrated an inverse relationship with the level of ABPI and cardiovascular morbidity and mortality ${ }^{11,23}$, in line with our results. The Cardiovascular Health cross-sectional study described an inverse dose-response relationship of the ABPI with prevalent subclinical and clinical cardiovascular disease ${ }^{2.3}$. In the Edinburgh Artery longitudinal study, a significant trend was observed with the level of ABPI at baseline and the occurrence of non-fatal and fatal cardiovascular events after 5 years of follow-up ${ }^{i l}$. Referral-based studies have also reported similar trends $19,24,25$.

\section{Prognostic value of signs and symptoms in subjects with an $A B P I<0.95$}

The current study is, to our knowledge, one of the few to longitudinally investigate the independent prognostic value of signs, symptoms and the ABPI level in PAOD subjects. Data especially on the prognostic value of physical examination findings in subjects with an $A B P I<$ 0.95 are practically non-existent. Therefore, comparison of our results with other studies is difficult. Two referral-based studies reported almost similar findings as ours, by demonstrating that older age, male gender, a history of congestive heart failure, elevated blood pressure and a low ABPI were significant predictors of death in PAOD subjects and diabetes and a history of other coronary heart diseases almost significant prognostic factors ${ }^{21,26}$.

\section{Clinical implications}

The ABPI is a clinically significant diagnostic supplement to the physical examination if PAOD is suspected ${ }^{7}$. It is appropriate as a screening instrument for the identification of high-risk groups: subjects with one or more atherosclerotic risk factors or abnormal physical examination findings. As shown in our and other studies, the lower the ABPI the poorer the prognosis, indicating that it is suitable to detect those who are at particular higher risk. Furthermore, the quantitative outcome allows for a more objective observation of possible deterioration of a subjects' atherosclerotic status.

Preventive efforts should be focused on particularly modification of risk factors as hypertension and diabetes. These risk factors affect the long-term prognosis, in particular mortality. Smoking should be strongly discouraged, considering the extra negative impact it has on the clinical course of PAOD subjects ${ }^{27-29}$. 
The ABPI, a valid and relatively simple non-invasive procedure, is appropriate for use in a general practice setting. In addition with palpation of the pedal pulses, the general practitioner could gain valuable prognostic information with its use.

\section{Acknowledgements}

We thank the participating general practitioners, physicians and their practice assistants for their contribution to this study. The Limburg PAOD Study was supported by a research grant of the Netherlands Organization for Scientific Research (900-715.154) and the Dutch "Praeventiefonds" (28-1323). The longitudinal study was supported by a research grant from the Netherlands Heart Foundation (92.170). Doppler devices were donated by Asta Medica BV. 


\section{References}

1. Hooi JD, Stoffers HEJH, Knotnerus JA, Ree JW van. The prognosis of non-progressive limb ischamia: a systematic review of population-based evidence. Br I Gen Pract (accepted).

2. Leng GC, Lee AJ, Fowkes FGR, Whiteman M. Dunbar J, Housley E, Ruckley CV. Incidence, natural history and cardiovascular events in symptomatic and asymptomatic peripheral arterial disease in the general population. Int J Epidermol 1996;25:1172-81.

3. Criqui MH, Langer $R D$, Fronek A, Feigelson HS, Klauber MR, McCann TJ, Browner $\mathbb{D}$. Mortality over a period of 10 years in patients with peripheral arterial disease. N Engl I Med 1992;326:381-6

4. Davey Smith FD, Shipley M. Rose G. Intermittent claudication, theart disease risk factors, andi mortality; The Whitehall Study. Circulation 1990,82:1925-31.

5. Bowlin SJ, Medalie JH, Flocke SA. Zyzanski SJ, Yaari S, Goldbourt U. Intermittent daudication in 8343 men and 21-year specific mortality follow-ap. AEP 1997;7:180-7.

6. Criqui MH, Langer RD, Fronek A, Feigelson HS. Coronary disease and stroke in patients with large-vessel peripheral arterial disease. Dngs 1990;5:16-21

7. Stoffers HEJH, Kester ADM, Kaiser V, Rinkens PELM, Kitslaar PJEHM, Knottnerus JA. The diagnostic value of the measurement of the ankle-brachial systolic pressure index in primary health care. $\mathrm{J}$ Clin Epidenaiol 1996;49:1401-1405.

8. Criqui MH, Fronek A, Klauber MR, Barrett-Connor $E_{n}$ Gabriel S. The sensitivity, specificity and predictive value of traditional clinical evaluation of peripheral arterial disease: results from noninvasive testing in a defined population. Circulation 1985;3:516-22.

9. Fowkes FGR, Housley E, Macintyre CCA, Prescon RJ, Ruckley CV. Variability of ankle brachial systolic pressures in the measurement of atherosclerotic peripheral arterial disease. $J$ Epideniol Community Health $1988 ; 42: 128-33$

10. Kontzer M, Dramaix M, Sobolski J, Degre S, De Backer G. Ankle/arm pressure index in asymptomatic middleaged males: an independent predictor of ter-year coronary heart disease mortality. Angiology 1995;46:211-9.

11. Leng $G C_{3}$ Fowkes FGR, Lee $A J$, Durbar $J_{3}$ Housley $E$, Ruckley $C V$. Use of ankle brachial pressure index to predict cardiovascular events and death: a cohort study. BMJ 1996;313:1440-4.

12. Vogt MT, Cauley JA, Newman AB, Kulter LH, Hulley SB. Decreased ankle/arm blood pressure index and mortality in elderly women. JAMA 1993;270:465-9.

13. Stoffers HEJH, Rinkens PELM, Kester ADM, Kaiser $V$, Knottnerus JA. The prevalence of asymptomatic and urrecognized peripheral arterial occlusive disease. Int J Epidemiol 1996;25:282-290.

14. Stoffers HEJH, Kester ADM, Kaiser V, Rinkens PELM, Knottrenus IA. Diagnostic value of signs and symptoms associated with peripheral arterial occlusive disease seen in general practice. Med Decis Making 1997;17:61-70.

15. Stoffers HEJH, Kaiser V, Kester ADM, Schouten HJA, Knotnerus JA. Peripheral arterial occlusive disease in general practice: the reproducibility of the ankle-arm systolic pressure ratio. Scand J Prim Health Care 1991;9:109. 114.

16. Rose GA, Blackbum H, Gillum RF, Prineas RJ, Cardiovascular survey methods. $2^{\text {nd }}$ Edn. Geneva: WHO, 1982, pp $162-5$.

17. Lamberts $\mathrm{H}$, Wood $M$, Eds. Intemational classification of primary care. Oxford: Ox ford University Press; 1987.

18. Newton Peabody C, Kannel WB, MeNamara PM. Intermittent claudication. Surgical significance. Arch Surg 1974; 109: 693-697

19. Howell MA, Colgan MP, Seeger RW, Ramsey DE, Sumner DS. Relationship of severity of lower limb peripheral vascular disease to mortality and morbidity: a six-year follow-up study. J Vasc Surg 1989;9:691-7.

20. Naschitz IE, Ambrosio DA, Chang IB. Intermittent claudication: predictors and outcome. Angiology 1988;39:16. 22.

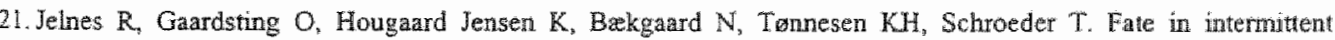
claudication: outcome and risk factors. BMJ 1986:293:1137-40.

22. Rosenbloom MS, Flanigan DP, Schuler JJ, Meyer JP, Durbam JR, Eldrup-Jorgensen J, Scliwarcz TH. Risk factors affecting the natural history of intermittent claudication. Arch Surg 1988;123;867-70.

23. Newman AB, Siscovick DS, Manolio TA, Polak J, Fried LP, Borhani NO et al. Ankle-arm index as a marker of atherosclerosis in the Cardiovascular Health Study. Circulation 1993;88:837-45.

24. O'Riordain DS, O'Donnell JA. Realistic expectations for the patient with intermittent claudication. B I Surg $1991 ; 78: 861-3$.

25. Mckenna $M$, Wolfson $S$, Kuller $L$. The ratio of ankle and ant arterial pressure as an independent predictor of mortality. Atherosclerosis $1991 ; 87: 119-28$.

26. McGrae McDermott M, Feinglass J, Slavensky R, Pearce WH. The ankle-brachial index as a predictor of survival in patients with peripheral vascular disease. J Gen Intern Med 1994:9:445-9.

27. Jonason $T$, Ringquist $I$. Changes in peripheral blood pressures after five years of follow-up in non-operated patients with intermittent claudication. Acta Med Scand 1986;220:127-32. 
28. Jonason $T$, Ringqwist I. Factors of prognostic importance for subsequent rest pain in patients with internittent cladication. Acta Med Scand 1985;218:27-33.

29. Hughtson WG, Mann $\mathrm{N}$, Tibbs DJ, Woods HF, Walion I. Intermittent claudication: factors determining outcome. BMU $1978 ; 1: 1377-9$. 
General discussion 


\section{General discussion}

In this chapter the results of the Limburg PAOD Longitudinal Study on the incidence, clinical course and prognosis of PAOD will be discussed in a broader perspective. First, a short summary of the main results and a critical reflection on the methodology used, will be given. Next, the implications of the results for general practice will be discussed. In addition, attention will be focused on recommendations for future research.

\section{Main results}

The preceding chapters presented the clinical course and prognosis of asymptomatic and symptomatic PAOD over a mean period of 7.2 years.

By reviewing the scientific literature it became apparent that data on the incidence, clinical course and prognosis of asymptomatic PAOD were scanty (chapter 2 ).

Cross-sectional studies, available at the time, indicated that PAOD, defined as an ABPI $<0.90$ (including asymptomatic subjects) was related to cardiovascular co-morbidity ${ }^{\mathrm{l}-3}$. Among the asymptomatic PAOD subjects of the Limburg PAOD cohort, coronary heart disease and cerebrovascular disease were more prevalent than among the non-PAOD subjects. Moreover, the risk-factor profile of asymptomatic subjects was comparable to that of claudicants (chapter 3 ).

Data on the frequency of erection problems or impotence in male (asymptomatic) PAOD subjects is practically non-existent. Impotence may be caused by impaired blood supply to the penis and is furthermore associated with atherosclerotic risk factors such as smoking, diabetes, hypertension and hypercholesterolaemia., Male PAOD (both asymptomatic and symptomatic) subjects from the Limburg PAOD cohort reported erection problems more often than male non-PAOD subjects (chapter 4).

Symptomatic PAOD has been consistently associated with increasing risk of cardiovascular montality ${ }^{6-9}$. The lack of population-based evidence on the incidence, clinical course and prognosis of especially asymptomatic PAOD prompted the Limburg PAOD Longitudinal Study. The incidence of asymptomatic PAOD appeared to be higher in the general population compared with the incidence of symptomatic PAOD. The incidence of both asymptomatic and symptomatic PAOD increased with age and was not more elevated in men compared with women. Nevertheless, once asymptomatic disease was present, men tended to develop intermittent claudication (IC) more often than women. The risk-factor profile of asymptomatic subjects was, when investigated longitudinally, comparable to that of claudicants, with increasing age, smoking, diabetes and hypertension as the most important risk factors (chapter 5). After a mean of 7.2 years, 
asymptomatic and symptomatic PAOD was significantly associated with non-fatal and fatal coronary heart disease and cerebrovascular disease (chapter 6). The ankle-brachial pressure index (ABPI) level was inversely associated with particularly cardiovascular death. In addition, increasing age, IC symptoms, abnormal pedal pulses, elevated blood pressure and prevalent cardiovascular disease at baseline were the most significant prognostic factors for one or more of the following outcome events: progressive ischaemia, cardiovascular morbidity and mortality (chapter 7).

The results presented in chapters $5-7$ have been extensively discussed in the light of other propulation-based studies.

\section{Methodological considerations}

To investigate the clinical course and prognosis of asymptomatic and symptomatic PAOD, a prospective cohort study design was used. This study design is methodologically attractive because the study factor level of each subject is observed at the beginning of the follow-up period. Furthermore, in a similar manner to randomised clinical trials, direct calculations of associations can be made by comparing outcome rates in exposed and non-exposed subjects. Compared to casecontrol studies, cohort studies are relatively free of certain types of selection bias. However, this type of study design is more time-consuming and expensive than case-control studies, and is not suitable for investigating rare diseases ${ }^{10,11}$.

Cohort studies, especially when the prognosis of certain types of diseases is the main focus, depend mainly on assembling a proper inception cohort of subjects who are at an early and uniform point in the course of their disease. Clearly described pathways by which subjects entered the study must be available and loss to follow-up must be kept to a minimum ${ }^{10.12}$. When these methodological criteria are not met, severa] types of bias can be introduced: selection bias due to major losses to follow-up; information bias resulting in misclassification of subjects (either the disease under investigation in prognostic studies or the outcome event) ${ }^{10,12}$.

\section{Methadological strengths of the Limburg PAOD Longitudinal Study}

When reviewing the points mentioned above in light of the Limburg PAOD Longitudinal Study, the following strengths should be mentioned:

Firstly, this study demonstrated that prospective cohort studies can be conducted in a general practice setting, while meeting all three criteria as stated above. As mentioned in the previous chapters, nearly all Dutch citizens are registered at a general practice. Thus, by sampling study 
subjects from general practices, a study population can be compounded, relatively equal to the general population.

Secondly, the general practice setting proved to be a suitable epidemiological "laboratory", to assess PAOD among the participants (appropriate facilities, participants often living in the vicinity of the general practice).

Thirdly, in a general practice setting, the gathering of data on background variables of interest or certain outcome events (e.g. deaths or mon-fatal cardiovascular events) is relatively simple. This is due to the collaboration between primary care physicians and specialists, when a patient is referred to a specialist. Through this source, relevant information concerning a subjects ${ }^{3}$ complete disease status can be collected. In addition, subjects that are lost to follow-up are relatively easy to trace, because of the administrative assignment between the former general practitioner and the new one. This, in tum, can limit the loss to follow-up.

Despite these advantages, complicated calculations had to be perfomed in order to extrapolate some of the results onto the general population. This was necessary because of a complex sampling procedure, which was required to meet the demands of both former parts of the Limburg PAOD study. The sampling procedure has been described in the previous chapters and in a former thesis ${ }^{13}$.

Data collection for the Limburg PAOD Longitudinal Study could have been facilitated and its efficiency improved by flagging each participants" medical record at baseline.

\section{Methodological limitations of the Limburg PAOD Longitudinal Study}

In order to minimise potential bias, it was imperative that the follow-up was as complete as possible. The several safeguards that were implemented to restrict losses to follow-up were addressed in several earlier chapters (reminder phone calls, home visits for participants who could not visit their general practice). Furthemore, the loss of subjects during the follow-up was relatively random across the various categories: $15.7 \%$ of the non-PAOD group, $17.8 \%$ of the asymptomatic group and $13.0 \%$ of the symptomatic PAOD group did not participate in the followup measurements. Therefore, it is not likely that bias severely affected the results. However, a certain loss of power is obvious, since there were fewer participants with the disease under investigation at the end of the follow-up.

Misclassification of the disease variable (symptomatic PAOD) could have occurred in our study population. Symptomatic subjects who adapted their lifestyle to avoid symptoms or those with a sedentary lifestyle, preventing the onset of symptoms, may have been classified as asymptomatic. 
Empirical evidence on the magnitude of this problem is practically non-existent. Misclassification of PAOD subjects in our study could have resulted in a bias that may overstate or underestimate an effect. During the quantitative investigation of this misclassification, it appeared that only $3.8 \%$ of the asymptomatic subjects $(\mathrm{ABPI}<0.95)$ reported very low or no mobility. Since this group, potentially exhibiting the misclassification described above, is comparatively small, the occurrence of misclassification bias is not likely to be substantial.

Another form of miscliassification bias can be introduced by the phenomenon of spuriously elevated ABPIs that are sometimes found in diabetic patients with neuropathy, due to calcified vessels ${ }^{1 / 4}$. These subjects can wrongfully be classified as non-PAOD subjects. In our data, only two diabetics $(0.5 \%)$, who in addition were non-neuropathic, had an ABPI greater than 1.50. This cutof point is considered to be indicative for calcification of the arteries. Thus, possible misclassification of diabetics in our study population was at the most fractional.

\section{Practical implications for general practice}

As life expectancy increases in the western society, an increase of chronic conditions, including PAOD, in the elderly can be expected. Consequently, the quality of life may deteriorate. General practitioners have important gatekeeping functions (diagnosis, therapy and referral) ${ }^{15}$. For providing specific and well-balanced advice, prognostic data of unselected populations are indispensable. Therefore, prospective studies in a primary care setting are relevant ${ }^{16}$.

What are the clinical and practical implications of the results of the Limburg PAOD Longitudinal Study for the general practitioner?

To answer this question, the focus must be based on two areas: the usefulness of an ABPI measurement as a possible screening and prognostic instrument in general practice and the effectiveness of preventive efforts to slow down deterioration of leg ischaemia and other non-fatal. and fatal atherosclerotic events from the circulatory system.

\section{ABPI as a screening and prognostic instrument}

Identification of asymptomatic atherosclerosis in the extremities was not always feasible due to a lack of valid markers for subclinical disease. The ABPI could be a potential marker, showing that subclinical atherosclerosis is more prevalent in the general population than clinical atherosclerosis 1,17 .

The diagnostic value of the ABPI has extensively been investigated and deseribed in the $L$ imburg PAOD prevalence and diagnostic study and other studies ${ }^{18.20}$. These studies indicate that the ABPI 
is sufficiently accurate to guide clinical decision making. Measurement of the ABPI was recommended by the Dutch College of General Practitioners as a supplementary diagnostic test in subjects who present themselves at the general practitioner with symptoms suggestive for $\mathrm{PAOD}^{21}$. In the recent consensus on diagnostics and treatment of arterial intermittent claudication, the Collaborating Centre for Quality Assurance in Health Care (Centraal Begeleidingsorgaan voor de Intercollegiale Toetsing) endorsed the value of the ABPI measurement for diagnostic purposes in both claudicants and asymptomatic patients ${ }^{22,23}$.

The ABPI should not merelly be interpreted as a relevant supplementary diagnostic instrument for PAOD, but should also be seen as a marker of overall atherosclerosis. As shown in the Limburg PAOD Longitudinal Study, and supported by the results of other studies ${ }^{924-28}$, a low ABPI has a relevant prognostic value for subsequent fatal cardiovascular events in subjects with both clinical and subclinical atherosclerosis. Herein lies one of the major potential advantages of an ABPI measurement. The results of this thesis and other recent studies, ${ }^{9,29,30}$ emphasise the relevance of detecting asymptomatic PAOD from a prognostic point of view. The population most suitable for screening purposes has been discussed in the preceding chapters. Middle-aged or elderly subjects with one or more atherosclerotic risk factors are the most eligible candidates.

What should the cut-off point be? From population-based perspective, the cut-off value used in the Limburg PAOD Longitudinal Study is appropriate ${ }^{19}$. But, for clinical purposes in a primary care setting, it is important to have a cut-off point that will most likely identify only those who are most eligible for aggressive monitoring, treatment or preventive measures. There is no universal consensus on the best cut-off values for clinical purposes, even though an index of $\leq 0.90$ is recommended ${ }^{18,25}$.

\section{Preventive measures in high-risk subjects}

Patients with both asymptomatic and symptomatic PAOD constitute a high-risk group for nonfatal cardiovascular events and early mortality. The scope for prevention from general practitioner"s point of view lies clearly in that field ${ }^{31}$. The ABPI should be seen as a measure indicative of generalised atherosclerosis. Therefore, targeting subjects with both subclinical and clinical atherosclerosis in the legs with the use of ABPI measurements and implementation of preventive actions may result in reduced risks of non-fatal and fatal coronary heart disease and cerebrovascular disease. That preventive measures in high-risk groups are appropriate, has recently been shown for example in two randomised controlled clinical trials on prevention of coronary heart disease througlt cholesterol-lowering interventions ${ }^{32,33}$. 
Primary prevention, by means of population screening for risk factors and population-directed health promotion for lifestyle changes, may be useful, but not a task primarily for the general practitioner. The most important preventive actions to be taken by the general practitioner have been described in the previous chapters ("stop smoking and keep walking" and treatment of atherosclerotic risk factors such as hypertension and diabetes).

Strategies to optimise preventive services for cardiovascular diseases in Dutch general practices have recently been investigated ${ }^{34,35}$. The multifaceted outreach visit, a trained nurse who visit the general practice on a regular basis to help organise preventive services, seems to be promising, ewen though this approach is time consuming and therefore expensive $e^{34,35}$.

\section{Recommendations for future research}

As is often the case when conducting a study, new hypotheses are generated and lack of scientific evidence is found in numerous topics related to the disease under investigation. Research initiatives are required in the following areas:

Aetiological studies: - Nested case-control studies derived from the Limburg PAOD cohort gives the opportunity to investigate several possible risk factors for PAOD (hyperhomocysteinaemia, haemostatic or theological factors and genetic predisposition) that have recently been mentioned in the literature ${ }^{36,37}$. Furthermore, the role of antioxidants and hormone replacement therapy in women, as protective factors for atherosclerosis can also be explored.

Chinical trials: - Necessary to assess the effectiveness of exercise programmes on intermittent claudication, the efficacy of vitamin use (antioxidants) as a therapeutic approach, and the effect of aggressive reduction of cardiovascular risk factors in subjects with an abnomal ABPI. Quality of life questionnaires should be incorporated in clinicall trials, to assess the impact of PAOD in subjects with this disorder. The use of aspirin seems to have little beneficiall effects on PAOD in the legs, but it may, on the long term, be effective in reducing the risk for coronary and cerebrovascular events in PAOD subjects ${ }^{38}$. Evidence from clinical trials on the preveritive effectiveness of aspirin use in both asymptomatic and symptomatic PAOD subjects are necessary. It is also of interest to combine our data with data of other population-based studies for pooling purposes, to further elucidate the prognosis of male and femalie PAOD subjects. Sufficient power can be gained in such a way, which would allow the investigation of the effect of gender or environmental differences for outcome. 


\section{Weferences}

1. Fowkes FGR, Housley E, Cayood EHH. Macintyre CCA, Ruckley CV, Prescot RJ Edinburgh Artery Study: Prewalence of asymptomatic and symptomatic peripheral arterial disease in the general population. Ini $\int$ Epidemol $1991 ; 20: 384.92$

2. Newman AB, Siscovick DS, Manolio TA, Polak J, Fried LP, Bortani NO Wolfon SK for the Cardiowascalar Hiealh Study (CHS) Collabonatiwe Research Group. Ankle-am index as a marker of atherosclerosis in the Cardiovascular Health Study. Chiculation 1993;88:837-45.

3. Zheng Z-J, Sharrett AR, Chambless LE, Rosamond WD, Nieto FJ, Sheps DS, Dobs A, Evans GW, Heiss G. Associations of ankle-brachial pressure index with clinical coronary heart disease, stroke and preclinical carotid and pophlteal atheroselerosis: the Atherosclerosis Risk in Commumities (ARIC) Sndy. Atherosclerosis $1997 ; 131: 115-25$

4. Virag $\mathrm{R}$, Boully $\mathbb{P}$, Feydman $\mathrm{D}$. Is impotence an arterial disotder? Lancet $1985,1: 181-4$.

5. Shabsigh $\mathrm{R}$, Whman $\mathrm{U}$, Schum $\mathrm{C}$, Dunm $\mathrm{KK}$. Cigarette smoking and other vascular risk factors in vasculiogenic impotence. Urology $1991,38: 227-31$.

6. Dawey Smith FD, Shipley MJ, Rose G. Intermittent claudication, beart disease risk factors, and mortality; The Whitehall Study. Circulation $990 ; 82: 1925-31$

7. Dagenais GR, Maurice S, Robitaille N.M, Gingras S, Lupien PJ. Internintent claudication in Quebec men from 1974-1986: the Quebec Cardiovascular Study. Clim Invest Med 1991;14:93-100.

8. Kannel WB, McGee DL. Update on some epidemiologic features of internitent claudication: The Framingham Study. J Am Geriatr Soc 1985,33:13-8.

9. Criqui MH, Langer RD, Fronek A, Feigelson HS, Klatber MR, McCun TJ, Browner D. Mortality over a period of 10 years in patients with peripheral arterial disease. N Engl J Med 1992;326:381-6.

10. Kleinbaum DG, Kupper LL, Morgenstern H. Epidemiologic research. Principles and quantitative methods. New York: Var Mostrand Reimhold, 1982.

11. Rothman KI. Modem epidemiollogy. Boston: Litte, Brown and Conpany, 1986.

12. Sackett DL, Haynes RB, Tugwell P. Clinical epidemiology. A basic science for clinical medicine. Borton: Little, Brown and Company, 1991.

13. Stoffers HEJH. Peripheral arterial occlusive disease. Prevalence and diagnostic management in general practice $[P h D$ thesis]. Matastricht: Universitaine Pers Matstricht, 1995.

14. Young MJ, Adams JE, Mnderson GF, Boulton AJM, Cavangh PR Medial arterial calcification in the feet of diabetic patients and matched non-diabetic control subjects. Diabetologia 1993,36:615-21.

15. Knottnens JA. Medical decision making by general practitioners and specialists. Farn Pract 1991;8:305-7.

16. Knotmerus $J A, K$ Kupschild $P G$, Sturmans $F$. Symptoms and selection bias: the influence of selection towards specialist care on the relationship between symptoms and diagnoses. Theoreticall Medicine 1989;10:67-81.

17. Stofers HEJH, Rinkens PELM, Kester ADM, Kaiser V, Knotnerus JA. The prevalence of asymptomatic and unrecognized peripheral arterial occlusive disease. Int I Epidemiol 1996;25:282-90.

18. Stoffers HENH, Kester ADM, Kaiser V, Rinkens PELM, Kitslaar PJEHM, Knottnerus JA. The diagnostic value of measurement of the anklembrichal systolic pressure index in primary health care. I Clin Epidemiol 1996,49:1401. 05.

19. Hiat WR, Marshall JA, Baxter J Sandoval R, Hildebrandt W, Katu LR, Hammar RF. Diagnostic methods for peripheral arterial disease in the San Luis walley diabetes study. J Clin Epidemiol 1990;43:597-606.

20. Criqu MM, Fronek A, Klauber MR. Barrett-Connor E, Gabriel S. The sensivity, specificity and predictive value of traditional clinical evaluation of peripheral arterial disease: results from noninvasive testing in a defined population. Circultution 1985,71:516-22.

21. Rutter GEHM, Thomas S, edirors. NHG-Standarden woor de huisats. (Clinical guidelines of the Dutch College of Ceneral Pratitioners). Unecht: Bunge, 1993.

22. Central Begeleidingsorgan voor Intercollegiale Toetsing. Diaginostiek en behandeling var arteriele claucticatio intermitters. Utrewht, 1997.

23. Kitslaar PMEHM. Consensus diagnostiek en behandeling van arteriele clatudicatio intermittens. Ned Tujdsche Geneeskd 199\%; $141: 2396-400$.

24. McGrae McDcmot M, Feinglass I. Slavensky R. Pearce WH. The arkie-brachial index as a predictor of survival in patients with peripheral vascular disease. J Gen Intern Med 1994:9:445.9.

25. Leng GC, Fowkes FGR, Lee AJ, Dubbar J, Housley E, Ruckley CV. Use of ankle-brachial pressure index to predict cardiovascular events and death: a cohort study. BMJ 1996; $313: 1440,4$.

26. Crigu MH, Langer RD, Fronek A, Feigelson HS. Coronary disease and stroke in patients with large-vessel peripheral arterial diserse. Drugs 1991;42(suppl 5):16-21

27. Wogt MT, Cauley JA, Newnan AB, Kuller LH, Hulley SB. Decreased ankle/am blood pressure index and mortaliv in elderly women. JAMA $1993,270,465469$. 
28. MeKenna $M$, Wolfson $S$, Kuller $L$. The ratio of ankle arm arterial pressure as an independent predictor of mortality. Atherosclerosis 1991;87:119-28.

29. Kornitzer M, Dramaix M, Sobolski J, Degre S, De Backer G. Ankle/arm pressure index in asymptomatic middle-aged males: an independent predictor of ten-year coronary heart disease mortality. Angiology 1995;46:211-9.

30. Leng GC, Lee AJ, Fowkes FGR, Whiteman M, Dunbar $\mathrm{J}$, Housley E, Ruckley CV Incidence, natural history and cardiovascular events in symptomatic and asymptomatic peripheral arterial disease in the general population. Int J Epidemiol 1996;25:1172-81.

31. Ree van J. Who is at risk of intervention? The role of the general practitioner in preventive cardiology. Eur J Gen Pract 1995; 1:99-100.

32. Scandinavian Simvastatin Survival Study Group. Randonised trial of cholesterol lowering in 4444 patients with coronary heart disease: the Scandinavian Sirnvastatin Survival Study (4S). Lancet 1994;344:1383-9.

33. Shepherd J, Cobbe SM, Ford I, Isles CG, Lorimer AR, Macfarlane PW, McKillop JH, Packard CN for the West of Scotland Coronary Prevention Study Group. Prevention of coronary heart disease with pravastatin in mert with hypercholesterolemia. N Engl J Med 1995;333:1301-7.

34. Hulscher MEJH. Implementing prevention in general practice: a study on cardiovascular disease [PhD thesis]. Nijmegen: Ponsen en Looijen BV, Wageningen, 1998.

35. Drenth van $\mathrm{B}$. Organizing cardiovascular preventive care in general practice [PhD thesis]. Nijmegen: Ponsen en Looijen BV, Wageningen, 1998.

36. Berg van den M, Boers GHJ, Franken DG, Blom HJ, Kamp van GJ Jakobs $C_{y}$, Rauwerda JA, Kluft $C_{y}$ stehouwert CDA. Hyperhomocysteinaemia and endothelial dysfunction in young patients with peripheral arterial occlusive disease. Eur J Clin Inwest 1995;25:176-81.

37. Bainton D, Sweetnam P, Baker I, Elwood P. Peripheral vascular disease: consequence for survival and association with risk factors in the Speedwell prospective heart study. Br Heart J 1994:72:128-132.

38. Antplatelet Trialists" colaboration. Collaborative overview of randomised trials of antiplatelet therapy. Prevention of death, myocardial infarction, and stroke by prolonged antiplatelet therapy in variuos categories of patients. BMJ 1994:308:81-106 
Summary 
This thesis describes a population-based study on the incidence and prognosis of peripheral arterial occlusive disease (PAOD) in a primary care setting. PAOD refers to the manifestation of atherosclerosis in the lower limb distal to the aortic bifurcation.

Chapter I discusses the background, rationale and aims of the Limburg PAOD Longitudinal Study.

PAOD is the most common chronic peripheral wascular disorder in the elderly. It has an asymptomatic and a symptomatic stage. The symptomatic stage can be classified in intermittent claudication and critical ischaemia.

The Limburg PAOD study started in 1987, in collaboration with 18 general practice centres. The first part of the Limburg PAOD study addressed the prevalence and diagnostics of PAOD, the second part focussed on the the effectiveness of calcium-carbasalate intervention on the progression of PAOD.

The third project that started in 1994, was the Limburg PAOD Longitudinal Study, on the incidence, natural course and prognostic determinants of symptomatic and asymptomatic PAOD. The results of the longitudinal study are presented this thesis.

\section{Aims of the Limburg PAOD Longitudinal Study:}

The Limburg PAOD Longitudinal Study has three main objectives:

1. To investigate the age- and sex-specific incidence and risk factors associated with asymptomatic and symptomatic PAOD;

2. To study the course of asymptomatic and symptomatic PAOD in subjects aged 40-78 with regard to progression, and also to determine the general cardiovascular morbidity and mortality;

3. To identify prognostic determinants and assess the prognostic value of data obtained through history, physical examination and the level of the ankle-brachial pressure index (ABPI) will regard to the clinical course and prognosis of PAOD.

Chapter mo of this thesis presents a critical review of population-based studies on the course and prognosis of asymptomatic as well as symptomatic PAOD. From the results of 13 population-based studies of high methodological quality it became apparent that data on the course and prognosis of asymptomatic PAOD were scarce. Only a small group of asymptomatic subjects seem to develop intermittent claudication symptoms in course of time. Yet asymptomatic PAOD appeared to be associated with an increased risk of cardiovascular morbidity and mortality. 
The course and prognosis of symptomatic PAOD was better documented. Increasing age, smoling, diabetes and hypertension were the most important risk factors for symptomatic POAD. Claudicants were at higher risk for non-fatal and fatal ischaemic hart diseases and cerebrovascular diseases compared with non-PAOD subjects. Intemittent claudication and a low ankle-brachial pressure index $(\mathrm{ABPI}<0.90$ or $<0.80$ ) were significant predictors for mortality. Men more often had intermittent claudication and symptom progression than women. Male PAOD subjects were also at higher risk for mortality compared with female PAOD subjects.

In chapter three the baseline characteristics of the Limburg PAOD study population are presented. Attention was focused on mainly the risk-factor profile and cardiovascular co-morbidity (ischaemic heart disease and cerebrovacular disease) of asymptomatic PAOD subjects. The study population consisted of 3649 participants, between the ages of 40 to 78 (mean age: 59 years) of whom $53 \%$ were females. PAOD was considered present when a subject twice had a resting ABPI $<0.95$ for at least one leg, measured with a pocket Doppler device and a mercury sphygmomanometer; on two occasions with a oneweek interval. Asymptomatic PAOD was defined as an ABPI < 0.95 without intermittent claudication complaints. Symptomatic PAOD was defined as an $\mathrm{ABPI}<0.95$ with intermittent claudication complaints.

Asymptomatic PAOD was present in $8.6 \%(n=314)$ and symptomatic disease in $3.8 \%(n=138)$ of the participants. The ratio of asymptomatic to symptomatic PAOD was higher among the younger age groups. Age, smoking, hypertension and diabetes were significantly associated with asymptomatic PAOD. Asymptomatic subjects had more cardiovascular co-morbidity compared with the non-PAOD subjects.

The cross-sectional analyses showed also that male asymptomatic PAOD subjects reported significantly more often reported perceived erection problems compared with male non-PAOD subjects (chapter four).

These findings suggest that the risk-factor profile and cardiovascular comorbidity of asymptomatic subjects is comparable to claudicants.

Chapter five addresses the first results of the follow-up study. It presents the incidence rates and possible atherosclerotic risk factors for asymptomatic as well as symptomatic PAOD. Additionally, this chapter examines the incidence of intermittent claudication symptoms among those who were asymptomatic at baseline. 
From the onginal cohort, 2589 participants were re-examined (mean age: 64.1 years; $54.2 \%$ female) between 1995 and 1997. During the follow-up period, 481 participants died. Owerall, $84.2 \%$ of the original cohort was followed up. After 7.2 years, the incidence of asymptomatic PAOD was higher $(n=200)$ than the incidence of symptomatic PAOD $(n=46)$. Women developed asymptomatic PAOD as often as men. Nevertheless, male subjects who were asymptomatic at baseline, appeared to develop intermittent claudication symptoms more often than women who were asymptomatic at baseline. Smoking, hypertension, diabetes and increasing age were the most important risk factors for asymptomatic as well as symptomatic PAOD.

From the Limburg PAOD Longitudinal Study it also became apparent that asymptomatic and symptomatic PAOD were significant predictors for cardiovascular morbidity and mortality, particularly cerebrovascular diseases and coronary heart diseases (chapter six). From the original cohort, $16.2 \%$ of the non-PAOD subjects developed a non-fatal cardiovascular disease, compared with $34.7 \%$ and $40.2 \%$ of the asymptomatic and symptomatic PAOD subjects at baseline, respectively. The same trend was observed for mortality: $10.9 \%$ of the non-PAOD subjects died during the follow-up, compared with $25.8 \%$ and $31.2 \%$ of the asymptomatic and symptomatic PAOD subjects, respectively. Subjects with asymptomatic PAOD had a risk comparable to claudicants.

Prognostic determinants for an unfavourable prognosis (worsening of the clinical course, cardiovascular morbidity and mortality), are described in chapter seven. For progressive ischaemia, the most important prognostic determinant was the presence of intermittent claudication at baseline. For cardiovascular morbidity, the most important prognostic determinants were increasing age, the presence of cardiovascular disease at baseline and abnormal pedal pulses. for cardiovascular mortality, an $\mathrm{ABPI}<0.70$ and cardiovascular co-morbidity at baseline, were the most important prognostic determinants.

As a result of the Limburg $P A O D$ Longitudinal Study, several conclusions can be drawn: Firstly, in the general population, the incidence of asymptomatic PAOD is much higher than the incidence of symptomatic PAOD. Secondly, not only symptomatic PAOD, but also asymptomatic PAOD (ABPI $<0.95$ ) is associated with an increased risk for cardiovascular morbidity and mortality. In high-risk subjects (subjects older than 55 years, diabetics, hypertensives, and smokers), measurement of the ABPI is appropriate. It is a clinically significant supplement to the physical examination, providing valuable information on the present and future atherosclerotic status of those at high risk. 
Chapter eight, the general discussion, provides a short summary of the results and a critical appraisal of the methodology used. Furthermore, the implications for primary health care are discussed and recommendations are given for future research.

This study demonstrated that prospective cohort studies can be conducted in a general practice setting. Nearly all Dutch citizens are registered at a general practice. Thus, by sampling a study population from general practices, a study population can be compounded, relatively equal to the general population. Potential bias that can be caused by major losses to follow-up was restricted to a minimum. Also bias that can occur as a consequence of misclassification of PAOD was not likely to be substantial in the Limburg PAOD Study.

PAOD is a manifestation of generalised atherosclerosis. As such, identification of high-risk subjects is relevant. Modifiable cardiovascular risk factors can then be aggressively managed (smoking, diabetes, hypertension). The ABPI measurement is useful not only as a diagnostic too], but also as a prognostic indicator, applicable in a general practice setting.

Research initiatives are required on:

- The aetiology of PAOD (hyperhomocysteinaemia, haemostatic or rheological factors, genetic predisposition);

- Clinical trials: to assess the effectiveness of exercise programs on intermittent claudication, to investigate the therapeutic effectiveness of antioxidants and aspirin, and the effect of aggressive reduction of cardiovascular risk factors in subjects with an abnormal ABPI. Quality of life questionnaires should also be one of the outcome measurements in these trials.

- Pooling of the Limburg PAOD data with other population-based studies on this topic, generating more power, to elucidate potential differences in sexes with respect to the prognosis of PAOD. 
Chuperer 10

Samenvatting 
Dit proefschrift gaat over de incidentie en prognose van perifeer arterieel obstructief vaatliden (PAV) in de eerstelijnsgezondheidszorg. Met "perifeer arterieel obstructief vaatlijen" wordt bedoeld arterieel vaatlijden distaal van de bifurcatie van de aorta, veroorzaakt door atherosclerose.

In hoofdstuk I worden de achtergrond, rationale en doelstellingen van het longitudinale gedeelte van de Limburgse PAV studie uiteengezet.

Perifeer arterieel obstructief vaallijden is de meest voorkomende perifere arteriele vaataandoening bij de oudere mens. PAV kent een asymptomatisch en een symptomatisch stadium. Het symptomatische stadium kan onderverdeeld worden in claudicatio intermittens en kritische ischaemie.

In 1987 is in 18 huisartspraktijken in de regio Limburg een onderzoek gestart naar PAV. Het eerste gedeelte van het PAV-project Limburg had als doel de prevalentie en diagnostiek van PAV. In het tweede gedeelte stond de effectiviteit van carbasalaatcalcium (aspirine) op het beloop van PAV centraal. Het derde project, het longitudinale deel van het PAV-project Limburg, begon in 1994. Het behelst een cohort studie naar de incidentie, het beloop en de prognostische determinanten van asymptomatisch en symptomatisch PAV. De resultaten van deze longitudinale studie worden in dit proefschrift beschreven.

\section{Doel van het longitudinale deel wan het PAV-project Limburg}

Het longitudinale deel van het PAV-project Limburg heeft een drieledig karakter:

1. Het beschrijven van leeftijd-en sexe-specifieke incidentie en risico factoren die samenhangen met asymptomatisch en symptomatisch PAV;

2. Het inventariseren van het beloop wan asymptomatisch en symptomatisch PAV en het optreden van cardiovasculaire morbiditeit en mortaliteit;

3. Het identificeren van prognostische determinanten voor het beloop en de prognose van PAV en het bepalen van de prognostische waarde van gegevens verkregen via anamnese, licharnelijk onderzoek en de hoogte van de enkel-arm index.

In hoofdstuk 2 wordt een systematisch overzicht gegeven van de literatuur over de prognose van zowel asymptomatisch als symptomatisch PAV. Uit de resultaten van 13 populatiestudies van hoog kwalitatief niveau bleek dat er weinig data beschikbaar waren over de incidentie, het beloop en de prognose van asymptomatisch PAV. Een relatief kleine groep van individuen met asymptomatisch PAV ontwikkelt in de loop der tijd claudicatio intermittens klachten. Verder bleek 
uit de schaarse gegevens dat asymptomatisch PAV geassocieerd was met een verhoogd risico op cardiovasculaire morbiditeit en mortaliteit.

Over het beloop en de prognose van symptomatisch PAV waren meer onderzoeksresultaten beschikbaar. Leeftij, roken, diabetes en hypertensie werden gerapporteerd als de meest belangrijke risicofactoren voor symptomatisch PAV. Verder bleek dat patienten met symptomatisch PAV een verhoogd risico hadden voor zowel niet-fatale als fatale coronaire hartziekten en cerebrovasculaire infarcten. Claudicatio intermittens en een lage enkel-amindex (EA-index $>0.90$ of 0.80 ) waren belangrijke prognostische determinanten voor mortaliteit.

Uit de literatuur bleek ook dat mannen met PAV, vaker klachten hebben en een emstiger beloop hadden, en bovendien een hogere mortaliteit vertoonden dan vrouwen met PAV.

In hoofdstuk 3 worden de karakteristieken van de onderzoekspopulatie bij de voometing gepresenteerd. Door middel van deze cross-sectionele data werd met name het risicoprofiel en de cardiovasculaire co-morbiditeit (ischaemische hartziekten en cerebrovasculaire aandoeningen) van de respondenten met asymptomatisch PAV in kaart gebracht.

De onderzoekspopulatie bestond uit 3649 respondenten van 40 tot 78 jaar oud (gemiddelde leeftijd: 59 jaar) waarvan $53 \%$ vrouw was. De diagnose $P A V$ werd gesteld als de respondenten een EA-index $<0.95$ hadden aan minimaal één been, tweemaal binnen een week bepaald met behulp van een Doppler apparaat. Asymptomatisch PAV werd gedefinieerd als een EA-index $<0.95$ zonder claudicatio intermittens klachten. Symptomatisch PAV werd gedefinieerd als een EA-index $<0.95$ mét claudicatio intermittens klachten.

Van de onderzoekspopulatie had $8.6 \%$ (n=314) van de respondenten asymptomatisch PAV en 3.8\% symptomatisch PAV. In de jongere leeftijdsgroepen waren er onder de PAV patienten naar verhouding meer personen met asymptomatisch PAV dan met symptomatisch PAV. Leeftijd, roken, hypertensie en diabetes waren significant geassocieerd met asymptomatisch PAV. Deze groep had vaker cardiowasculaîre co-morbiditeit dan de niet-PAV respondenten.

Uit de cross-sectionele analyses kwam ook naar voren dat mamen met asymptomatisch PAV vaker erectieproblemen rapporteerden dan mannen zonder PAV (hoofdstuk 4).

Concluderend kan gesteld worden dat het risicoprofiel en de cardiovasculaire comorbiditeit wan asymptomatische individuen vergelijkbaar is met die van symptomatische PAV patiënten.

Hoofdstuk 5 beschrijt het eerste deel van de longitudinale studie, waarbij de incidentie en potentiële risicofactoren van zowel asymptomatisch als symptomatisch PAV centraal staari. Van 
het originele cohort werden 2589 respondenten in de periode 1995 - 1997 opmieuw onderzocht (gemiddelde leeftijd 64.1 jaar, $54.2 \%$ vrouwen). Verder waren er 481 respondenten overleden tijdens de follow-up periode. In total werd $84.2 \%$ het originele cohort opgevolgd. De non-respons Was 15.8\%. Uit de follow-up studie bleek dat na gemiddeld 7.2 jaar de incidentie van asymptomatisch PAV hoger was $(n=200)$ dan de incidentie van symptomatisch PAV $(n=46)$. Vrouwen ontwikkelden asymptomatisch en symptomatisch PAV net zo vaak als mannen. Echter, de mannen die bij de voormetingen asymptomatisch waren, leken vaker claudicatio-klachten te ontwikkelen in vergelijking met de asymptomatische vrouwen. Roken, hypertensie, diabetes en leeftijd waren de belangrijkste risicofactoren voor zowel asymptomatisch als symptomatisch $\mathrm{PAV}$. De follow-up studie liet verder zien, dat asymptomatisch en symptomatisch PAV beide geassocieerd waren met een verhoogd risico voor cardiovasculaire morbiditeit en mortaliteit, met name cerebrovasculaire aandoeningen en ischemische hartziekten (hoofdstuk 6). Van het totale cohort kreeg $16.2 \%$ van de respondenten zonder PAV een niet-fatale cardiovasculaire ziekte vergeleken met $34.7 \%$ respectievelijk $40.2 \%$ van de respondenten met asymptomatische en symptomatische PAV. De mortaliteit binnen het cohort vertoonde eenzelfde beeld: $10.9 \%$ van de respondenten zonder PAV overleed tijdens de follow-up periode, vergeleken met $25.8 \%$ respectievelijk $31.2 \%$ van de respondenten met asymptomatische en symptomatische PAV. Respondenten met asymptomatisch en symptomatisch PAV bij de voormeting, hadden een vergelijkbaar risico.

Prognostische variabelen voor een ongunstig beloop (verergering van klachten, cardjovasculaire morbiditeit, cardiovasculaire mortaliteit) bij de PAV groep staan beschreven in hoofdstuk 7. De belangrijkste prognostische determinant voor zodanige verergering van de klachten, dat de patient een ingreep moest ondergaan, was het aanwezig zijn van claudicatio-klachten bij de voormeting. Voor het ontwikkelen van cardiovasculaire morbiditeit waren de belangrijkste prognostische determinanten leefijd, cardiovasculaire co-morbiditeit bij de voometing en abnormale perifere pulsaties. Voor cardiovasculaire mortaliteit waren cardiowasculaire co-morbiditeit bij de voometing en een $\mathrm{EA}$-index $<0.70$ de belangrijkste prognostische variabelen.

Op basis van het longitudinale deel wan het PAV-project Limburg kan ten eerste geconcludeerd worden dat asymptomatisch PAV in de algemene bevolking veel vaker voorkomt dan symptomatisch PAV. Ten tweede, dat niet alleen symptomatisch PAV, maar ook asymptomatisch PAV (EA-index < 0.95) geassocieerd is met een verhoogde kans op cardiovasculaire morbiditeit en mortaliteit. Dit onderstreept het belang van het opsporen van PAV in hoog-risico groepen (ouder dan 55 jaar, diabetes, hypertensie, roken). De EA-index kan een belangrijke aanvulling zijn 
op het lichamelijk onderzoek. Het geeft waardevolle informatie over de huidige en toekomstige cardiovasculaire status van hoog-risico patiënten.

In hoofdstuk 8 worden de belangrijkste resultaten van de longitudinale Limburgse PAV studie besproken, samen met de diverse methodologische aspecten van het onderzoek, de consequenties van de resultaten voor de huisarts en enkele ideeên voor verder onderzoek.

Prospectieve cohort studies zijn goed uitvoerbaar in de huisartspraktijk, vanwege het feit dat bijna iedereen in de Nederlandse samenleving ingeschreven is bij een huisartspraktijk. Een steekproef uit deze populatie komt vrij nauwkeurig overeen met de algemene bevolking. De "Ioss to followup", een vorm van bias die een handicap kan vormen in cohort studies, was relatief klein. Ook het vóórkomen van mogelijke misclassificatie van PAV vormde geen substantièle bias.

PAV is een uiting van gegeneraliseerde atherosclerose. Vroege opsporing in hoog-risico groepen is daarom relevant. Preventieve maatregelen kunnen dan gericht worden op het reduceren van cardiovasculaire risicofactoren (roken, diabetes en hypertensie). De EA-index is een geschikt diagnosticum voor wroege opsporing van $\mathrm{PAV}$, is daarnaast prognostisch ook van belang en geschikt voor gebruik in de huisartspraktijk.

Meer onderzoek is gewenst op de volgende gebieden:

- Etiologie van PAV (hyperhomocysteinemie, stollings- of reologische factoren, genetische predispositie);

- Klinische trials: interventies in de vorm van looptrainingsprogramma's bij claudicanten en medicamenteuze interventies (anti-oxidanten en aspirine). Effectiviteit van risicoreductie van. cardiovasculaire risicofactoren bij patiënten met PAV. De kwaliteit van leven zou één van de uitkomstmaten moeten zijn in toekomstige interventiestudies.

- Tot slot zou het nuttig zijn om de gegevens van het PAV-project Limburg te combineren met data van andere populatiestudies op dit gebied. Zo kan er voldoende "power" gegenereerd worden om met name potentiële sexe-verschillen in het ziektebeloop te exploreren. 



\section{Dankwoord}

Het eerste dat ik altijd doe als ik een proefschrift ontvang, is het dankwoord lewen. Op die manier meen ik me een beeld te kunnen vormen van de promovendus in kwestie. Nu het mijn beurt is om een dankwoord te schrijven, besef ik de moeilijkheidsgraad van zo'n exercitie. Moet ik het zakelijk houden of juist persoonlij]k? Kort of lang? Met gevaar dat andere mensen ook een dankwoord lezen zoals ik dat altijd doe, besluit ik toch maar om mezelf te blijven en een persoonlijk woord te richten, voor zover mogelijk, aan alle mensen die op de een of andere manier betrokken zijn geweest bij dit project.

Allereerst alle respondenten die mee hebben gedaan aan het PAV project: zonder hen was er geen follow-up studie geweest, en dus ook geen proefschrift.

Naast de medewerking wan de respondenten, was natuurlijk ook die van de huisartsen essentieel. De volgende huisartsen en de praktijkassistenten wil ik bedanken voor de tijd die zij vrijgemaakt hebben om de participanten op te roepen en te onderzoeken, soms tot twee, drie keer toe: JBM Stolte, MM Stolte (Kerkrade), GHMI Beusmans, WPM Vierhout, E Dubislav (Maastricht), HRM Schiffelers, A Jehnen, J Crutzen, G Ozek (Simpelveld), AA ten Berge, PFM van der Heyden, $M$ van Bilsen (Roemond), G Castermans (Maastricht), BHJM Otten, R Nijsten-Trinus, L Wintvaecken (Merkelbeek), MPJM Peeters, FHJA Vissers, A Muyskens, M Frijns, W Smeets, M$L$ de Bruyn (Maastricht), ESM Vijgen, TAH Vijgen-Hamers, L Otten, I Frenken (Geleen), EHJF Hubbers, (Kerkrade), F Soomers, M Soomers-Turlings, HEJH Stoffers, P Paffen (Kerkrade), PHM Passage, M-L Gielgens (Kerkrade).

Een deel van de dataverzameling werd door ons uitgevoerd. Dit kon echter alleen omdat de volgende huisartsen hun praktijkruimte hebben afgestaan aan ons: $T$ van Merode, GE Goudriaar (Maastricht), FI Guldemond (Ubachsberg), PBN Hulshof, RAM Panhuysen, ETIM Guldemond. Hecker, (Kerkrade), W Nieuwdorp (Brunssum), BTMG van der Werf, JVH Palmen (Heerlen), G van Zanten, JJ Michels, HAWJ van der Wissel, JW wan Ree (Kerkrade), JHM Eussen, JAM Ypma, C Stuurman (Landgraaf).

Bovenstaande huisartsen en de assistenten bleven mij geduldig additionele informatie toesturer, ook nadat zij klaar waren met het verzamelen van gegevens.

Robert Mol en Henriètte Janssen zorgden als basisartsen voor een gedeelte van de dataverzameling. Vragenlijsten moesten ingevuld worden met allerlei gegevens over tensie, voetarteriën, kleur en beharingspatroon van de benen, groene kaart gegevens en alles wai enigszins kon wijzen op perifeer vaatijiden. 
Thea van det Waart sprong belangeloos in op momenten dat Robert of Henriette vanwege omstandigheden verstek moesten laten gaan.

Melanie van der Veeke was de eerste 3 jaren de onderzoeksassistente van het project. Toen duidelijk werd dat wij zelf voor een gedeelte van de gegevens moesten zorgen, nam ze het 'doppler' werk en de administratieve logistiek die erbij hoorde grotendeels voor haar rekening.

Bema Schouten hielp ook mee met het 'doppleren' toen het project, onder de grote werkdruk 'oververhit' dreigde te raken.

Marjon Overdijk sprong in als onderzoeksassistente tijdens de eindfase van het project; codeer- en analysewerk waren toen in volle gang.

De data werden ingevoerd door de datatypistes van MEMIC.

Paula Rinkens: bij jou moet ik ewen heel goed nadenken hoe ik zo kort en bondig mogelijk alles kan omschrijven dat we de afgelopen jaren hebben gedaan en meegemaakt. Het was namelijk erg veel. Je geduld, om mij weer eens iets van het PAV bestand uit te leggen, al was het woensdagmiddag 6 uur: "kijk Jureme het zit zo..." Je bereidheid om samen met mij tot in den treuren inconsistenties in het bestand op te sporen, zelfs als ik je in het weekend thuis belde. We hebben gezwoegd en gezweet, maar ook gelachen. Met jou heb ik heel erg goed samen gewerkt!

Amold Kester, van jou heb ik geleerd dat statistiek erg lleuk kan zijn. Zelfs op de benauwde momenten als je me weer ging 'overhoren' over missing data in het bestand. Zoals jij zal ik logica nooit kunnen beheersen!

Jelle Stoffers, co-promotor. Een 'woorval' tijdens het tweede sollicitatiegesprek. Twijfel rees eventjes in mijn hart. Zal ik voor deze baan wel gaan? Nu, ruim 4 jaar later weet ik dat ik de goede keuze heb gemaakt. Jouw conscièntieuze en intensieve manier van begeleiden "dwong" mij on te proberen het allerbeste te leveren.

Andrế Knottnerus, promotor. Zonder in clichés te willen vervallen moet ik toch herhalen wat je al van je meeste promovendi hebt gehoord. De stimulerende manier van sturen, aardig maar toch vollhardend is, denk $\mathrm{ik}$, jouw gave.

Jan van Ree, promotor. Van jouw huisartsgeneeskundige "blik" kon ik goed gebruik maken. De nist en ruimte die je me gaf en het vertrouwen dat je in mij stelde heb ik erg gewaardeerd.

Marjan van de Akker. Trip, trip, trip..."Zeg Marjan, ik moet even wat kwijt", en hup, er werd tijd vrijgemaakt. Collega's zoals jij en Trudy van der Weijden waren van onschatbare waarde en zotgden ervoor dat ik met plezier naar het werk kwam. En toch Marjan, geloof ik heilig in mijn therapie voor gespannen lui!

Cathelijne van Hasselt: $\mathrm{ik}$ wil winnen met squashen! 
Ad de Bruyne en Hanka Zwanikken, waren de kamergenoten van het eerste uur. Saskia Mol, het was goed om even bij jou uit te blazen op ons kamertje en daama "back to basic"!

Marion de Leeuw, Victor Kaiser, Karin Aretz, Marga van der Aa, Jim Tatipata, Dorette Courtar, Marlon Buncamper, Friedrich Anselma, Lysandra Riley, Marco Swaen, Alice van Gorp, Laurindo Andrea, Angela Kinsella, Marjo Zwanenburg, Jason Petronilia: allen hebben op een bepaalde manier aan dit proefschrift bijgedragen.

Een dankwoord ook aan alle andere collega's die ik de afgelopen jaren nodig had voor een of ander probleem, vraag of ontspanning.

Laura Spanbroek, paranimf. 'SistahL, gall, Peace and Blackness... 'De "pow-pows' waren sterk in frequentie teruggegaan maar zoals je ziet was dit slechts van korte duur. De 'B-sessions" zijn inmiddels weer in volle gang. New York is weer aan de beurt, want 'Shadow's' wacht!

Raoul Galarraga, paranimf. "Rasclath, picture this': Ons vaste ritueel: het uitzwaaien op Schiphol, al was mijn afwezigheid van korte duur...Meeting point op station... rugzak vol lijsten en eet laptop, tas met wat kleren... "In hemelsnaam Jurenne, wat heb je in die rugzak? Je gaat je toch ontspannen?"'. Jij en ik kunnen GTST herschrijven!"

Familie en vrienden bedank ik woor de uren plezier, liefde en geduld die ze hebben gehad met mij de afgelopen tijd.

Papai, van jou heb ik vroeg geleerd dat het belangrijkste wapen van een vrouw, kennis is. Jij bleef mij aansporen en in mij geloven. Mamai, jou bewonder ik vanwege je humor, standvastigheid en kracht. Hopelijk heb ik daar ook een beetje van. Elco, Luti, Mavis, Migda, Mirelva, Jocène, met aanhang en kroost, familie reünies werden steeds moeilijker vanwege afstand en daardoor steeds specialer als we allemaal weer eens met $z$ 'n allen bij elkaar konden zijn.

Camavals 'Gang' op Curaçao: februari weer ok? 'Sunflower: amazing grace, your existence..."

En tot slot Gerard. Jij besefte het afgelopen jaar als geen ander: "een broedende kip moet je niet storen". Thuis gekookte malijijen, vakanties, tijd samen schoten er allemaal bij ir.. Ik moest weer eens werken... Je vermogen om te relativeren werkte positief, wooral op de monenten die ik als "miss Drama Queen' thuiskwam, omdat Jelle weleens, zoals hij het zelf noemt 'primair" reageerde op een van mijn velle concepten of ideeèn. Lieve Gerard, op naar de volgende fase! 


\section{Curriculum Vitae}

Jureme Hooi werd geboren op 8 april 1965 te Curaçao. In 1984 behaalde zij haar VWO diploma. aan de Peter Stuyvesant College te Curaçao. In september van dat jaar startte zij met de studie Gezondheidswetenschappen aan de Universiteit Maastricht. In jamuari 1991 studeerde ze af in de richting Biologische Gezondheidskunde.

Na het behalen van haar doctoraal examen ging ze werken bij P\&O en Interne Geneeskunde, afdeling Gastro-enterologie (Academische ziekenhuis Maastricht) als onderzoeksassistente. Vanaf februari 1994 is ze part-time werkzaam bij de vakgroep huisartsgeneeskunde (tot 1 januari 1999) aan de Universiteit Maastricht als toegevoegd onderzoekster, vanwege haar werkzaamheden aan bovengenoemd proefschrift. Verder is ze vanaf $\mathbb{1}$ mei 1998 ook werkzaam bij het Nederlands Huisartsen Genootschap waar ze een bijdrage levert aan de herziening van de NHG standaarden 'Cholesterol' en 'Perifeer arterieel vaatlijden'. 